\title{
Review of FY2001 Development Work for Vitrification of Sodium Bearing Waste
}

C. M. Barnes
D. D. Taylor

September 2002

Idaho National Engineering and Environmental Laboratory Bechtel BWXT Idaho, LLC 


\title{
Review of FY2001 Development Work for Vitrification of Sodium Bearing Waste
}

\author{
Charles M. Barnes \\ Dean D. Taylor \\ September 2002 \\ Idaho National Engineering and Environmental Laboratory \\ High Level Waste Program Division \\ Idaho Falls, Idaho 83415
}

Prepared for the

U.S. Department of Energy

Assistant Secretary for Environmental Management

Under DOE Idaho Operations Office

Contract DE-AC07-99ID13727 


\begin{abstract}
Treatment of sodium-bearing waste (SBW) at the Idaho Nuclear Technology and Engineering Center (INTEC) within the Idaho National Engineering and Environmental Laboratory is mandated by the Settlement Agreement between the Department of Energy and the State of Idaho. This report discusses significant findings from vitrification technology development during 2001 and their impacts on the design basis for SBW vitrification.
\end{abstract}




\section{SUMMARY}

Waste currently stored in tanks at the Idaho Nuclear Technology and Engineering Center (INTEC), located at the Idaho National Engineering and Environmental Laboratory (INEEL), must be processed into waste forms suitable for permanent disposal as part of a Settlement Agreement between the DOE Idaho Operations Office (DOE-ID), the State of Idaho, and the Department of the Navy. In late FY 2000, a roadmap was prepared outlining the technology development required in order to treat this waste, called "sodium-bearing waste" (SBW), using three different technologies. At the direction of DOE-ID, development of vitrification, one of these three technologies, was vigorously pursued in FY-2001. Results from these development activities are contained in twenty-two documents and summarized in tabular form in this report.

During FY 2001, a baseline flowsheet for SBW vitrification was defined and a mass balance generated. To manage the assumptions used to generate the process mass balance, the process functional requirements, and all other data that will ultimately be part of the design basis for the SBW vitrification process, a database was created. Much of the knowledge gained in FY 2001 was incorporated into the database and the mass balance, and was published in September, 2001 (Ref. 28). However, results from experiments that were performed late in the year or work that extended into early FY 2002, were not incorporated into the database. Thus a thorough review of the development results from FY 2001 was performed in order to capture in a single source both the progress made in filling data gaps and the impact of these results on the database and hence the basis for the SBW vitrification flowsheet.

Significant results were obtained in the areas of feed characterization, feed pretreatment, glass formulation, melter operation, offgas characterization, offgas treatment and secondary waste disposal. Feed characterization data which suggested that the waste may likely contain a higher sulfate content than previously believed together with development of a flowsheet that recycled much of the sulfur in the offgas resulted in development of a glass formulation that tolerates higher sulfur concentration inf the feed, capturing a higher percentage of the feed sulfate in the glass. A maximum waste loading in the glass that forms no salt-layer was found, and the effects of different reductant additives, reductant concentrations, and other process parameters on the formation and growth of a salt layer on the melt were determined.

Simulant formulations were developed for both waste from tank WM-180 and a "worst case" composition. Tests were performed that compared glass compositions from simulant melts to those from actual SBW. Pretreatment studies demonstrated a method for removal of sulfate from the feed. Off-gas treatment studies demonstrated $\mathrm{NO}_{\mathrm{x}}$ abatement and mercury removal.

Results from FY 2001 development affected over 50 "design basis elements" (DBEs), the basic structural units of the database. The data obtained confirmed initial assumptions for many of the DBEs. However, results from several experiments indicate the need for additional development and possible alteration of the baseline flowsheet. These include: 
- The nominal waste loading for WM-180 was determined to be $20 \mathrm{wt} \%$ (equivalent to $0.91 \mathrm{wt} \% \mathrm{SO}_{3}$ in glass; waste loading scales with equivalent $\mathrm{SO}_{3}$ concentration for other SBW liquids). Sulfate removal from the feed offers a means to significantly increase the waste loading, and thereby reduce the volume of glass produced and associated glass storage and disposal costs. Another alternative that has been discussed is to adjust the feed reductant concentration (as needed) to convert sulfur to a volatile form which will not be recycled to the melter.

- In one small research-scale pilot test, a high percentage of mercury present in melter offgas was captured by the scrub system. This result, along with tests of simulated scrub neutralization that yielded precipitated solids, suggest that alternatives to the baseline process for offgas scrub treatment may need to be evaluated.

- A much higher air addition rate to the NOxidizer may be needed than originally assumed. If this is the case an SCR reactor may offer significant savings over the baseline NOxidizer scheme.

- Some of the melter separation factors determined from test data for both volatile and nonvolatile species were significantly different from the baseline mass balance assumptions. The new data should be incorporated into the database and mass balance updated in order to determine whether the impacts of these new separation factors on offgas treatment requirements are significant.

- The method previously used to measure the redox state in glass gives erroneous results when vanadium is present due to interferences between vanadium and iron. An alternate method was developed and shown to accurately estimate the redox state with vanadium present. 


\section{CONTENTS}

ABSTRACT

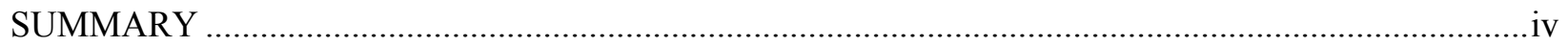

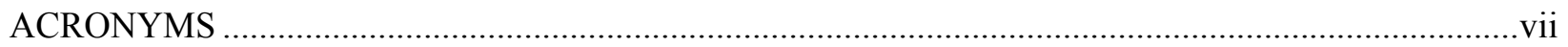

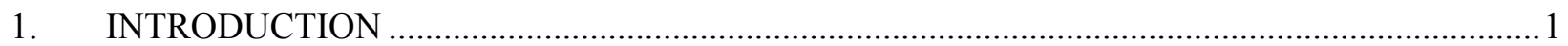

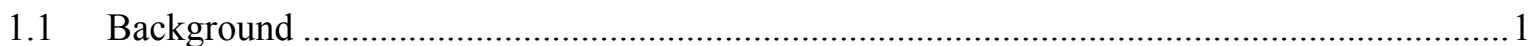

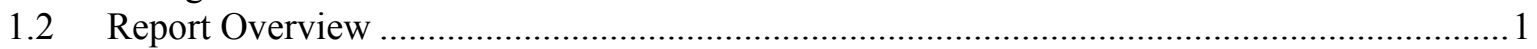

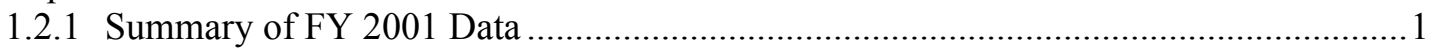

1.2.2 Impacts of FY 2001 Work on Technical Baseline .....................................................2

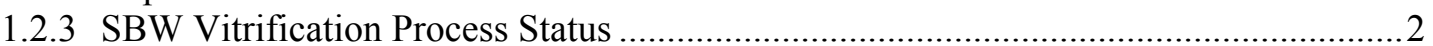

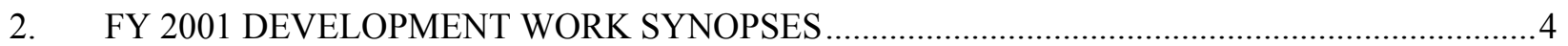

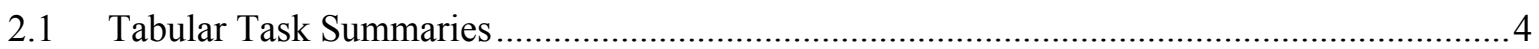

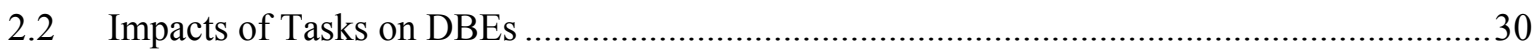

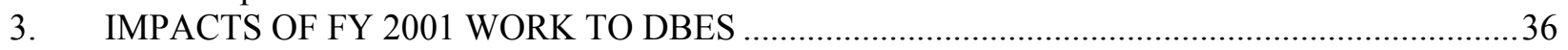

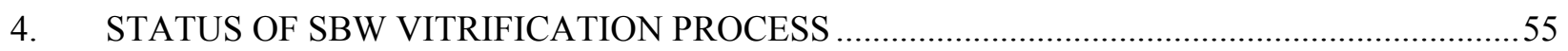

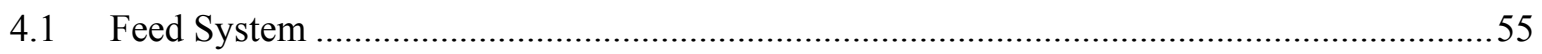

4.1.1 Feed Rheology, Feed Reactions and Frit Versus Glass Forming Components.............55

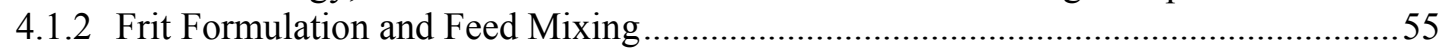

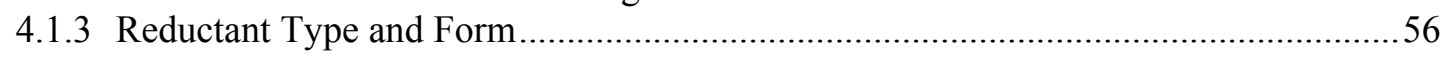

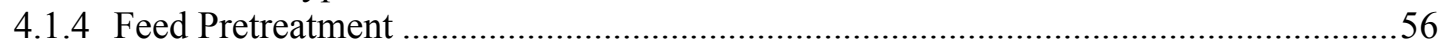

4.2 Melter and Canister Filling System ............................................................................ 56

4.2.1 Glass Waste Loading, Glass Formulation and Control of Salt Layer ...........................57

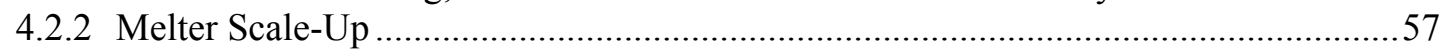

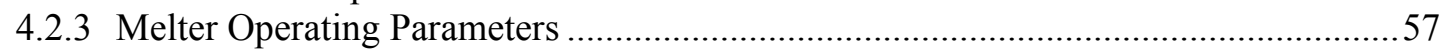

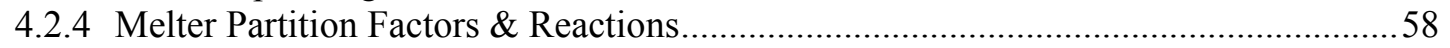

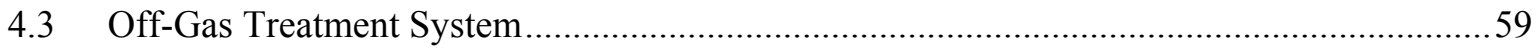

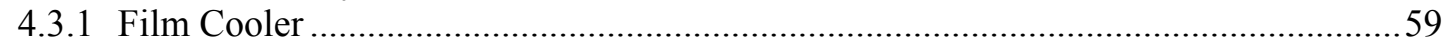

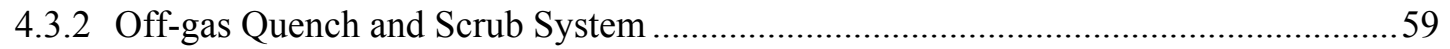

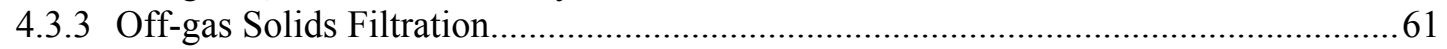

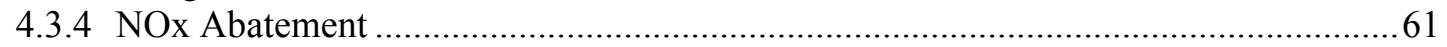

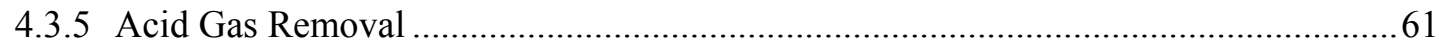

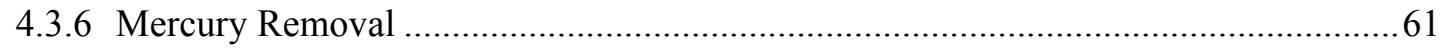

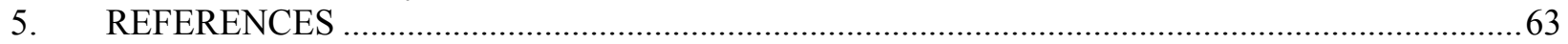

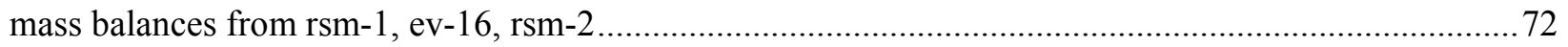

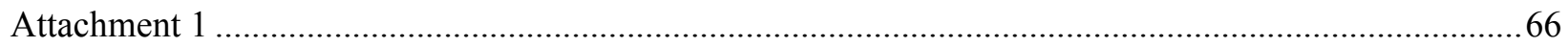

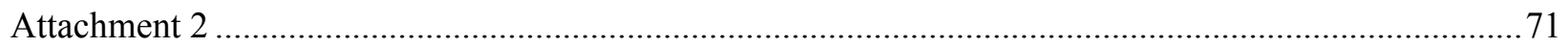

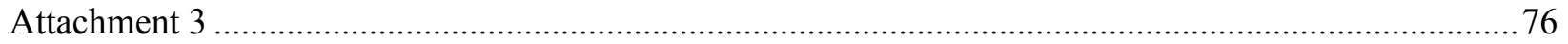

\section{TABLES}

Table 2-1: Principal results from FY-2001 development tasks..............................................................5

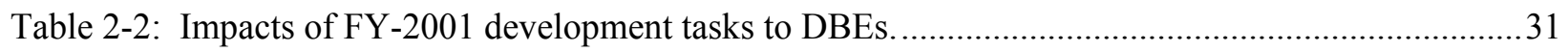




\section{ACRONYMS AND ABBREVIATIONS}

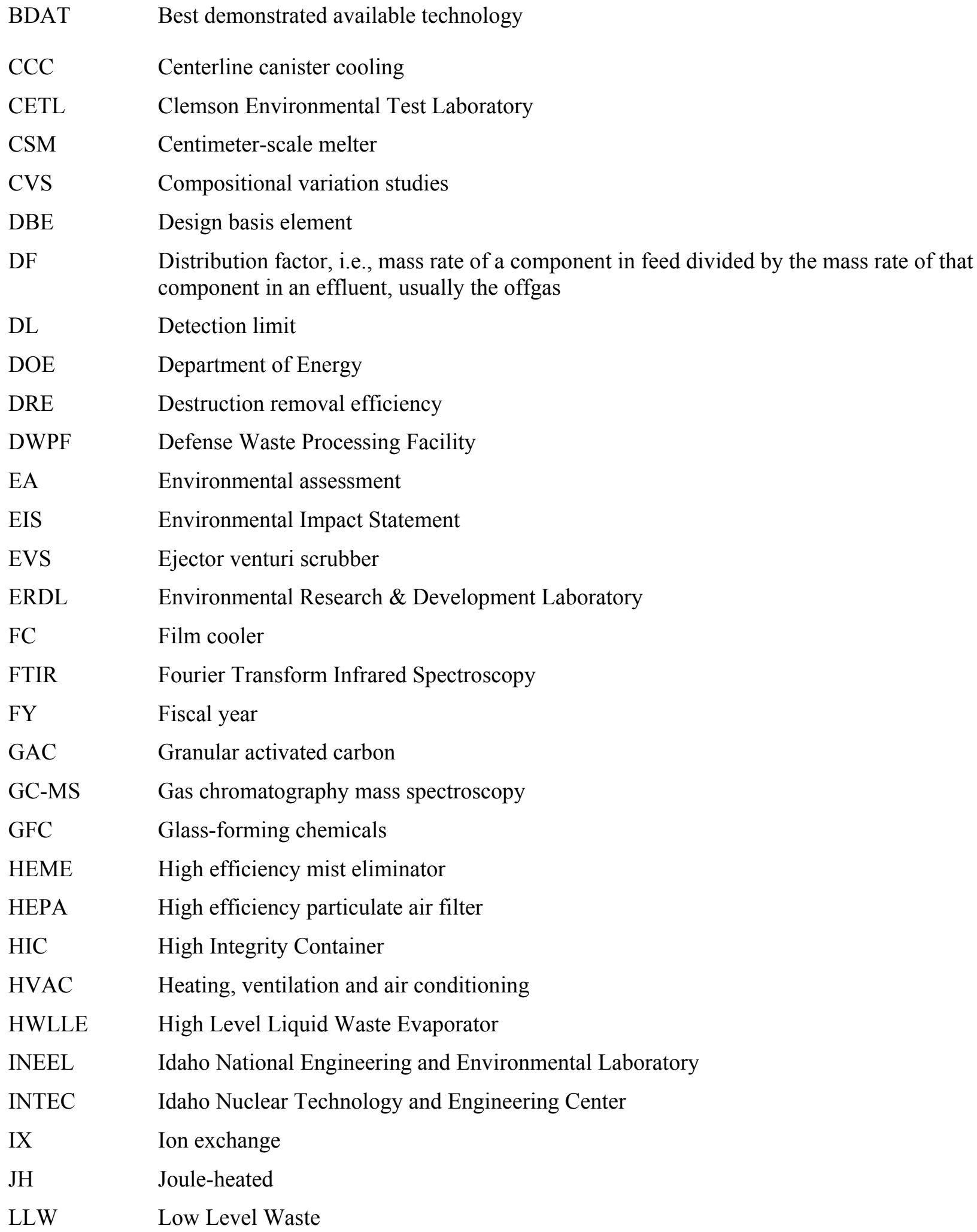


MACT Maximum achievable control technology

NGLW Newly generated liquid waste

NM Not meaningful or not measured

NRC Nuclear Regulatory Commission

NTS Nevada Test Site

NWCF New Waste Calcining Facility

OG Off-gas

PCT Product consistency test

PFD Process flow diagram

PNNL Pacific Northwest National Laboratory

PSD Particle size distribution

RR Redox Ratio $\left(\left[\mathrm{Fe}^{+2}\right] /\left[\mathrm{Fe}_{\text {tot }}\right]\right)$

RSM Research scale melter

SBW-9 The first "target" glass formulation used in FY01 pilot tests at PNNL and CETL. It was based on a feed consisting of SBW from WM-180 with composition as specified in Ref. 35 and GFCs (frit) as follows:

GFCs used

$\mathrm{H}_{3} \mathrm{BO}_{3}$

$\mathrm{Fe}_{2} \mathrm{O}_{3}$

$\mathrm{LiOH} \bullet \mathrm{H}_{2} \mathrm{O}$

$\mathrm{SiO}_{2}$

$\mathrm{Ca}(\mathrm{OH})_{2}$
Equivalent frit composition

$\begin{array}{lr}\mathrm{B}_{2} \mathrm{O}_{3} & 15 \mathrm{wt} \% \\ \mathrm{Fe}_{2} \mathrm{O}_{3} & 10 \mathrm{wt} \% \\ \mathrm{Li}_{2} \mathrm{O} & 5 \mathrm{wt} \% \\ \mathrm{SiO}_{2} & 65 \mathrm{wt} \% \\ \mathrm{CaOH} & 5 \mathrm{wt} \%\end{array}$

(see Table 4.6 of Ref. 11)

SBW-22 The second "target" glass formulation used in late-FY01 pilot test at PNNL and CETL. It was also based on an SBW feed from WM-180 but with composition as specified in Ref. 25. The principal differences between the SBW compositions assumed for SBW-9 and SBW-22 were higher levels of phosphate and sulfate in the latter formulation, reflecting the use of ICP analyses of $\mathrm{P}$ and S instead of IC analyses of $\mathrm{PO}_{4}{ }^{-3}$ and $\mathrm{SO}_{4}{ }^{-2}$.

The GFCs (frit) used for SBW-22 was as follows:

GFCs used

$\mathrm{H}_{3} \mathrm{BO}_{3}$

$\mathrm{Fe}_{2} \mathrm{O}_{3}$

$\mathrm{LiOH} \bullet \mathrm{H}_{2} \mathrm{O}$

$\mathrm{SiO}_{2}$

$\mathrm{Ca}(\mathrm{OH})_{2}$

$\mathrm{Mg}(\mathrm{OH})_{2}$
Equivalent frit composition

$\begin{array}{lc}\mathrm{B}_{2} \mathrm{O}_{3} & 6.0 \mathrm{wt} \% \\ \mathrm{Fe}_{2} \mathrm{O}_{3} & 1.5 \mathrm{wt} \% \\ \mathrm{Li}_{3} \mathrm{O} & 6.1 \mathrm{wt} \% \\ \mathrm{SiO}_{2} & 68 \mathrm{wt} \% \\ \mathrm{CaO} & 5.0 \mathrm{wt} \% \\ \mathrm{MgO} & 1.8 \mathrm{wt} \%\end{array}$




$\begin{array}{lll}\mathrm{NaOH} & \mathrm{Na}_{2} \mathrm{O} & 4.3 \mathrm{wt} \% \\ \mathrm{~V}_{2} \mathrm{O}_{5} & \mathrm{~V}_{2} \mathrm{O}_{5} & 4.9 \mathrm{wt} \% \\ \mathrm{ZrO}_{2} & \mathrm{ZrO}_{2} & 2.4 \mathrm{wt} \%\end{array}$

(see Table 4.6 of Ref. 17)

SCR Selective catalytic reduction

SFMRF Slurry Fed Melt Rate Furnace

SL Salt layer

SNCR Selective non-catalytic reduction

SRS Savannah River Site

SS Stainless steel

SVOC Semi-volatile organic compounds

TBDB Technical baseline database

TCLP Toxicity Characteristic Leaching Procedure

TDS Total dissolved solids

TFA Tanks Focus Area

THC Total Hydrocarbons

UDS Undissolved solids

UTS Universal Treatment Standards

VE Value engineering

VLE Vapor liquid equilibria

VOC Volatile organic compounds

WIPP Waste Isolation Pilot Plant

WL Waste loading

XRD X-Ray diffraction 


\section{Review of FY2001 Development Work for Vitrification of Sodium Bearing Waste}

\section{INTRODUCTION}

\subsection{Background}

Waste currently stored in tanks at the Idaho Nuclear Technology and Engineering Center (INTEC), located at the Idaho National Engineering and Environmental Laboratory (INEEL) must be processed into waste forms suitable for permanent disposal as part of a Settlement Agreement ${ }^{1}$ between the DOE Idaho Operations Office (DOE-ID), the State of Idaho, and the Department of the Navy. To treat the liquid waste, DOE-ID is considering the treatment options described in the draft environmental impact statement (EIS). ${ }^{2}$ In the summer of 2000, DOE-ID requested the Tanks Focus Area (TFA) to convene a review team of national experts to independently assess the technical alternatives bounded by the Draft EIS with regard to SBW treatment. The review team recommended vitrification as the preferred SBW treatment option. ${ }^{3}$ Subsequent to DOE-ID's concurrence with this recommendation Bechtel BWXT, Idaho was directed to vigorously pursue development of SBW vitrification. This report contains a summary of the progress of development activities during Fiscal Year (FY) 2001 and a discussion of the impacts of this work on the development of a process design basis for SBW vitrifcation.

In late FY 2000 a roadmap was prepared outlining the technology development required in order to treat SBW. ${ }^{4}$ The roadmap identified processing requirements and gave a technical needs assessment which identified uncertainties in each of the treatment technologies under consideration, development targets, definition of development tasks and deliverables, and a schedule for completing those activities. Development activities were prioritized based on estimated impacts of uncertainties on the viability and cost of the treatment process. The development schedule was tailored to address the highest impact uncertainties first. The roadmap was the first attempt to plan the development required to design, construct, and operate a vitrification facility to process SBW.

This report builds on the portion of the roadmap directed at vitrification. Data have been obtained through FY 2001 development activities that reduce some of the uncertainty present a year ago. However, as is common in technology development, some experiments led to discovery of additional issues that impact the performance and cost of the process. Having progressed along the path defined by the roadmap we have a clearer view of what lies ahead.

\subsection{Report Overview}

\subsubsection{Summary of FY 2001 Data}

The principal objective of this report is to document, in one place, significant information and insights gained from SBW vitrification development work done during FY 2001. The individual development tasks which are the foundation of this information are described in detail in Refs. 5 to 27 . The focus in preparing the current report was to identify and categorize only the salient results from these tasks. These results are summarized in a tabular format in Table 2-1. This table provides "one-stop shopping" for summaries of the technical reports published by the INEEL Environmental Research \& Development Laboratory (ERDL) and their subcontractors during FY 2001 in support of SBW vitrification. 


\subsubsection{Impacts of FY 2001 Work on Technical Baseline}

During FY 2001, a database (the Technical Baseline Database or "TBDB") was created to manage (a) the assumptions used to generate the process mass balance, (b) the assumed process functional requirements, and (c) all other data that will ultimately be part of the design basis for the SBW vitrification process. These items are collectively referred to as "design basis elements" (DBEs). The DBEs which are the central component of the TBDB encapsulate (in discrete portions) the knowledge gained through development activities. In addition to the DBEs, the database was designed to include the process flow diagram (PFD) and mass balance(s) for the process, an overall process description, and for each DBE, a description of its basis (where it came from and why it is accepted) and a validation plan if its basis is not considered firm. Although incomplete, the validation plans and bases associated with the DBEs provide a perspective of the maturity of the SBW vitrification process. In its entirety the TBDB constitutes the complete technical baseline for the process and is the basis for the report, INEEL SBW Vitrification Process. ${ }^{28}$

A secondary objective in preparing the present report was to identify impacts of FY 2001 development work to the technical baseline. With the TBDB as the vehicle for describing the baseline we have examined each of the significant results listed in Table 2-1 to determine which (if any) DBEs it might address. In Table 2-2 all 22 of the FY 2001 development tasks are listed across the top and those DBEs which are impacted by any of these tasks are listed vertically. [A complete list of the DBEs is provided in Attachment 1 (Table A-1). Comparison of the complete list with Table 2-2 indicates that not all the DBEs in the TBDB were addressed by FY 2001 development work.]

Following Table 2-2 we provide a brief discussion of the DBEs impacted listed in the table. In light of the decision by the Department of Energy (DOE) at the time of preparation of this report to terminate further consideration of vitrification as a candidate treatment process for SBW, the discussion in Section 3 is necessarily brief and serves primarily to indicate the authors' judgements relative to whether an acceptable basis has been established for each DBE discussed, and if not, what remains to be done.

\subsubsection{SBW Vitrification Process Status}

The primary focus of development is to determine acceptable ranges of process and design variables that will ensure the process design requirements are satisfied. When sufficient test data are obtained to show that all design requirements can be met, then the flowsheet for that design can be considered validated. The process design requirements for SBW vitrification include the following:

- The facility must process INTEC wastes

- All waste forms produced must be disposable

- The treatment facility must be licensed, permitted and comply with DOE Orders

- The project and treatment schedule must meet Settlement Agreement commitments

- $\quad$ The feed system must deliver homogeneous, qualified feeds to the melter

- The melter must produce glass in a safe and economical manner qualified for disposal

- The offgas treatment system must remove contaminants from the melter offgas 
- The secondary waste treatment system must produce disposable wastes containing species removed from the offgas that cannot be incorporated into the glass waste product

- Waste storage systems must be capable of storing wastes until they can be processed or transported to disposal sites

Though not obvious from the above list, the process design is also constrained by economic viability. For example, a glass with a waste loading of $10 \%$ would likely meet all disposal requirements. However, a 10\% waste loading would increase glass storage and disposal costs as well as plant operating costs due to the prohibitively long processing schedule that would result. Thus, while the primary development focus is to ensure satisfaction of design requirements, the economic viability of the process must also be considered. As development data are generated and technical hurdles are overcome it is necessary to review the overall process and the associated economics with an eye to minimizing cost if such can be done without compromising the other design requirements.

With this in mind the final objective in preparing this report was to provide a "top-down" view of the process and major elements therein; namely, the melter feed system, the glass formulation and the melter itself, and the offgas system (including the handling of the intermediate and waste streams generating thereby). The focus in this final discussion is to provide a more "global" perspective on the impacts of the development work completed in FY 2001 to the major process components, and identify possible improvements to the baseline process configuration and process variables to improve its economic viability and performance. 


\section{FY 2001 DEVELOPMENT WORK SYNOPSES \\ 2.1 Tabular Task Summaries}

Experimental data and results from FY 2001 testing and studies are encapsulated in two tables shown in this section. Table 2-1 contains summaries of significant results and data from the experiments, and Table 2-2 identifies which DBE the data relate to. In Table 2-1, the results are grouped by report (reference number provided immediately after test title) and broken down by subject or "keywords". Each row entry in Table 2-1 is given a unique ID number used for reference purposes throughout the report. Table 2-2 uses the ID numbers to map the information from Table 2-1 to the DBEs. 


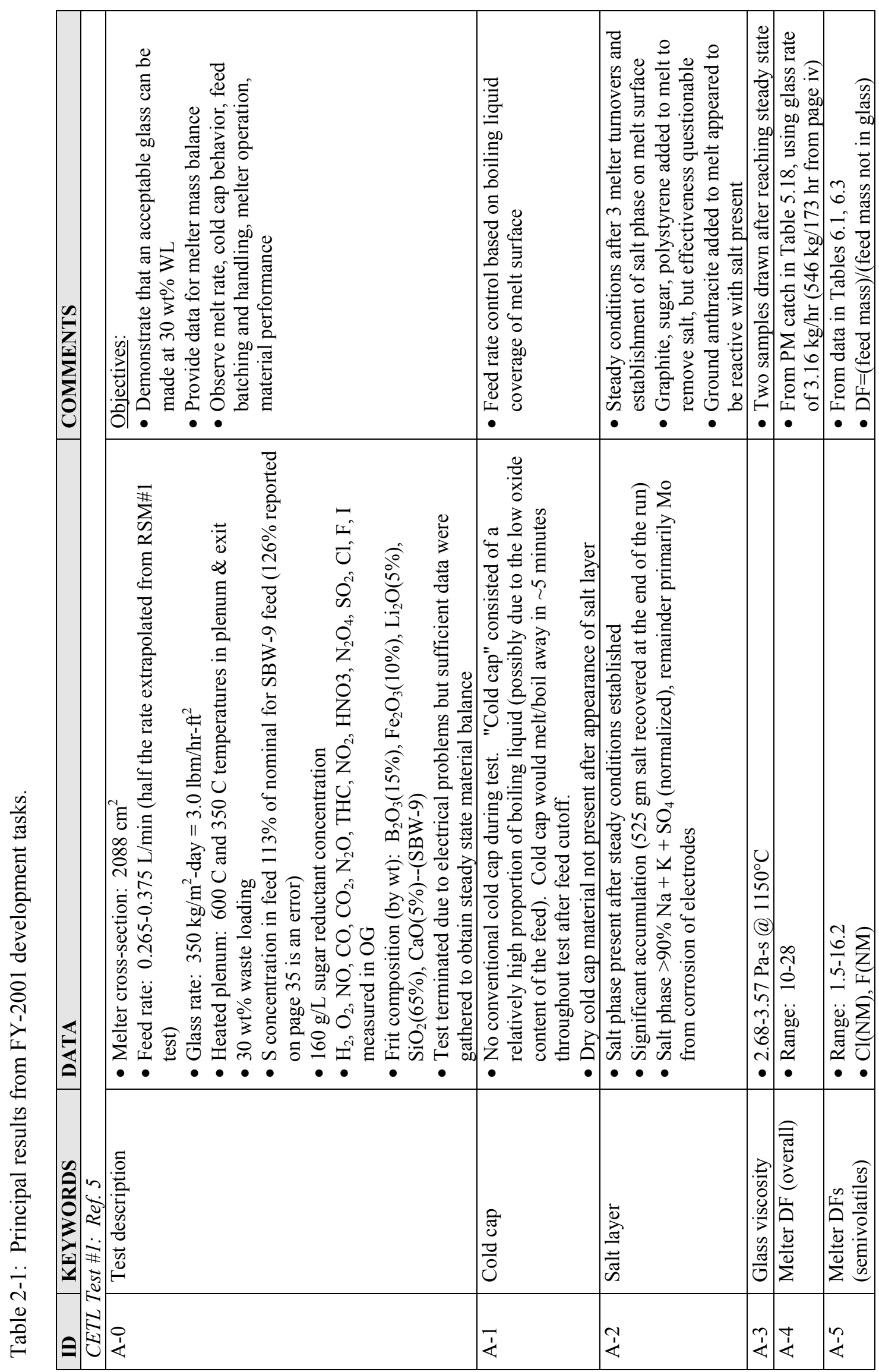




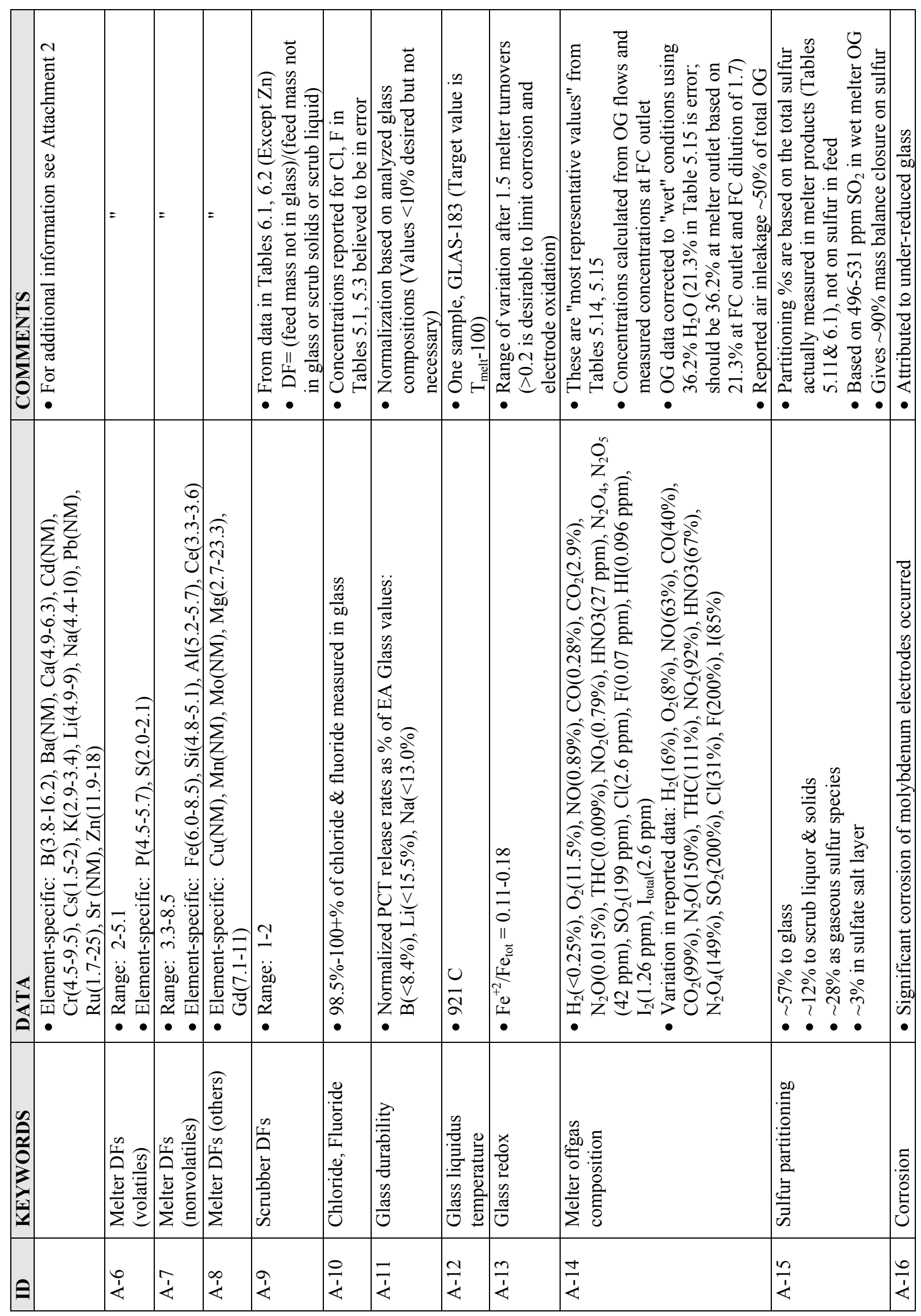




\begin{tabular}{|c|c|c|c|c|c|c|c|c|c|c|}
\hline & 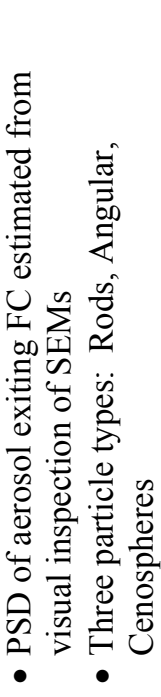 & 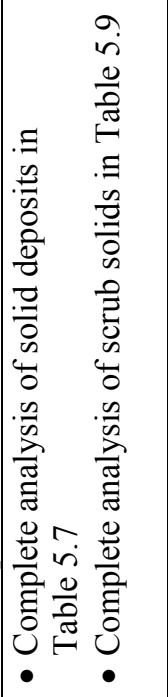 & 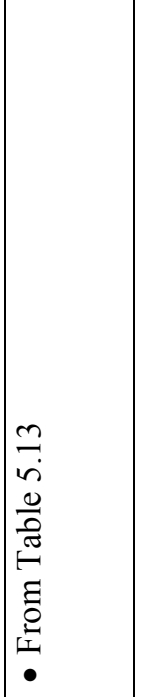 & 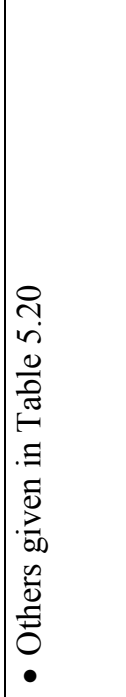 & 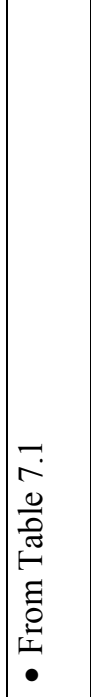 & 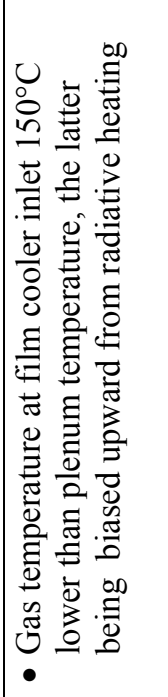 & 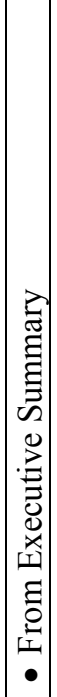 & 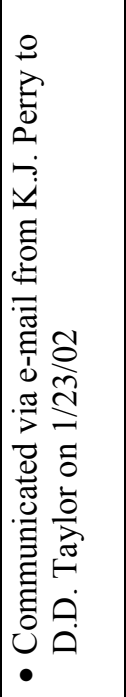 & 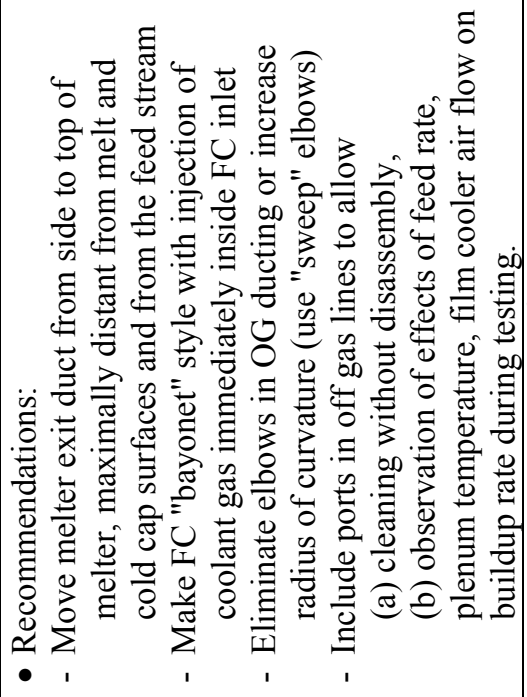 & 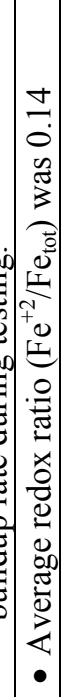 \\
\hline & 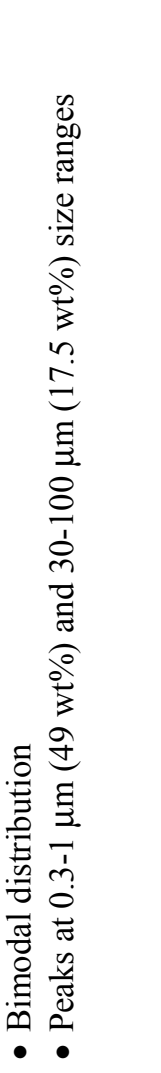 & 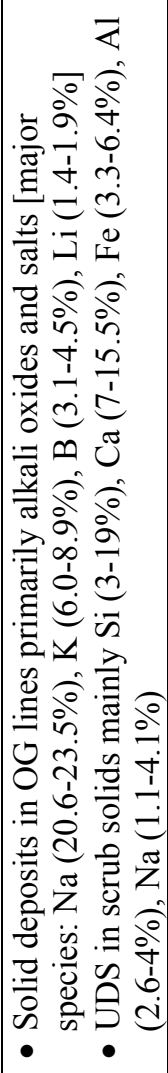 & 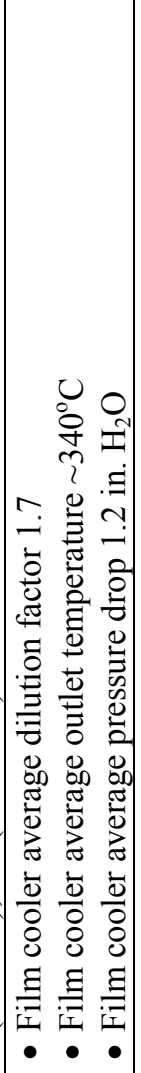 & 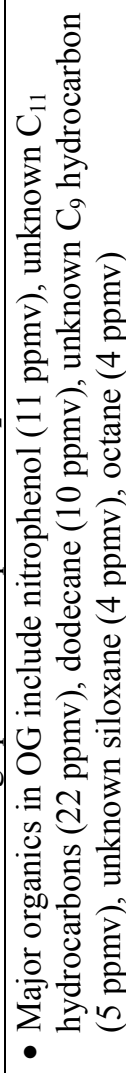 & 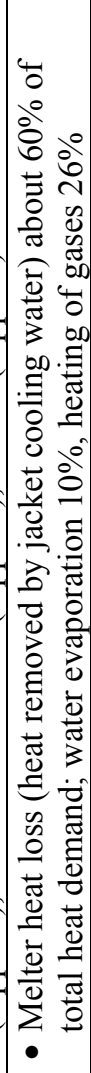 & 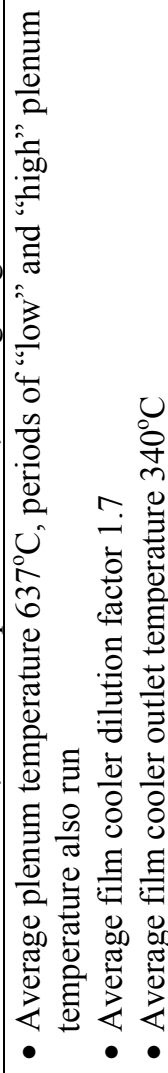 & 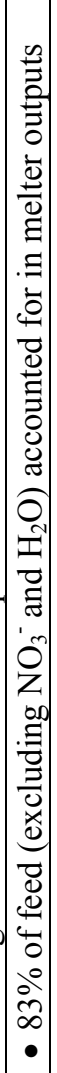 & 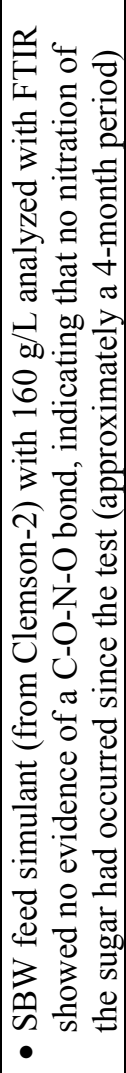 & 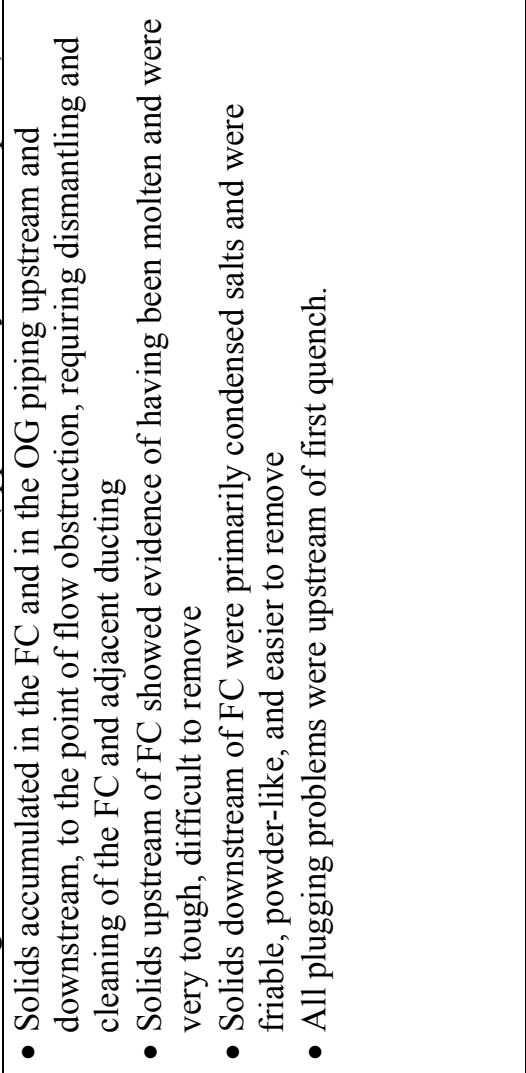 & 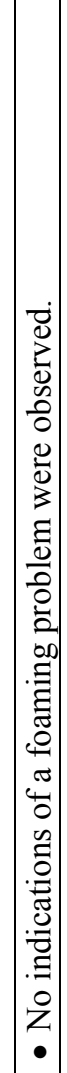 \\
\hline 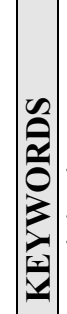 & 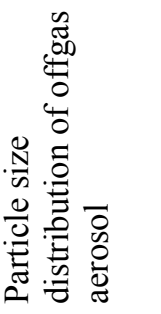 & 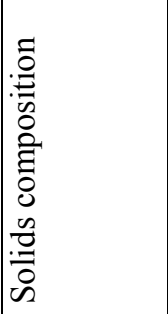 & 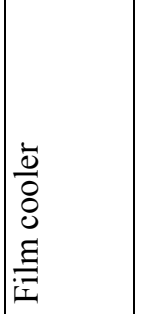 & 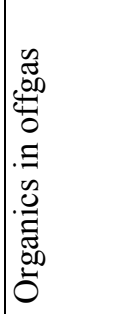 & 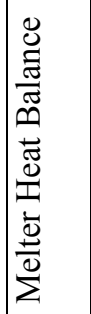 & 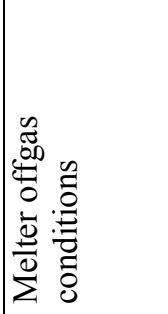 & 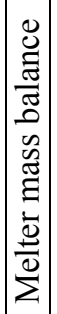 & 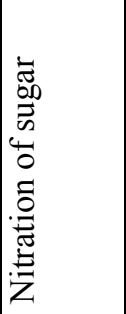 & 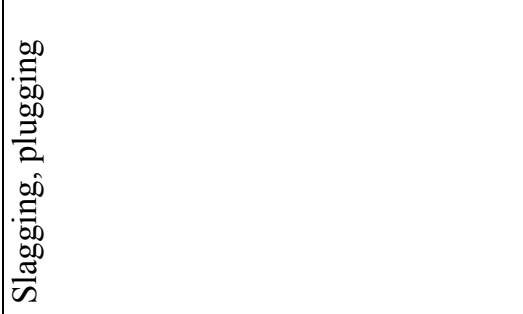 & 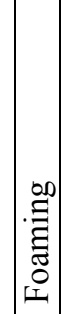 \\
\hline$\theta$ & $\overline{4}$ & $\frac{\infty}{\dot{z}}$ & $\frac{2}{\frac{1}{4}}$ & 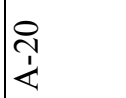 & 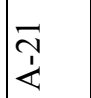 & $\underset{\sim}{N}$ & $\begin{array}{c}\tilde{N} \\
\frac{\pi}{\psi}\end{array} \mid$ & 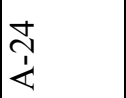 & 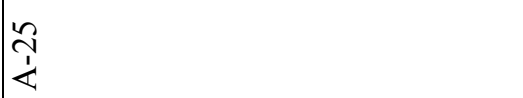 & $\begin{array}{l}\stackrel{0}{N} \\
\stackrel{1}{<}\end{array}$ \\
\hline
\end{tabular}




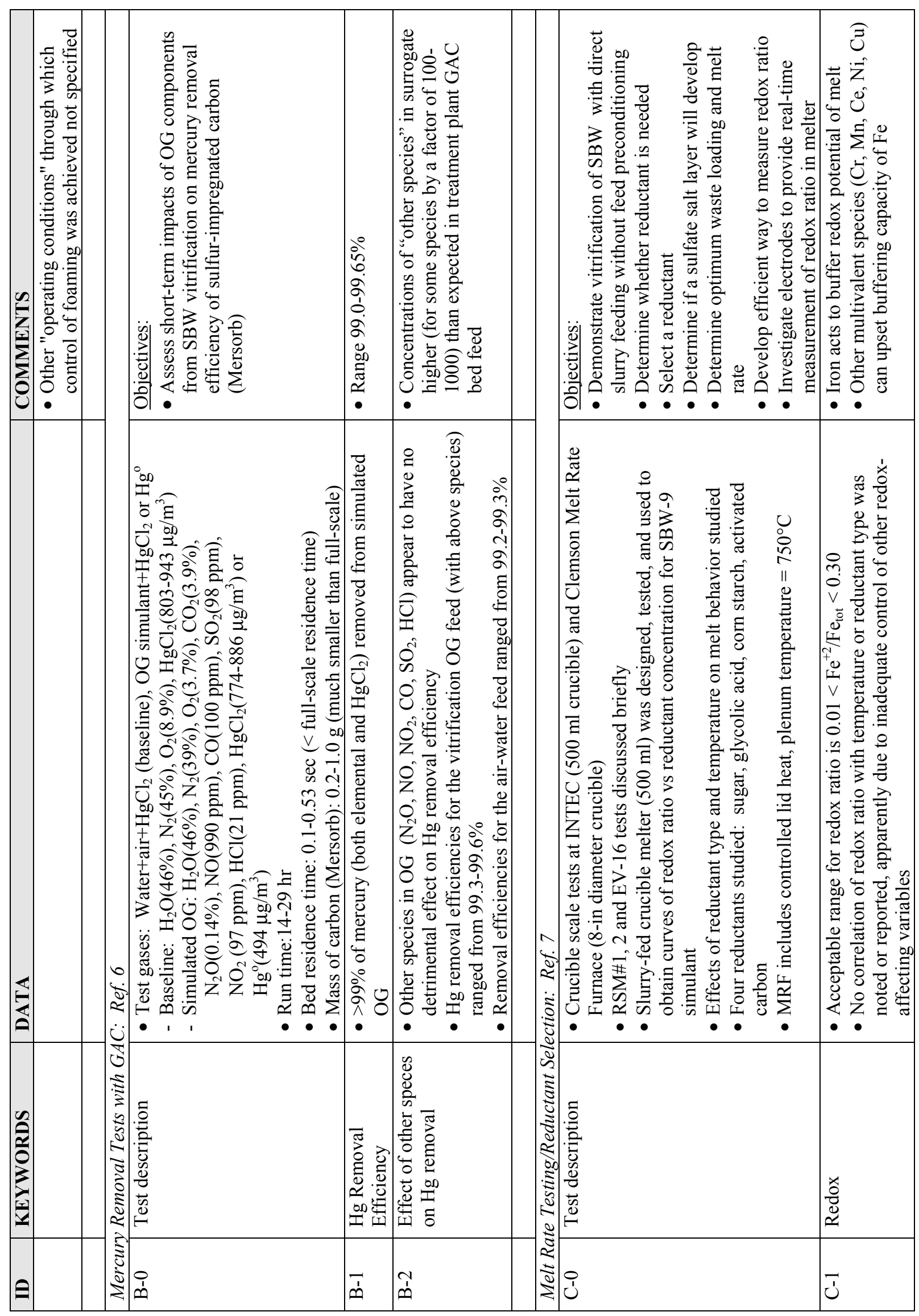




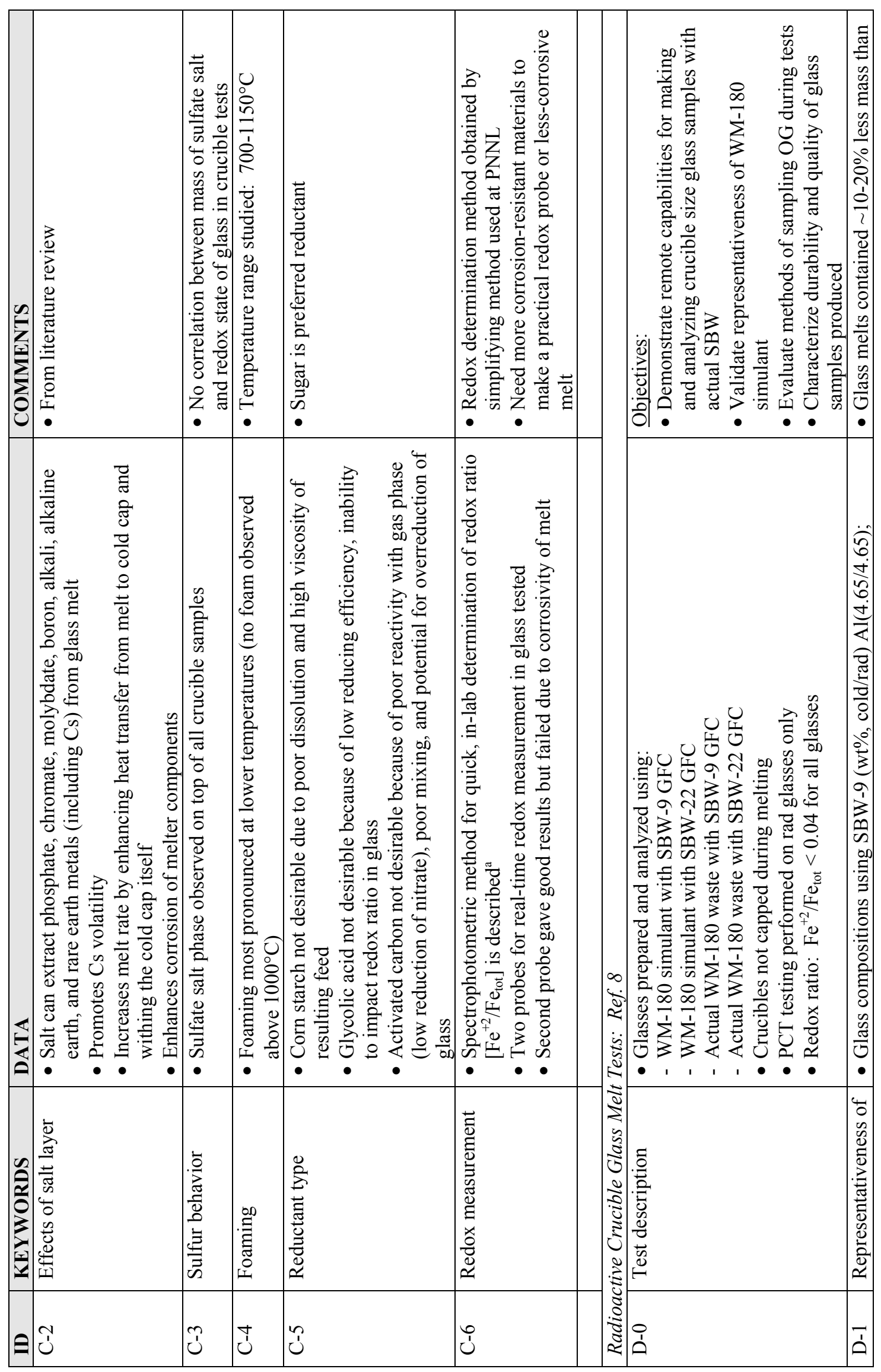

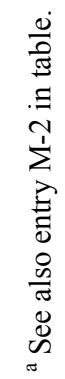




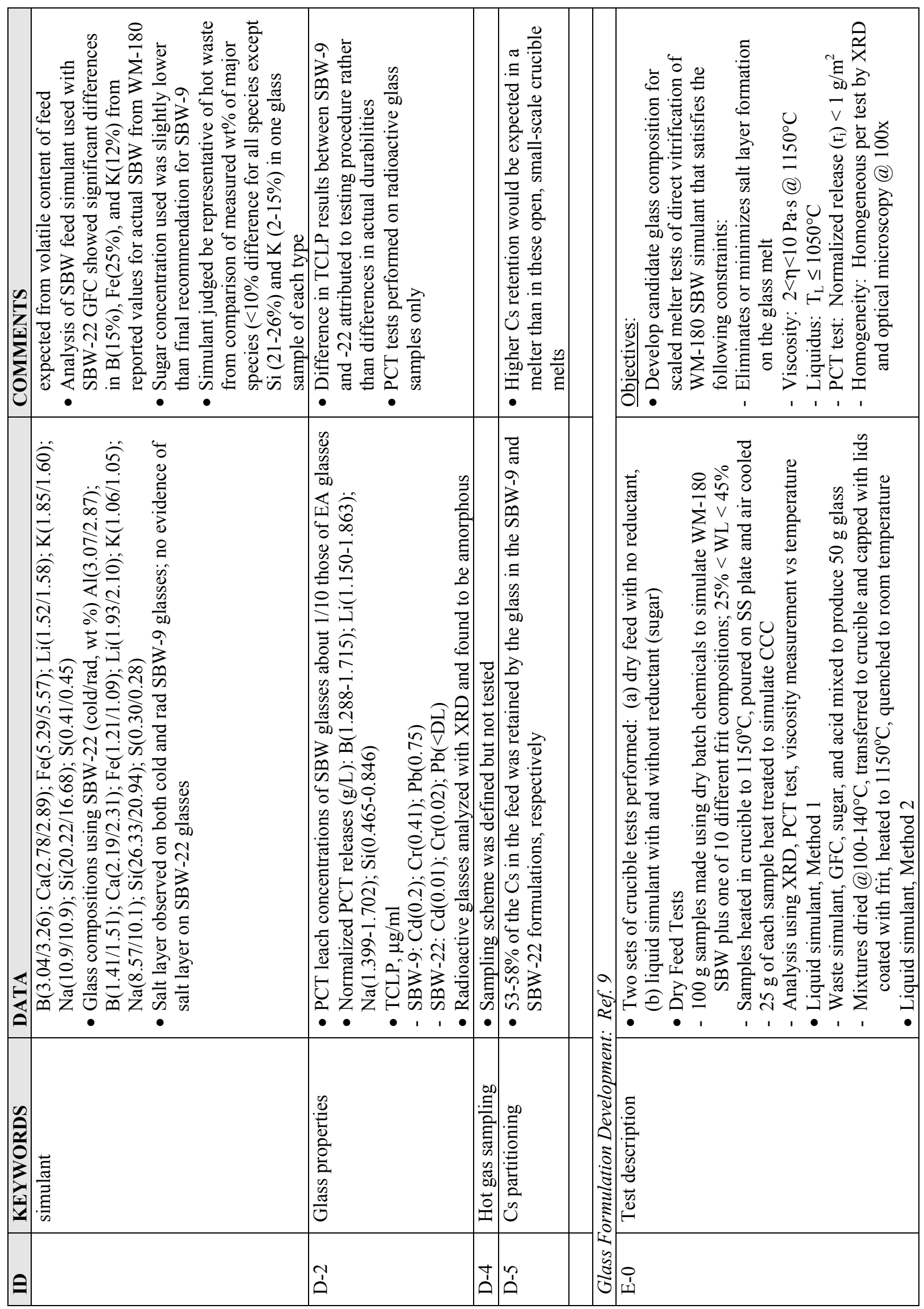




\begin{tabular}{|c|c|c|c|c|c|c|c|c|c|}
\hline & & 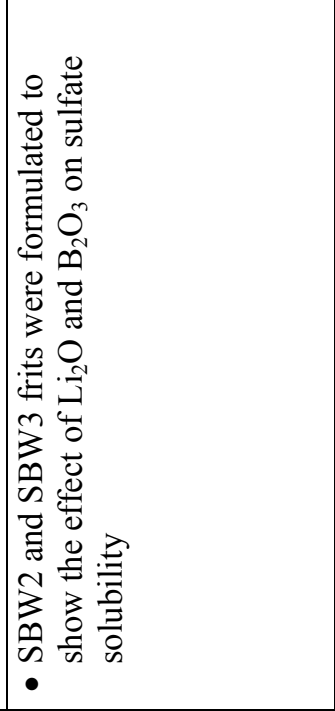 & & 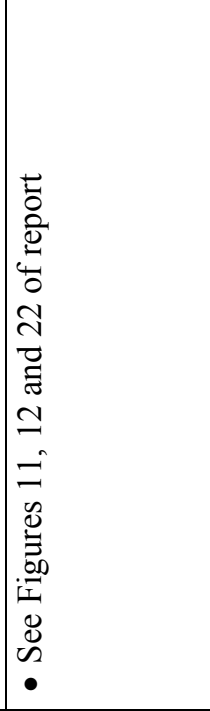 & & 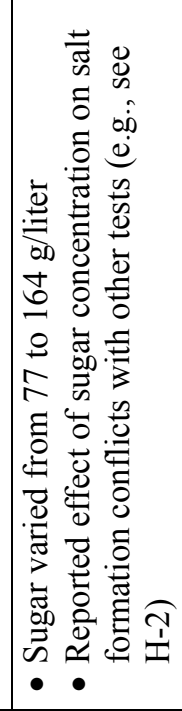 & 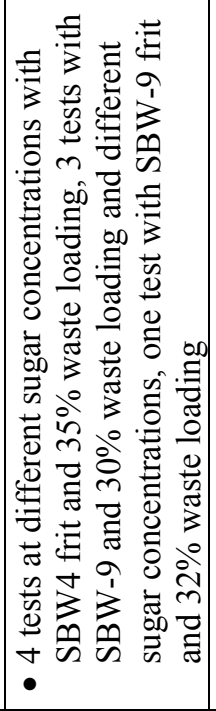 & & 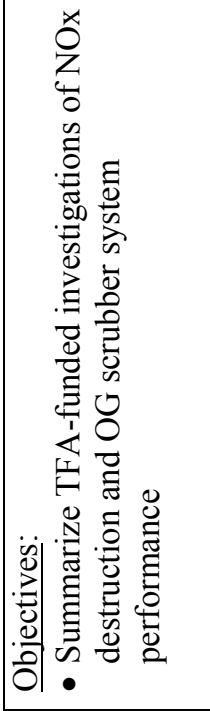 \\
\hline & 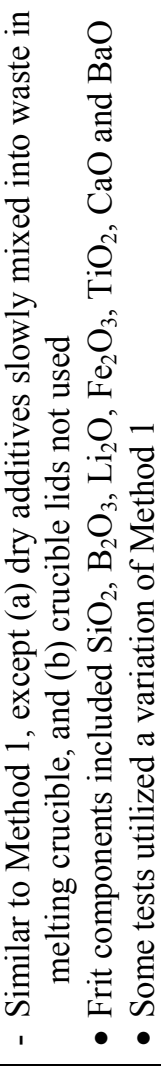 & 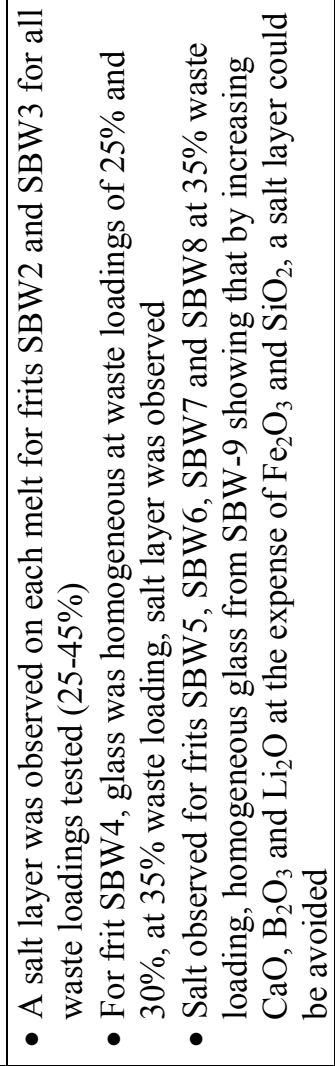 & 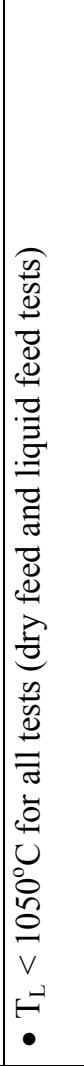 & 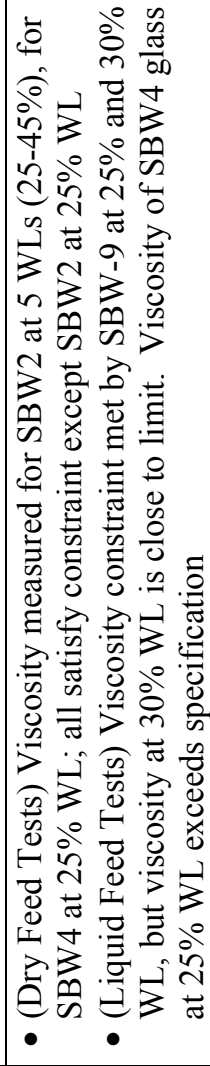 & 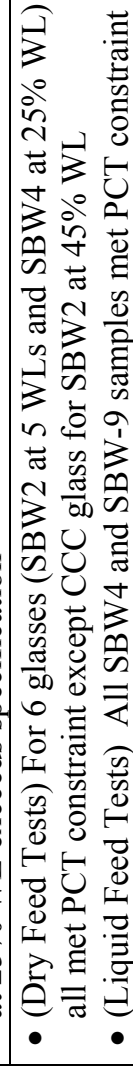 & 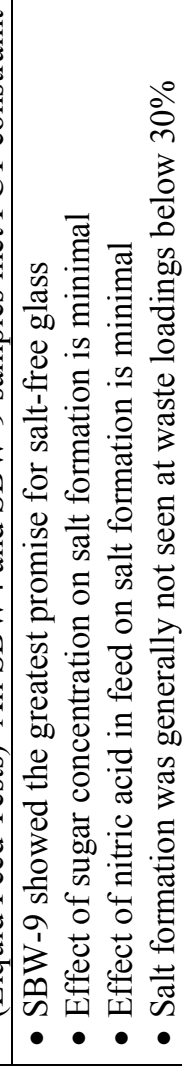 & 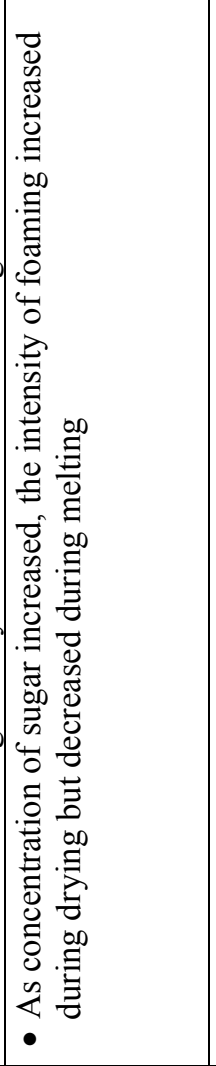 & 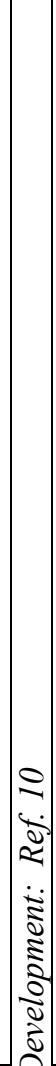 & 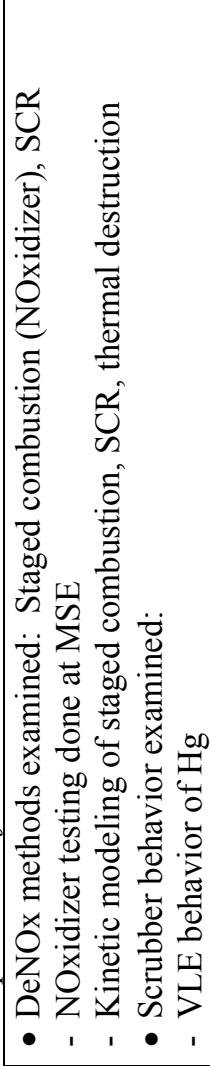 \\
\hline 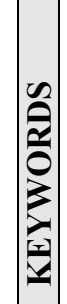 & & 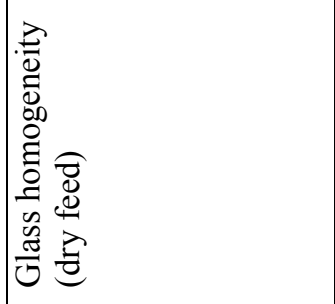 & 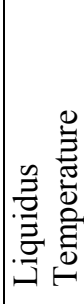 & & 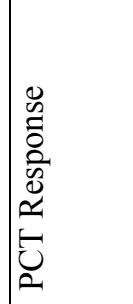 & 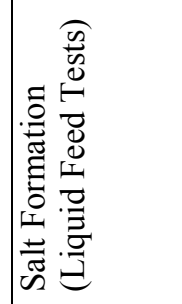 & & 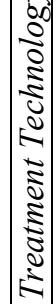 & 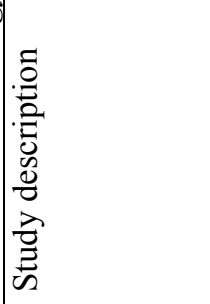 \\
\hline$\Theta$ & & $\overrightarrow{\mid \vec{c}}$ & 先 & $\begin{array}{l}\hat{r} \\
\hat{\omega}\end{array}$ & | & $\mid \begin{array}{l}n \\
1 \\
1\end{array}$ & |' & & $\mid \begin{array}{l}0 \\
\end{array}$ \\
\hline
\end{tabular}




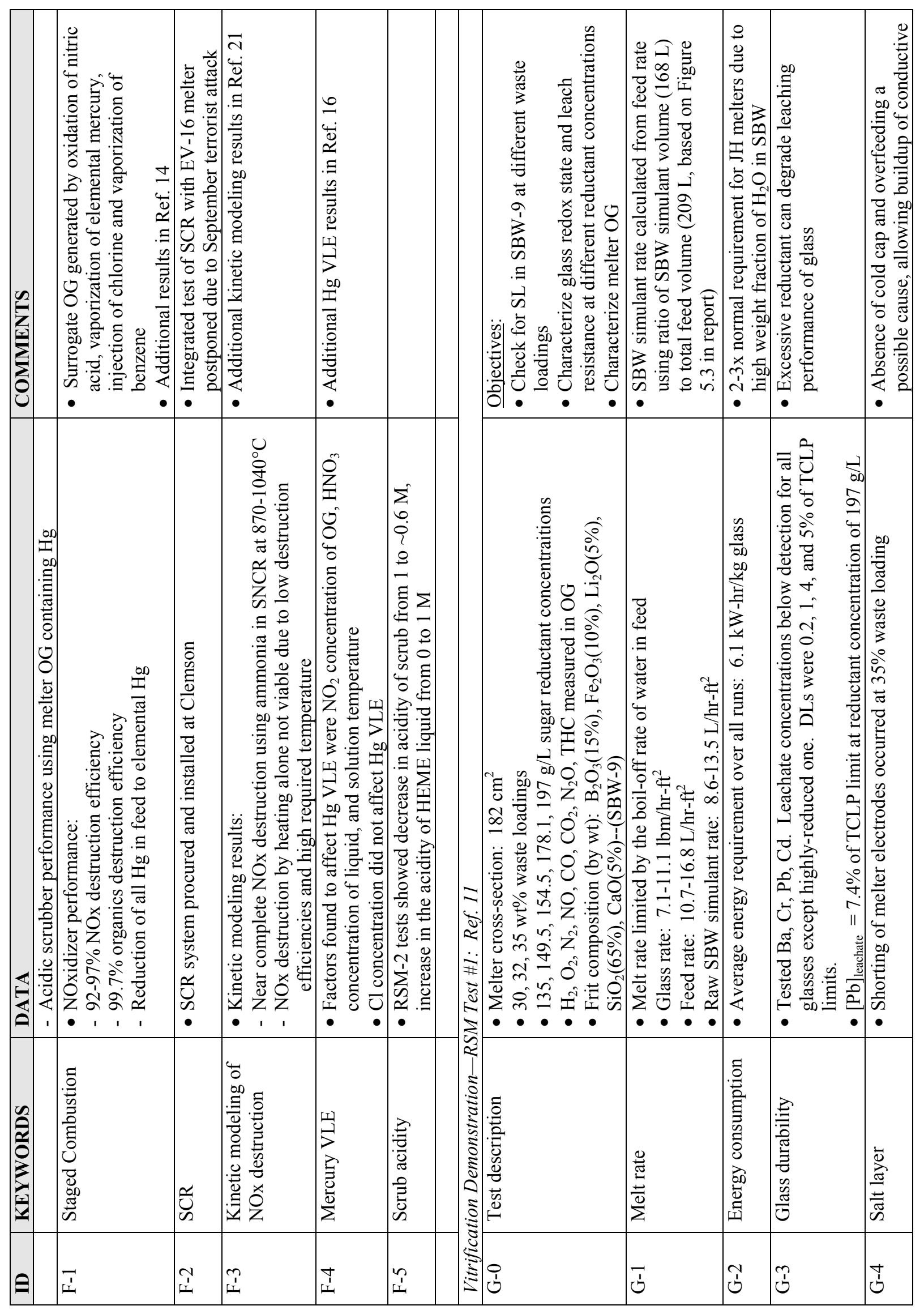




\begin{tabular}{|c|c|c|c|c|c|c|c|c|c|c|}
\hline & 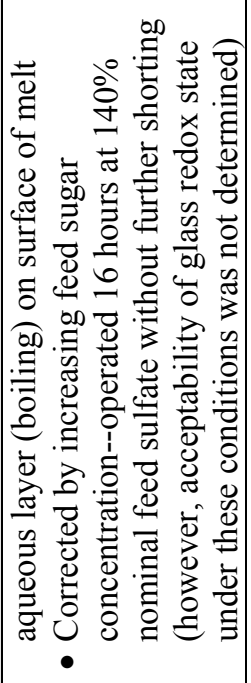 & 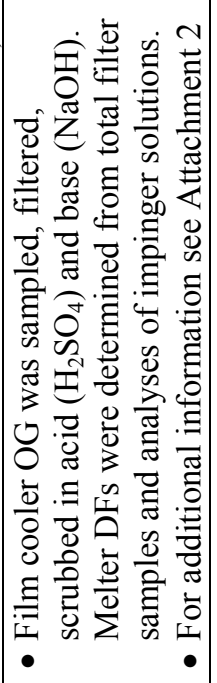 & & $=$ & $=$ & 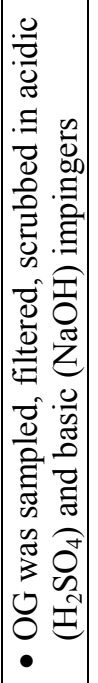 & 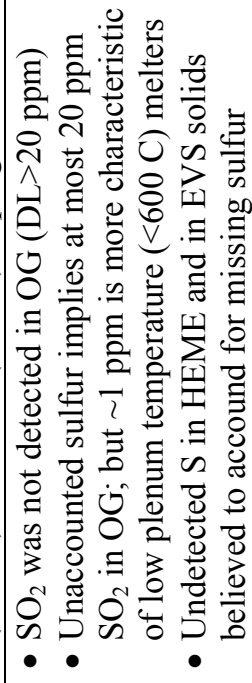 & 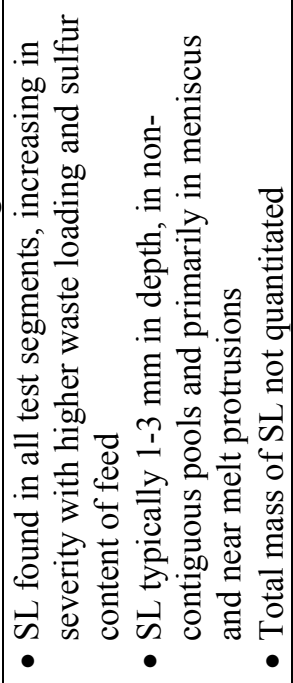 & & 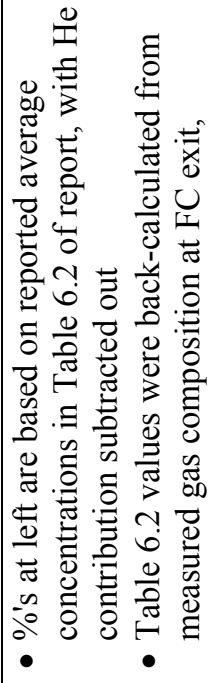 \\
\hline$\underset{\Xi}{\overleftarrow{b}}$ & & 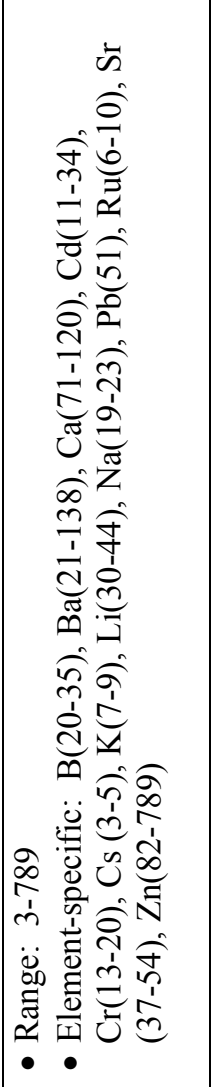 & 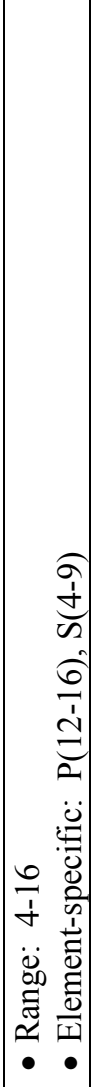 & 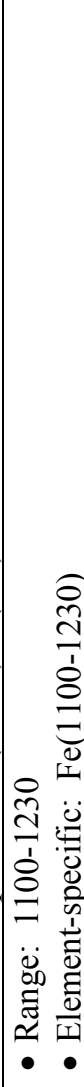 & 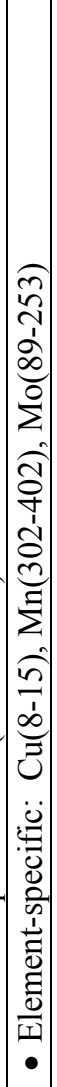 & 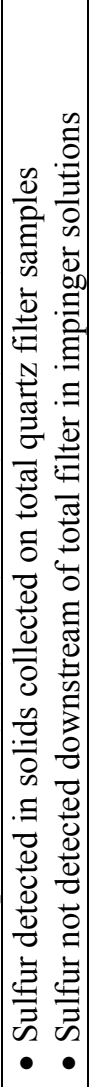 & 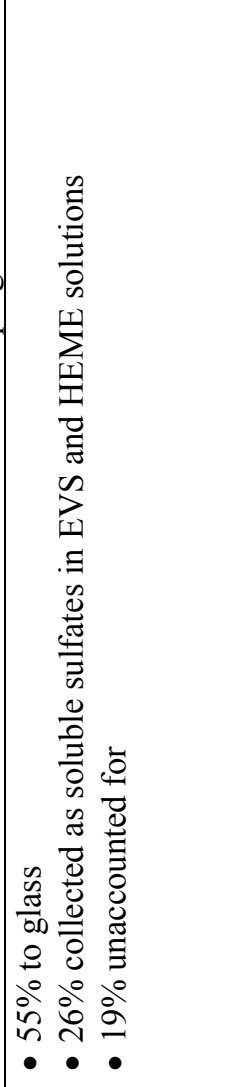 & 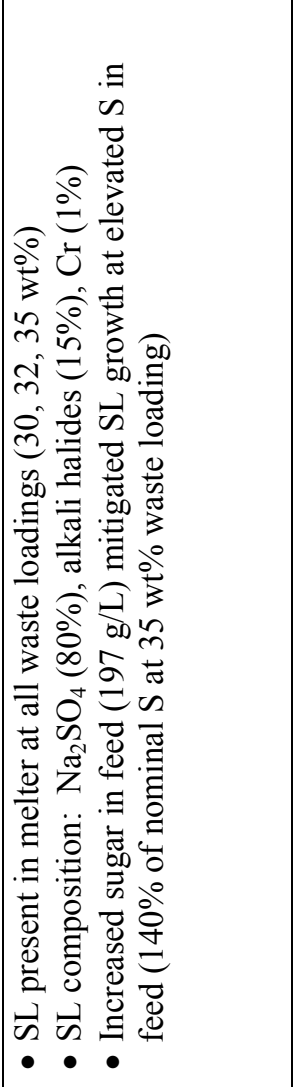 & 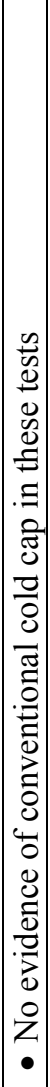 & 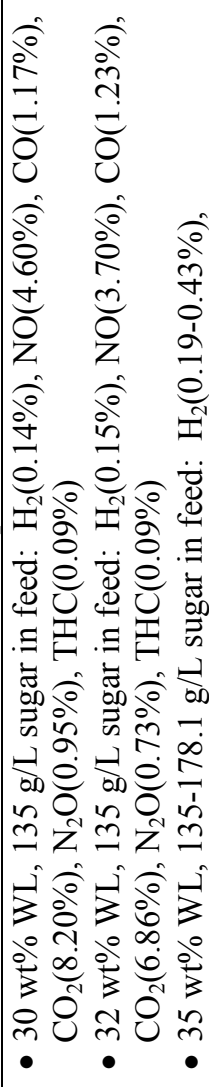 \\
\hline 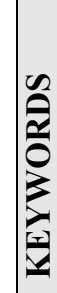 & & 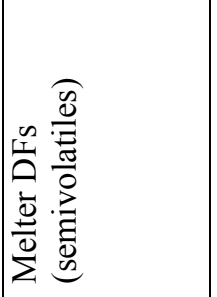 & 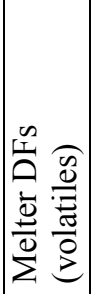 & 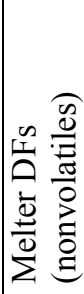 & 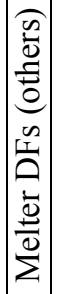 & 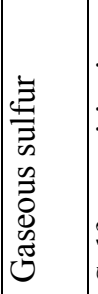 & 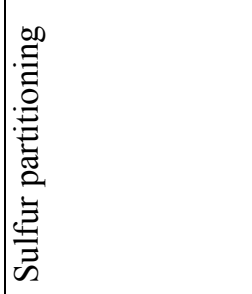 & 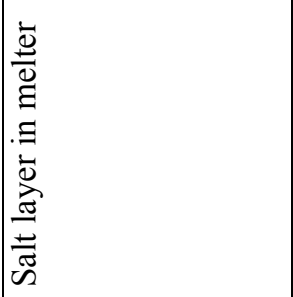 & $\begin{array}{l}\text { :0 } \\
0 \\
\frac{0}{0} \\
0 \\
0\end{array}$ & 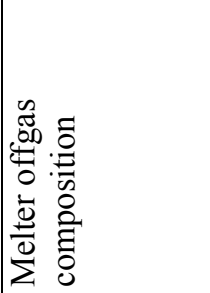 \\
\hline 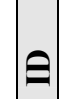 & & $\ddot{b}$ & فا & $\hat{0}$ & $\begin{array}{l}\infty \\
0 \\
0\end{array} \mid$ & 它 & $\frac{1}{0}$ & $\overrightarrow{\overline{0}}$ & $\frac{7}{0}$ & $\frac{m}{0}$ \\
\hline
\end{tabular}




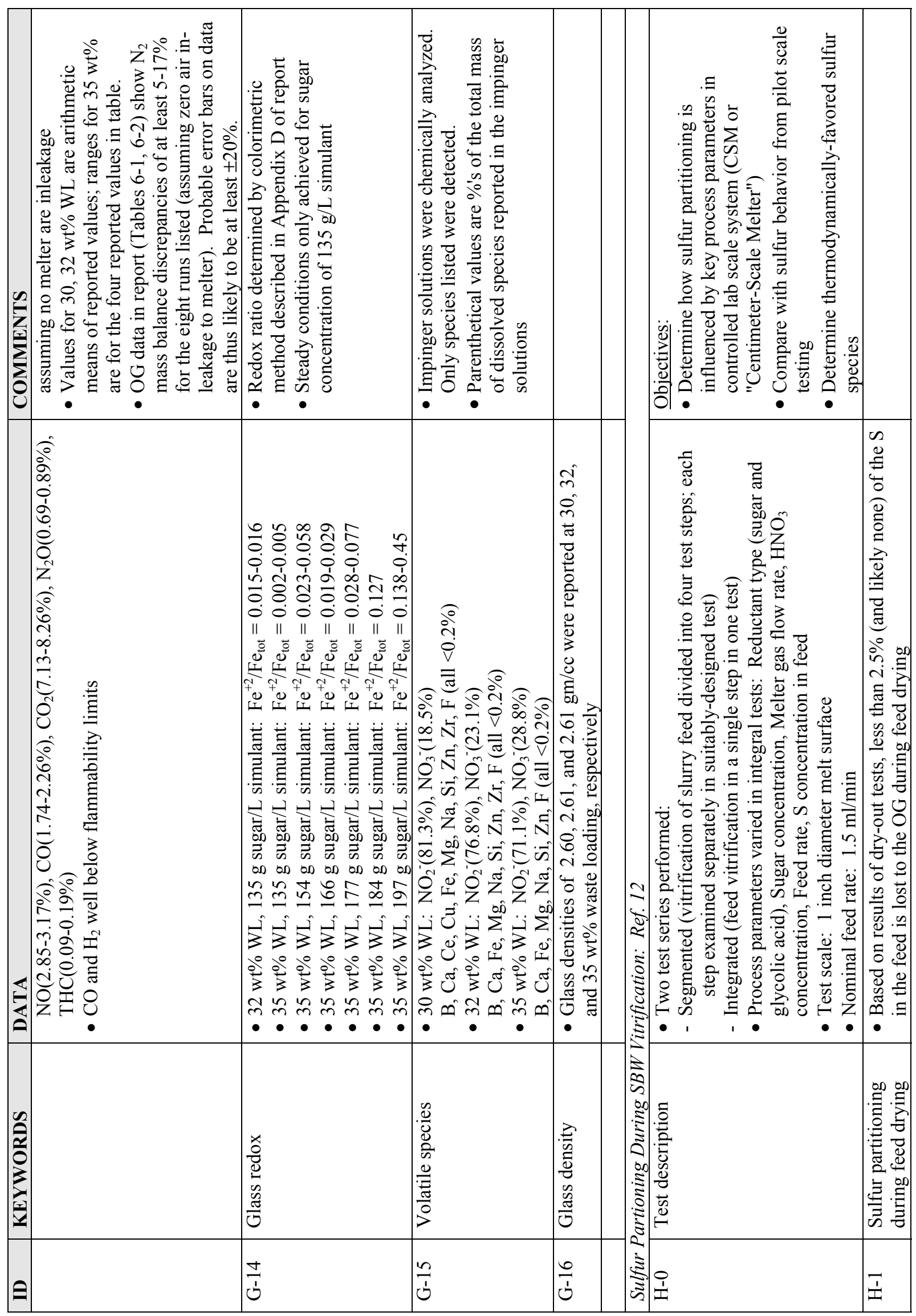




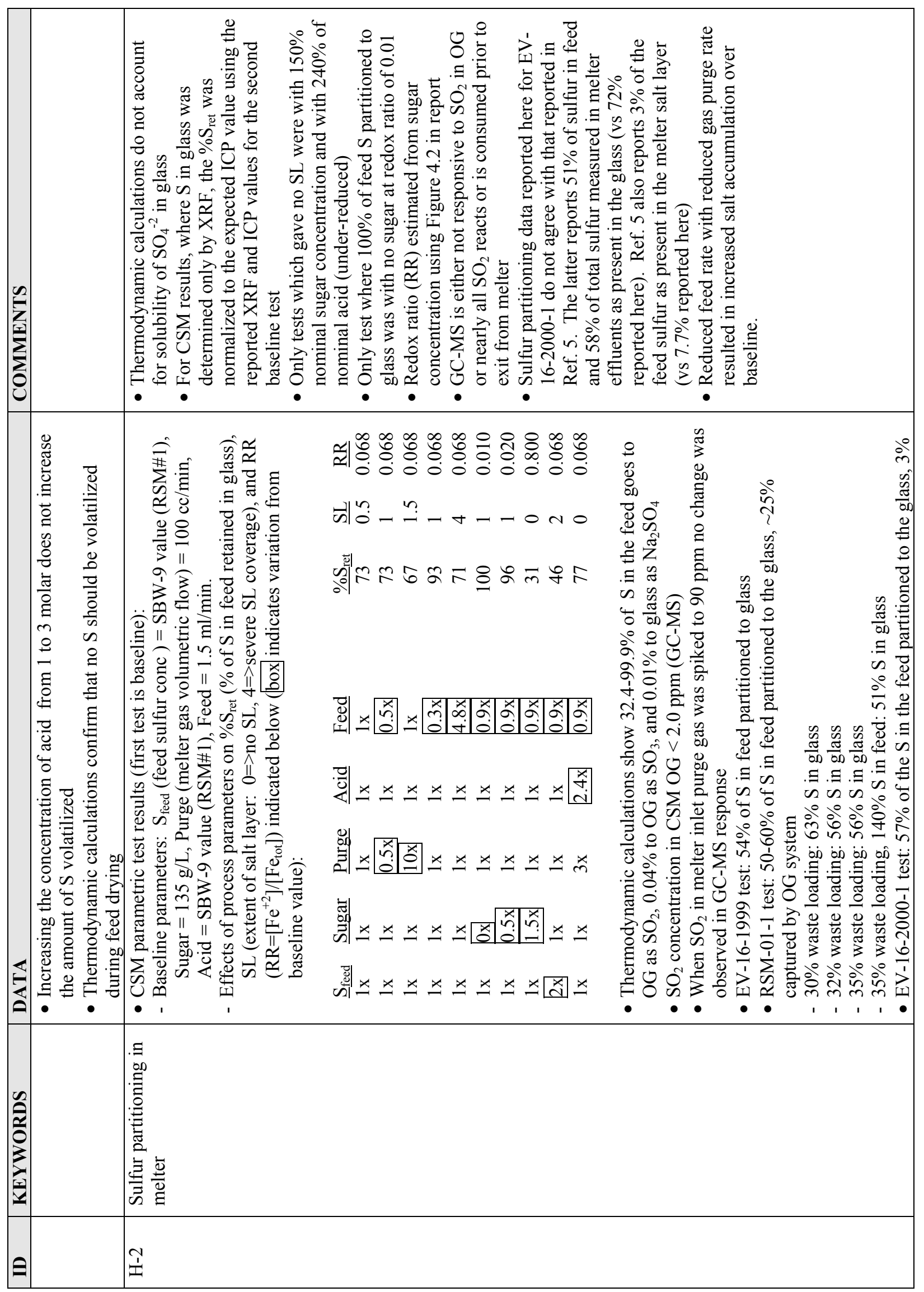




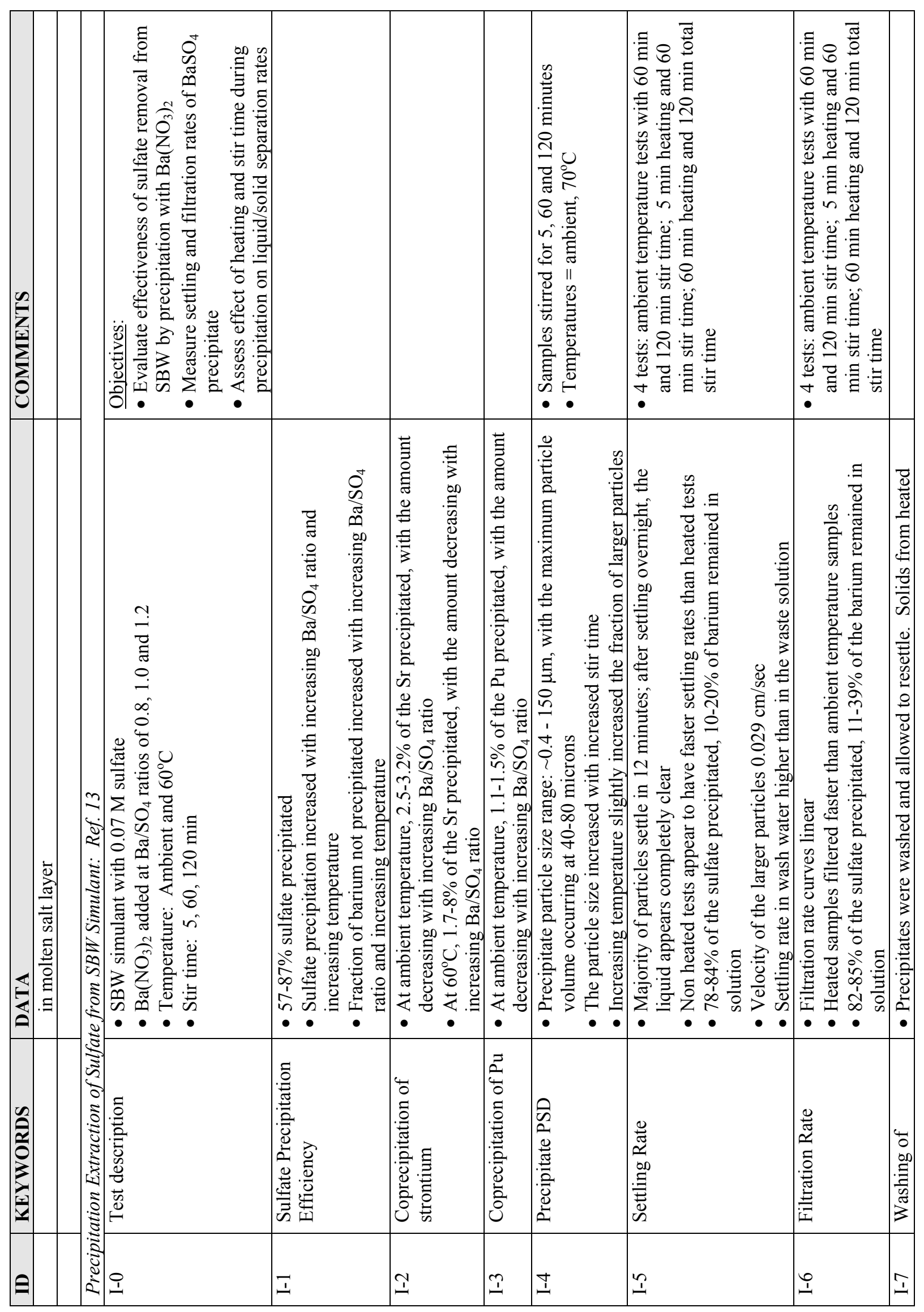




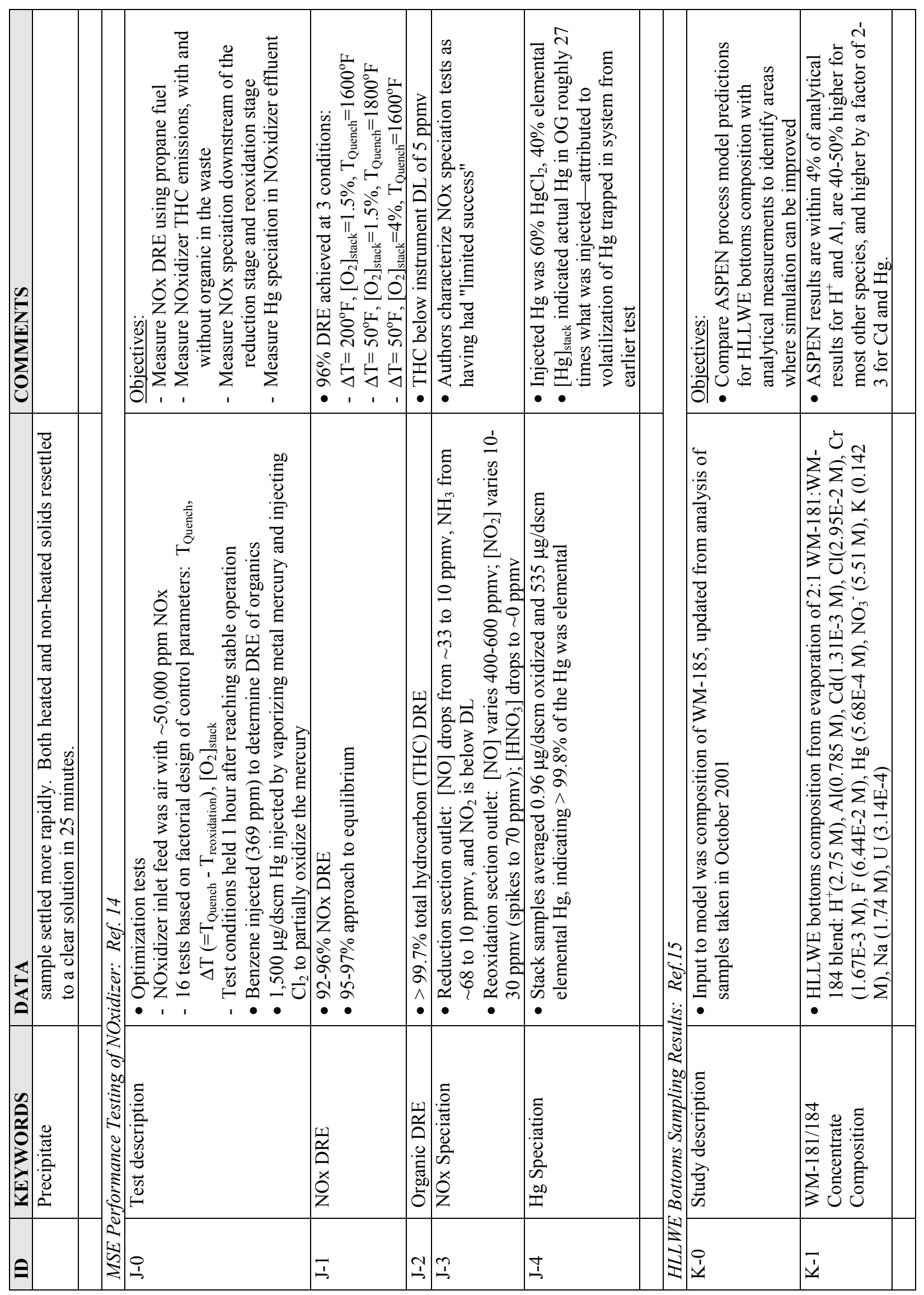




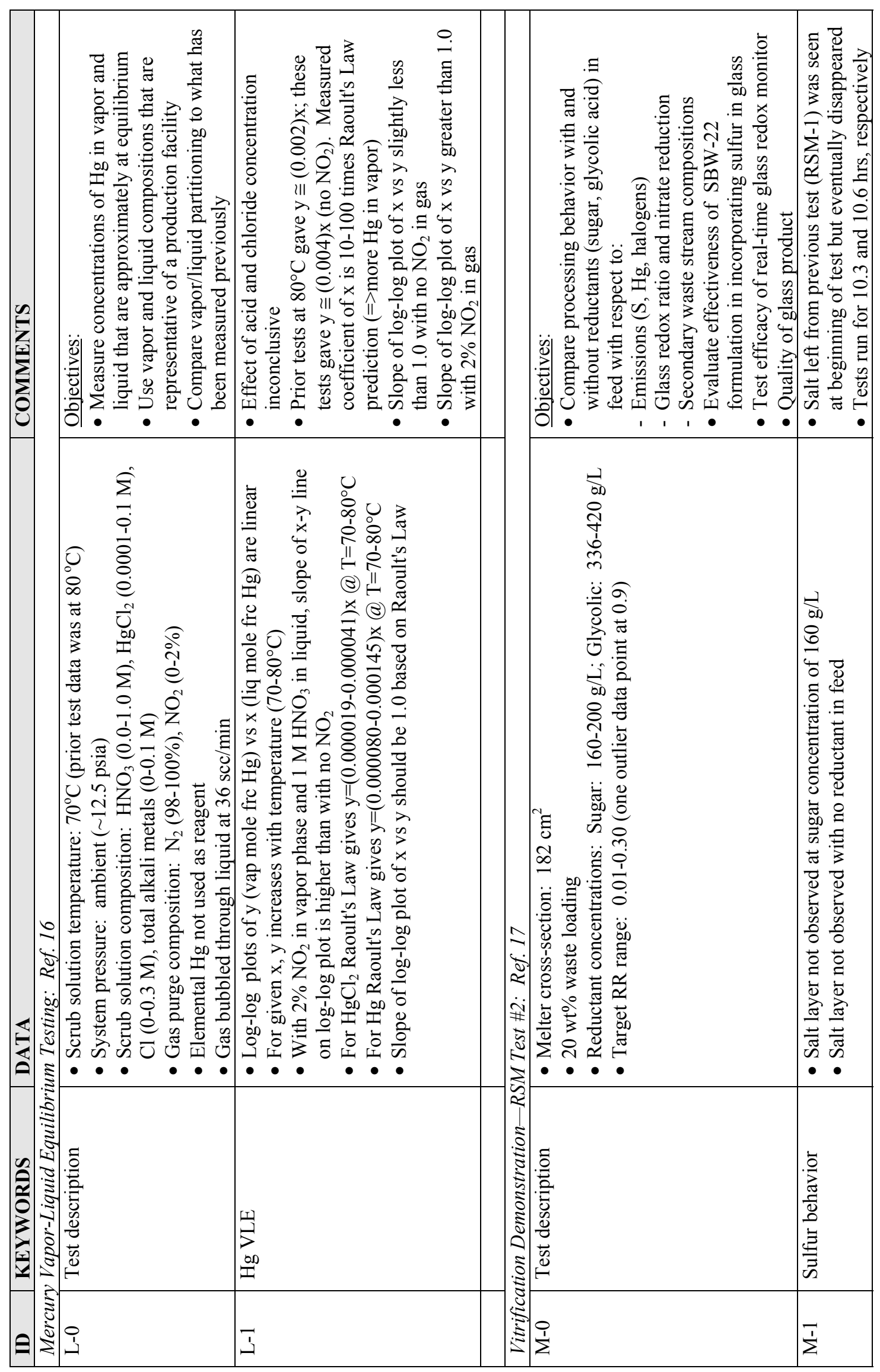




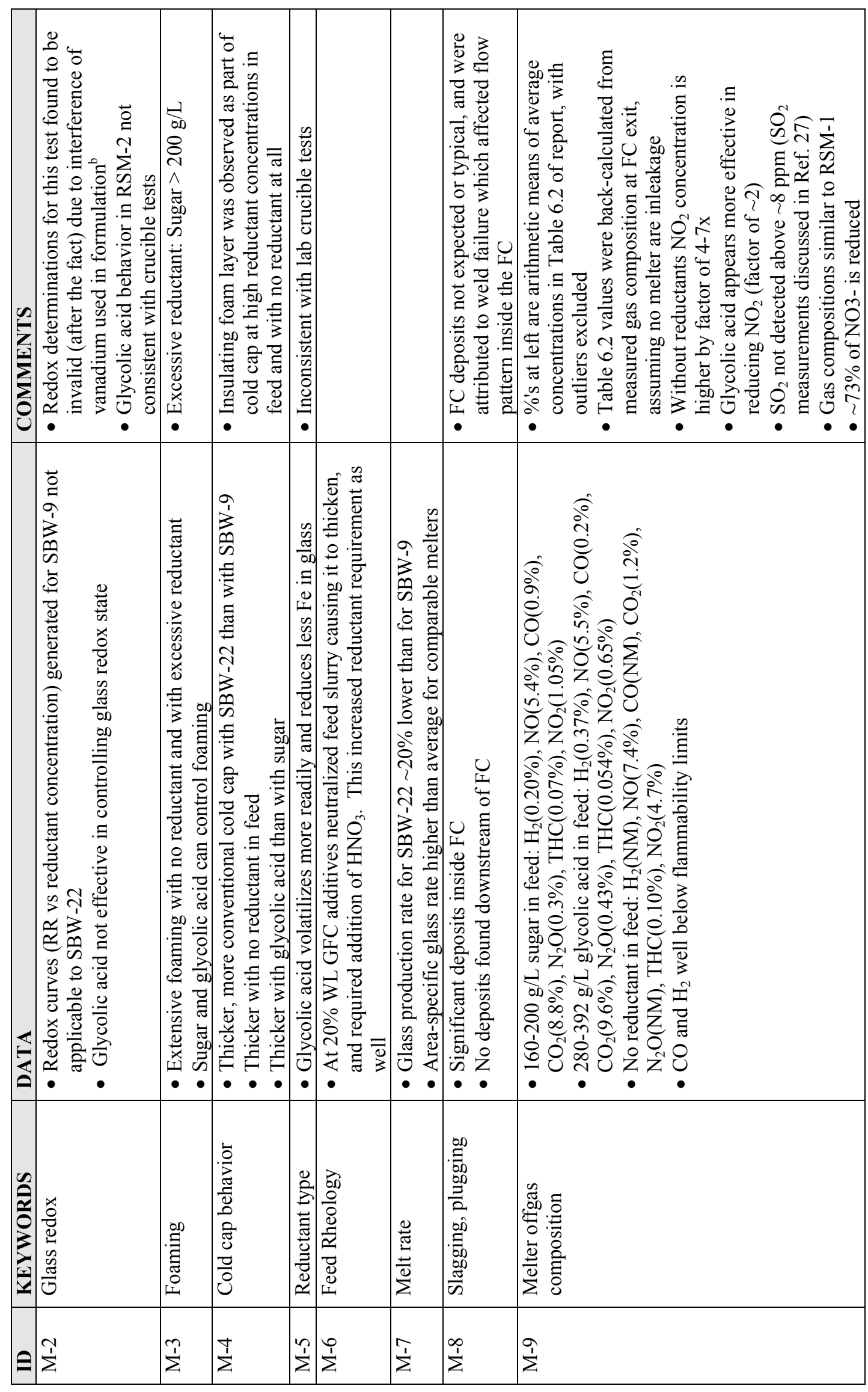

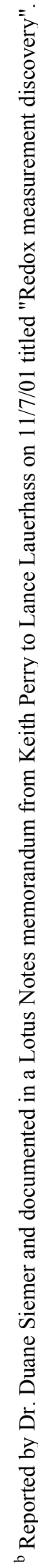




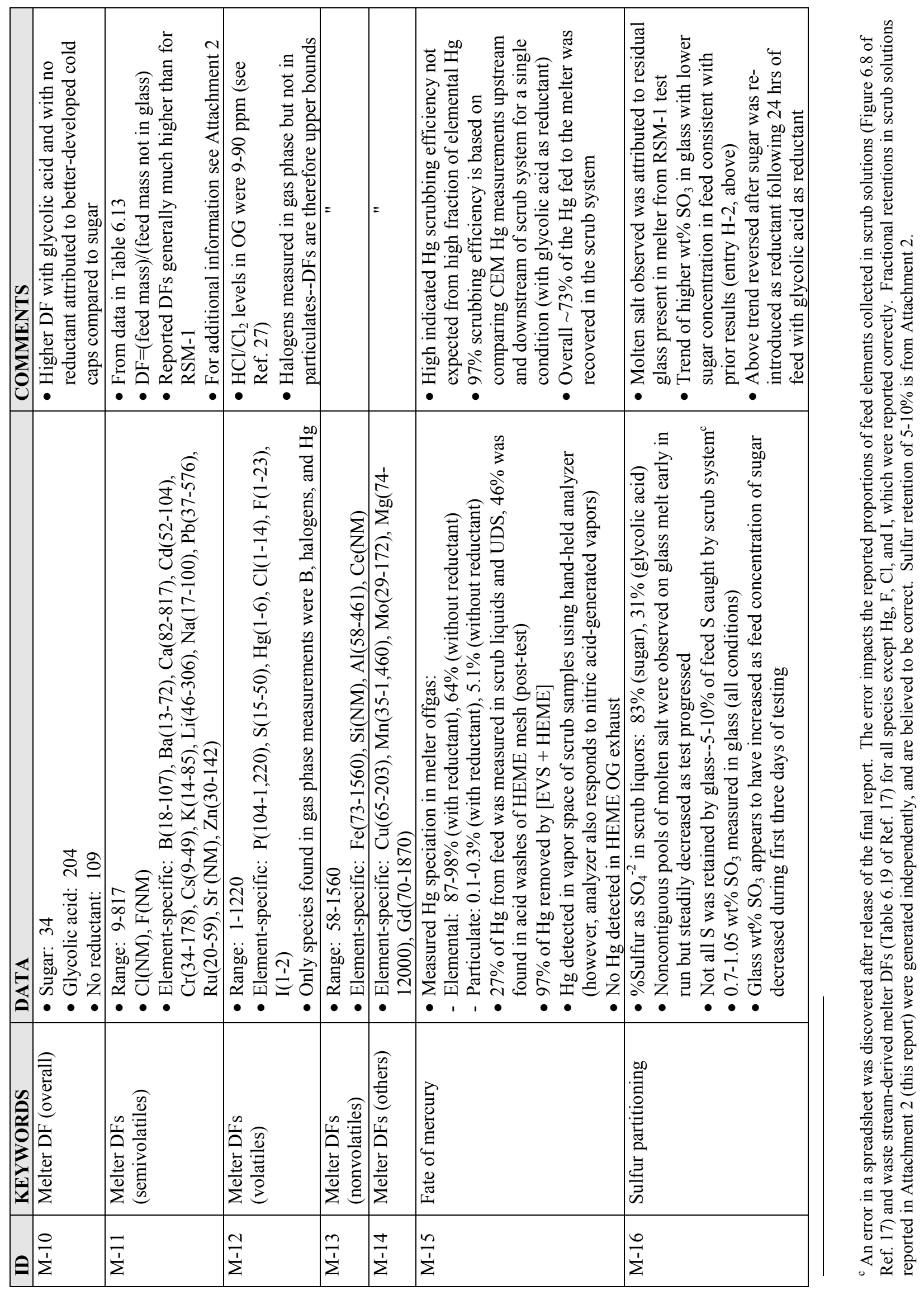




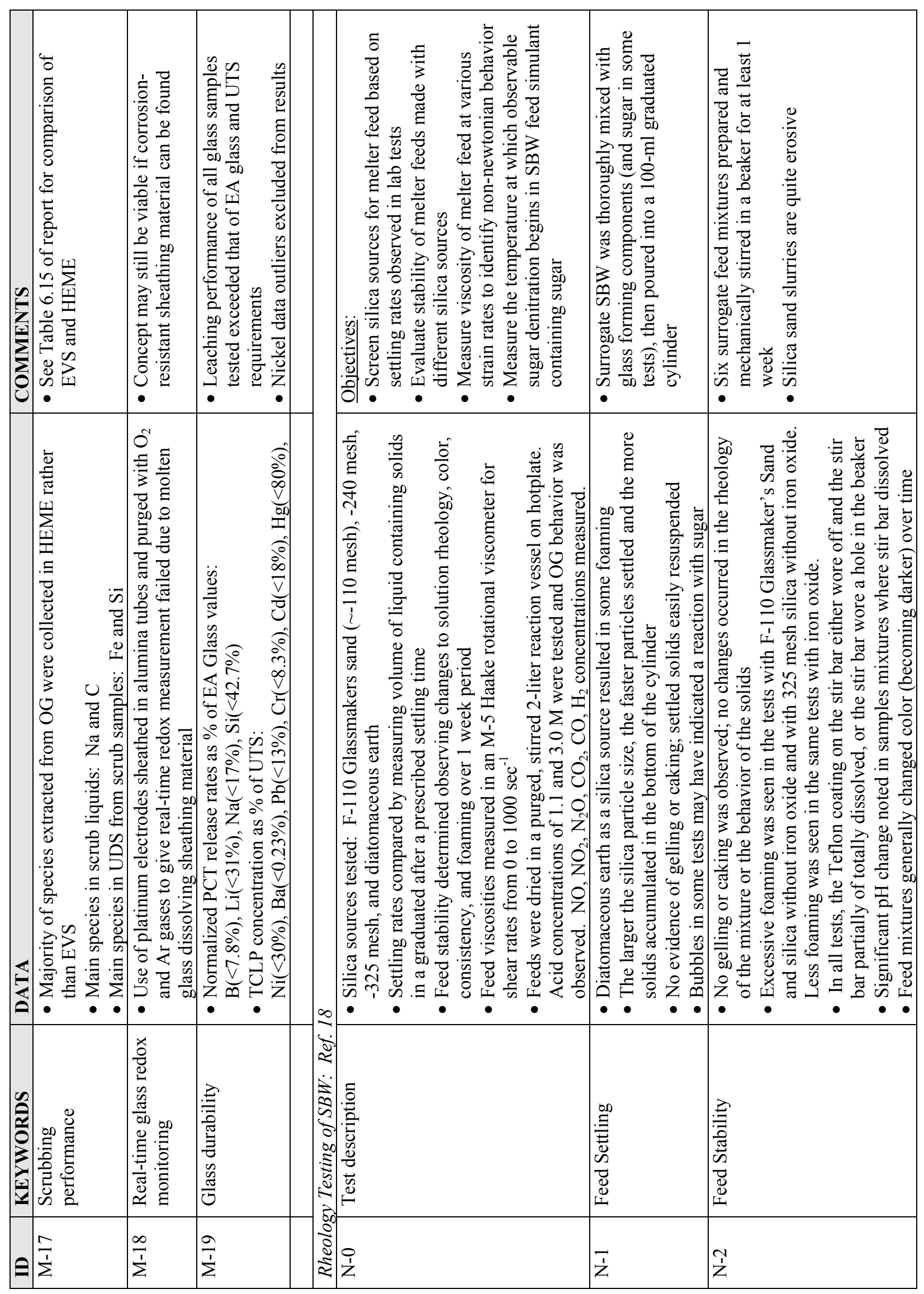




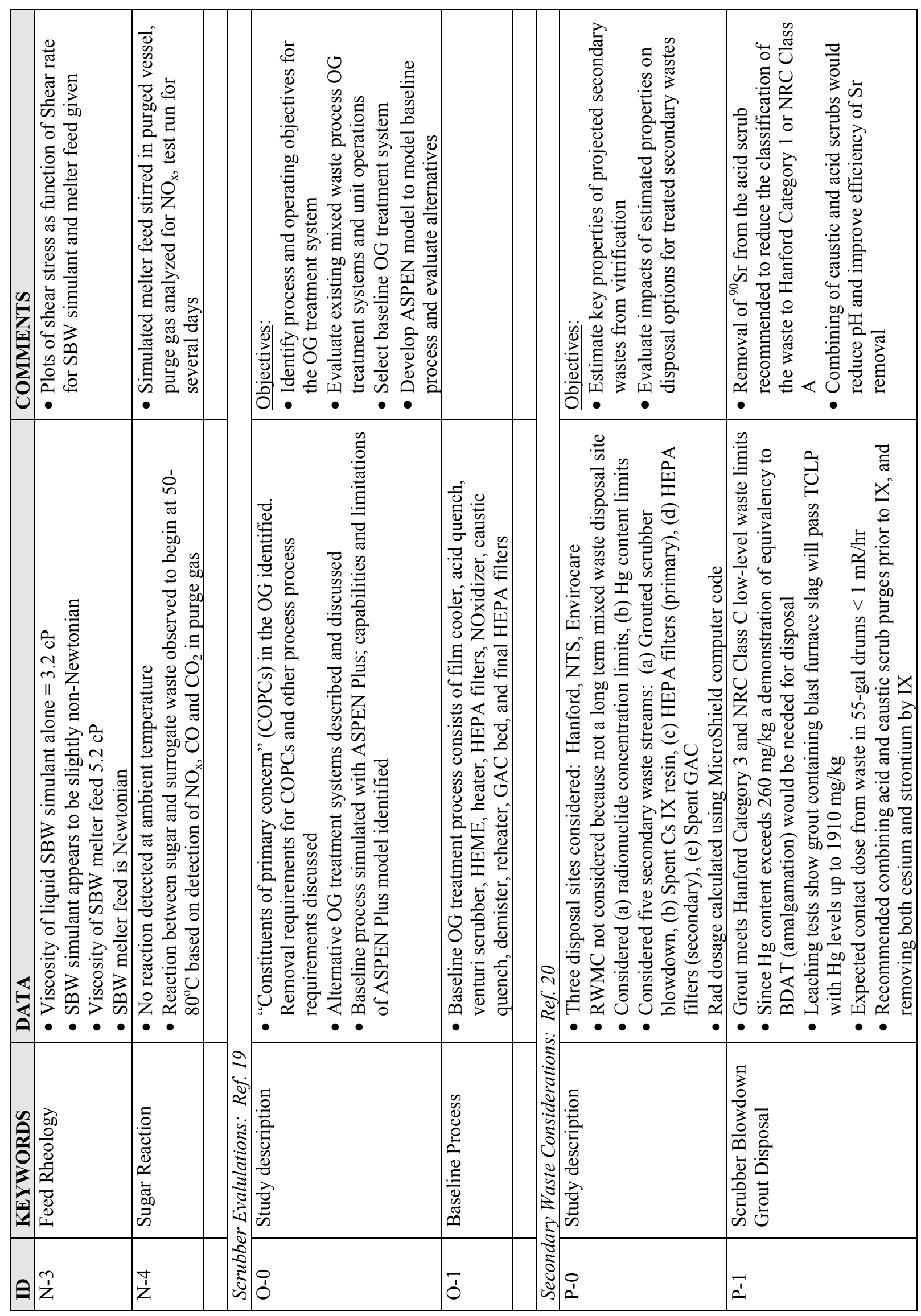




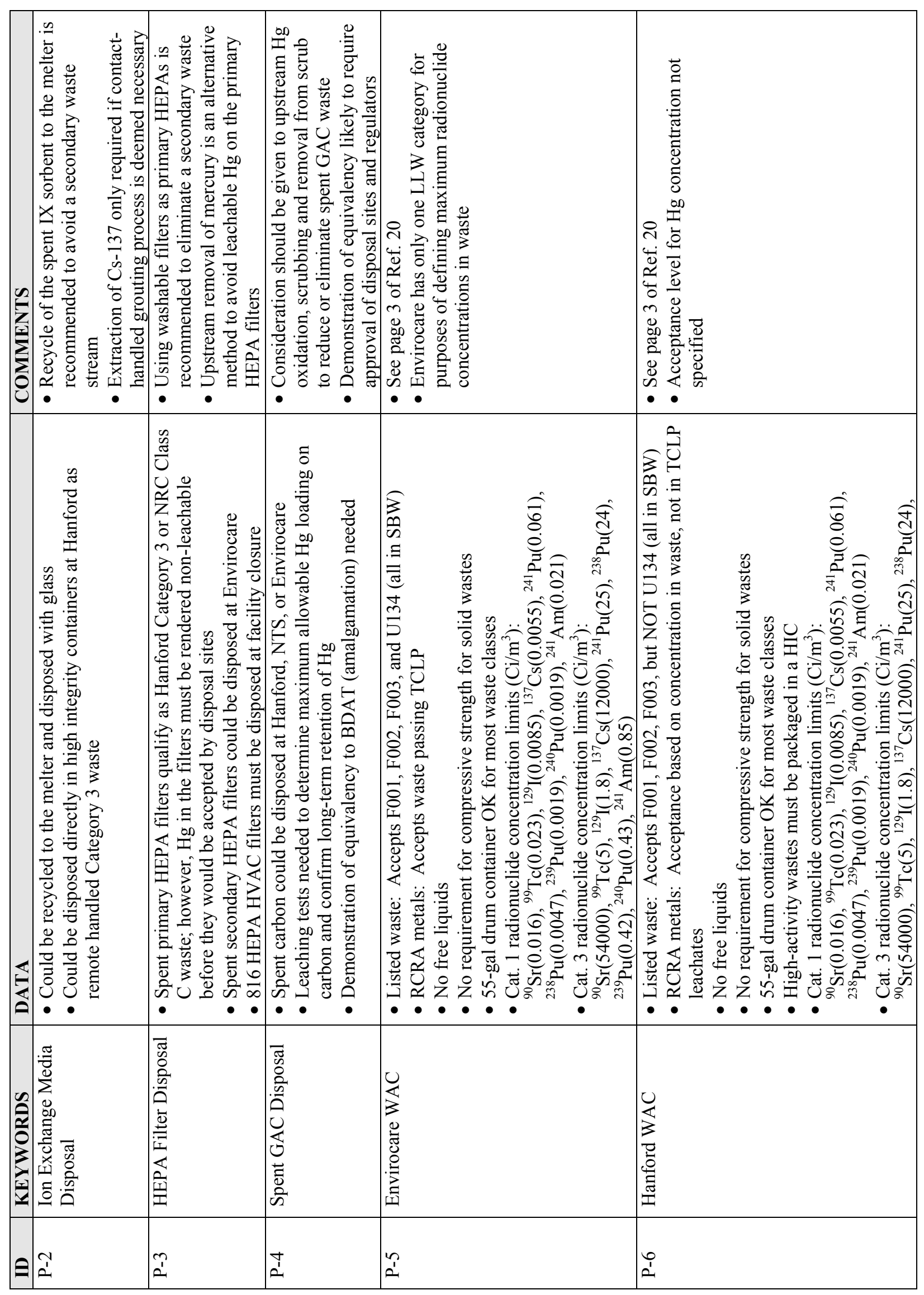




\begin{tabular}{|c|c|c|c|c|c|}
\hline & \multirow{4}{*}{\multicolumn{2}{|c|}{ 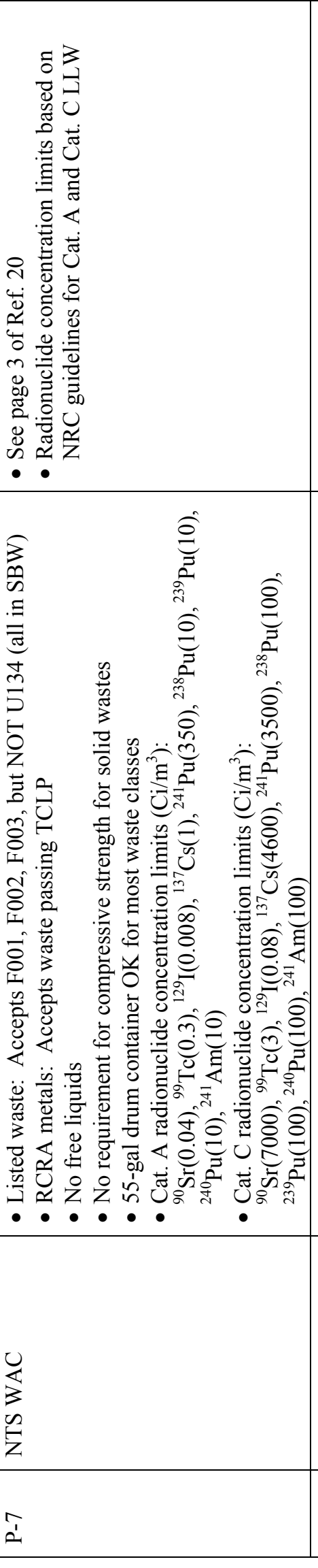 }} & \multicolumn{2}{|r|}{ 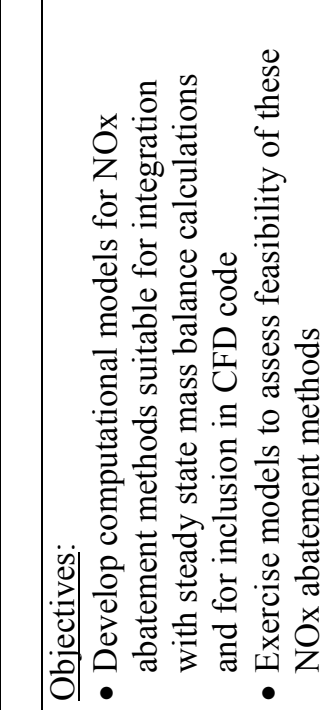 } & 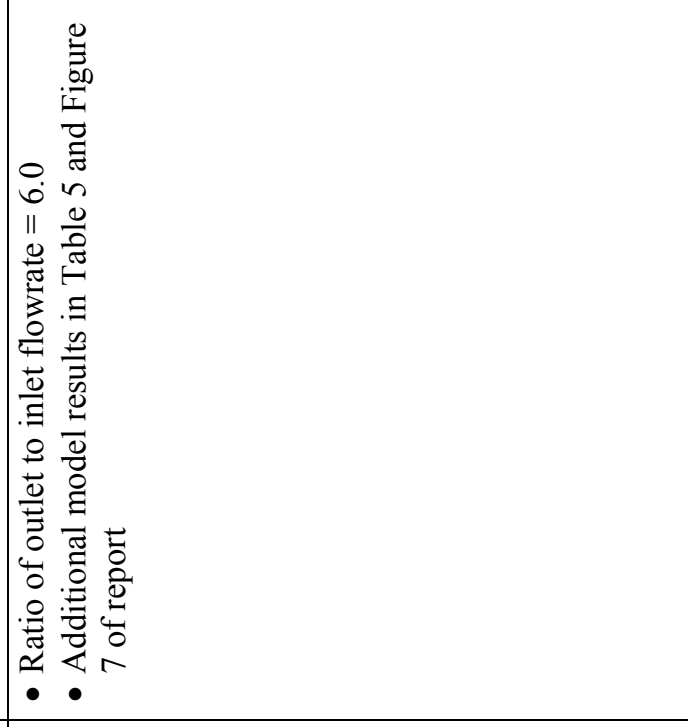 \\
\hline \multirow{3}{*}{ 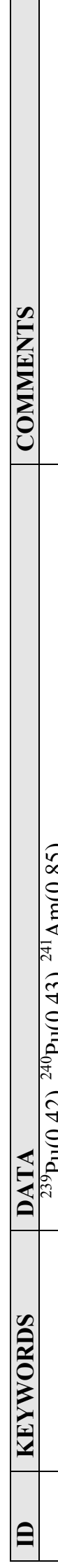 } & & & & 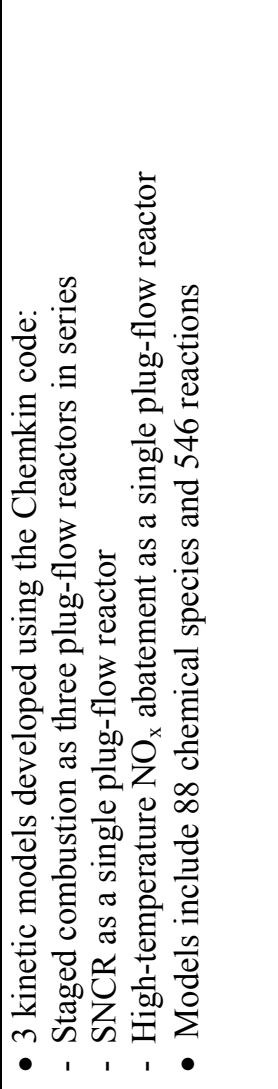 & 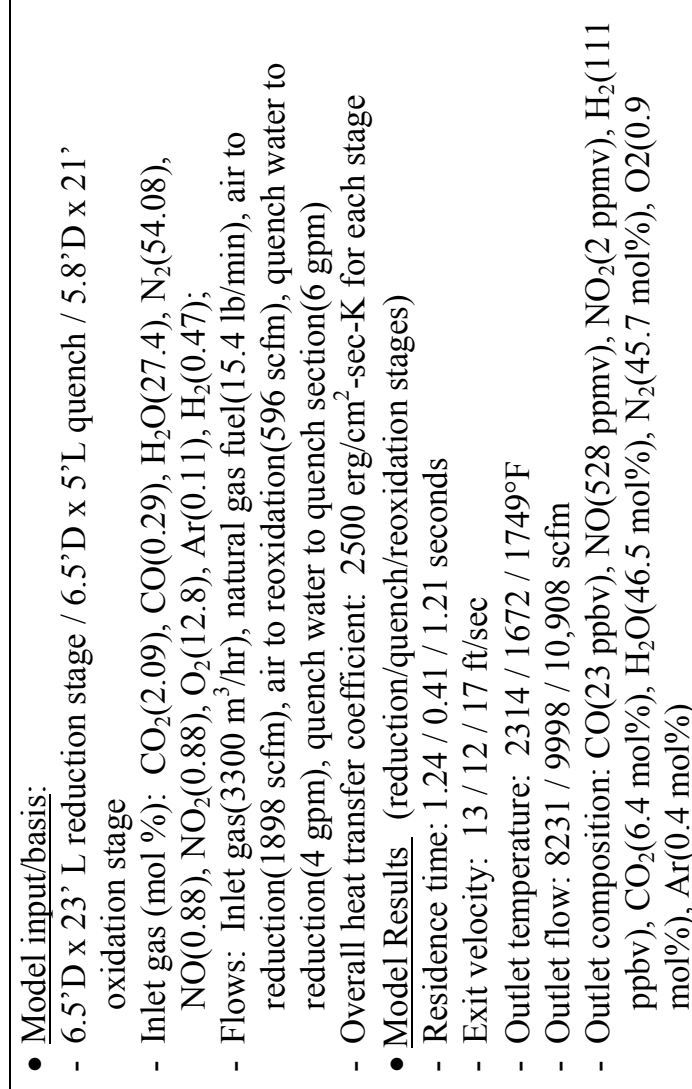 \\
\hline & & & & & \\
\hline & & & & & $\dot{\alpha}$ \\
\hline
\end{tabular}




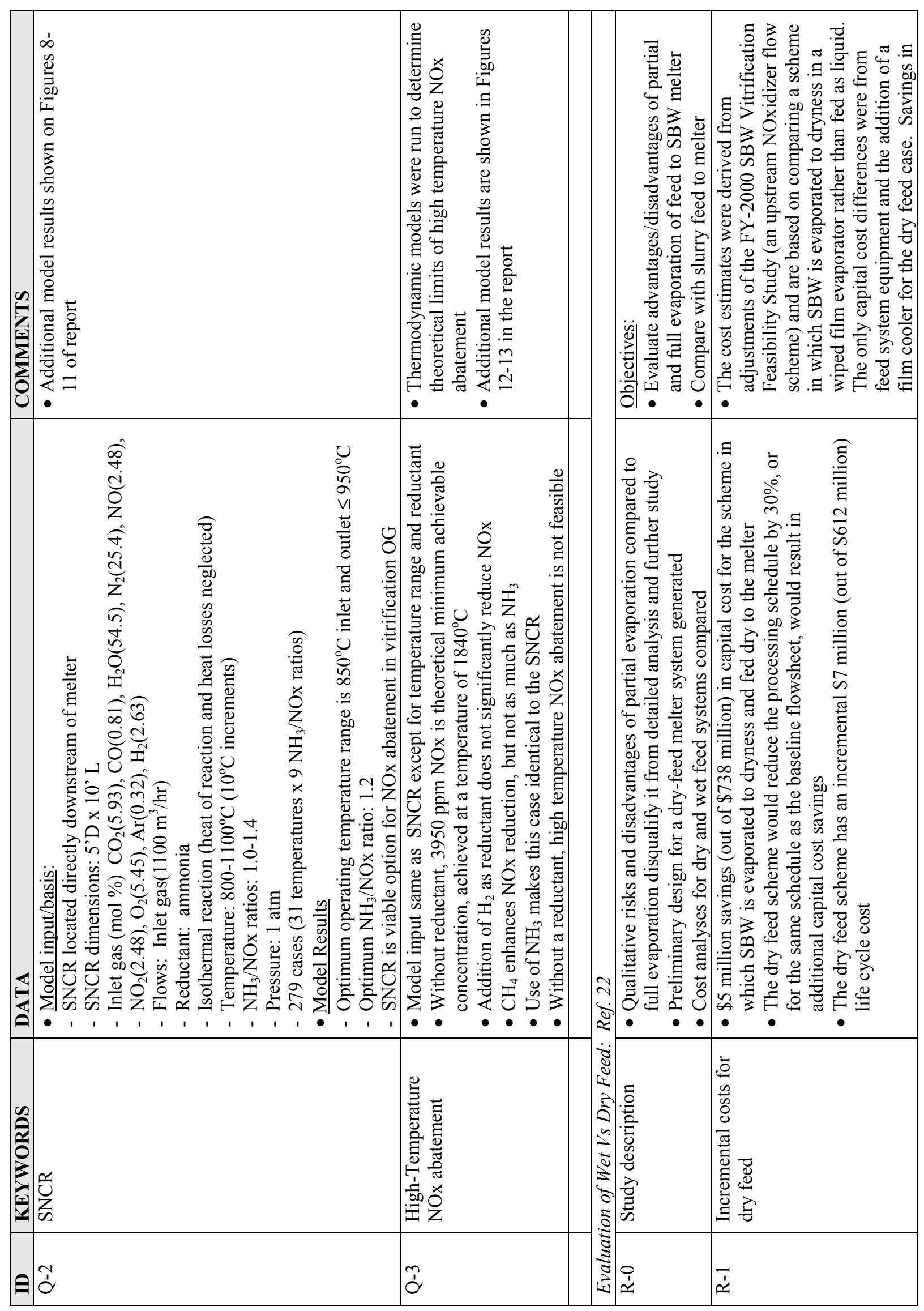




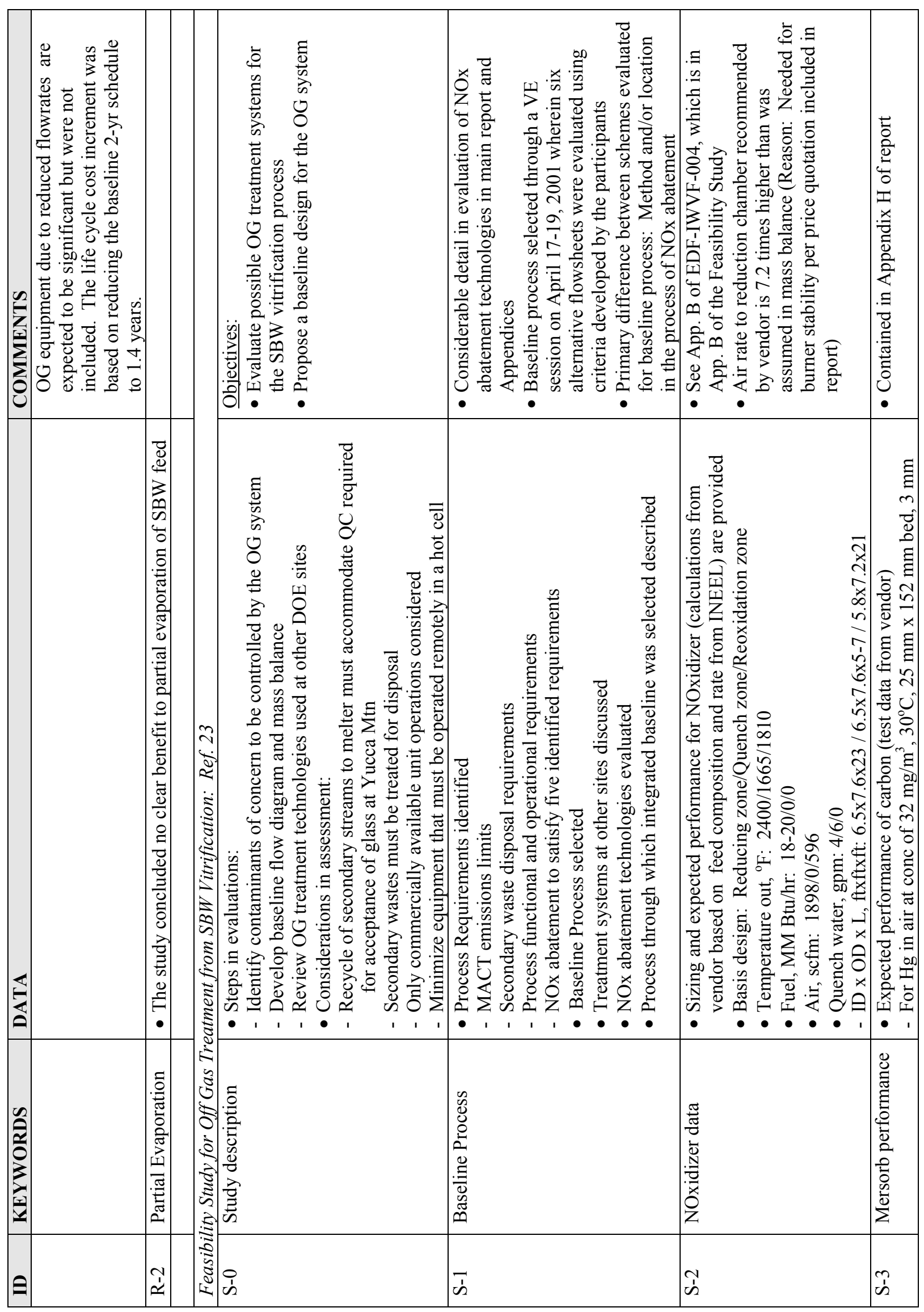




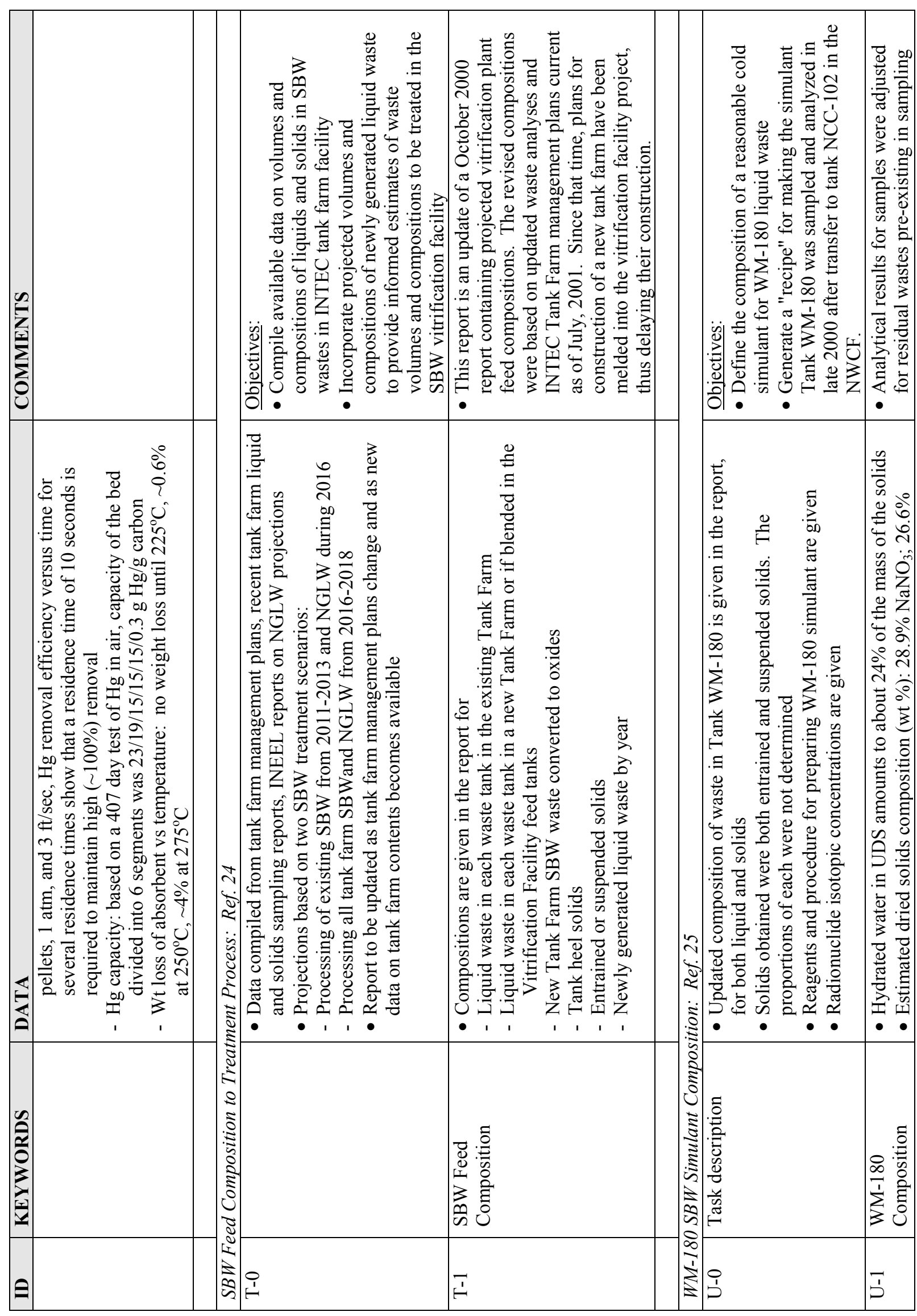




\begin{tabular}{|c|c|c|c|c|c|c|c|c|}
\hline 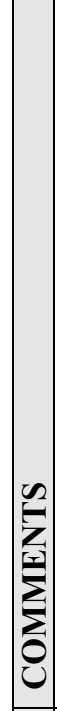 & 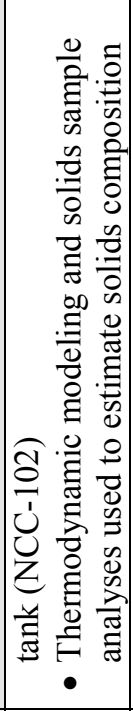 & 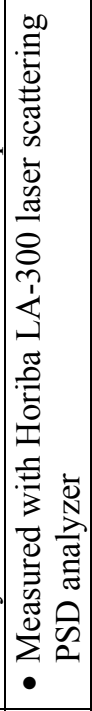 & 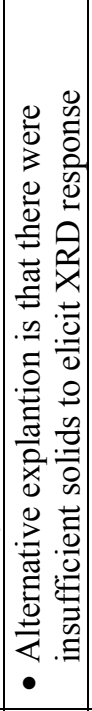 & & 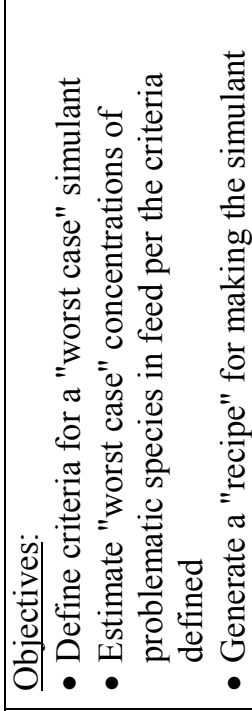 & 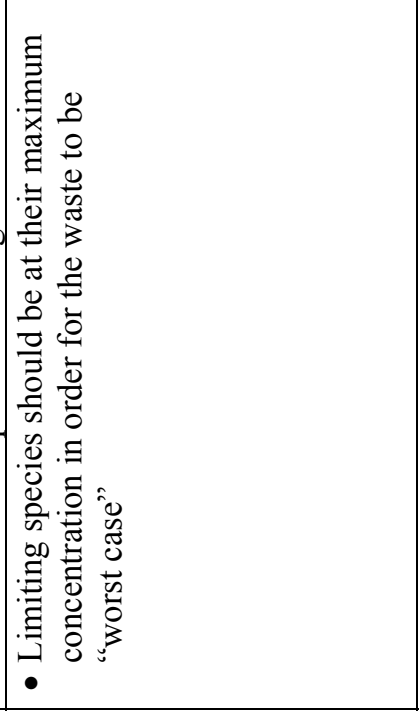 & 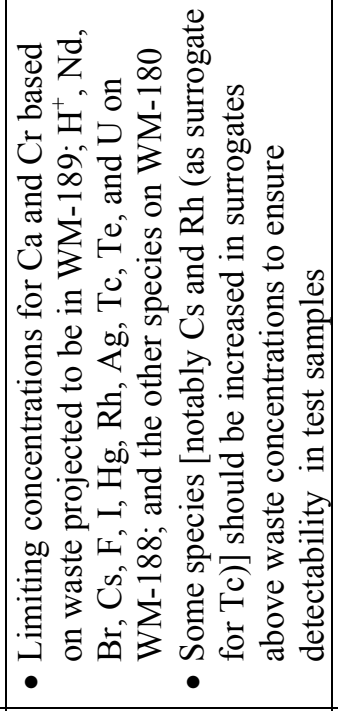 & 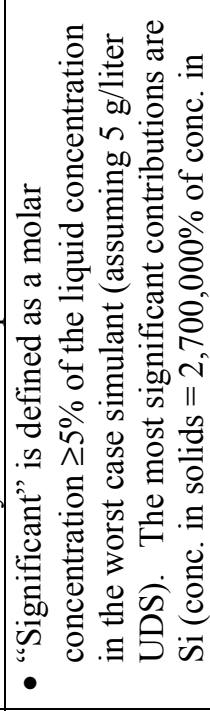 \\
\hline & 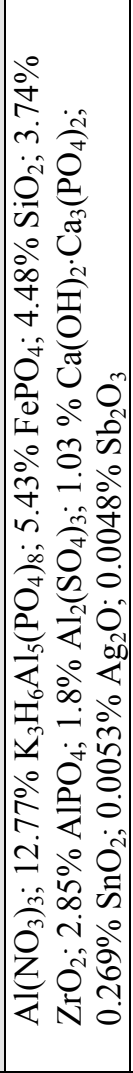 & 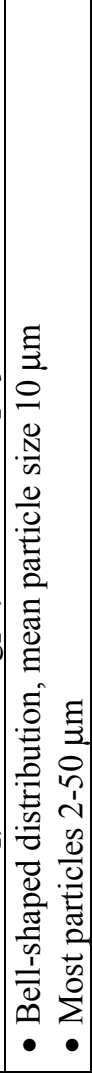 & 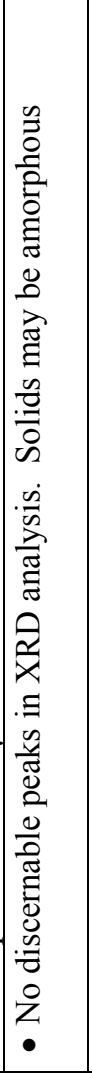 & 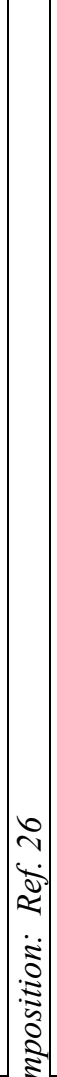 & & 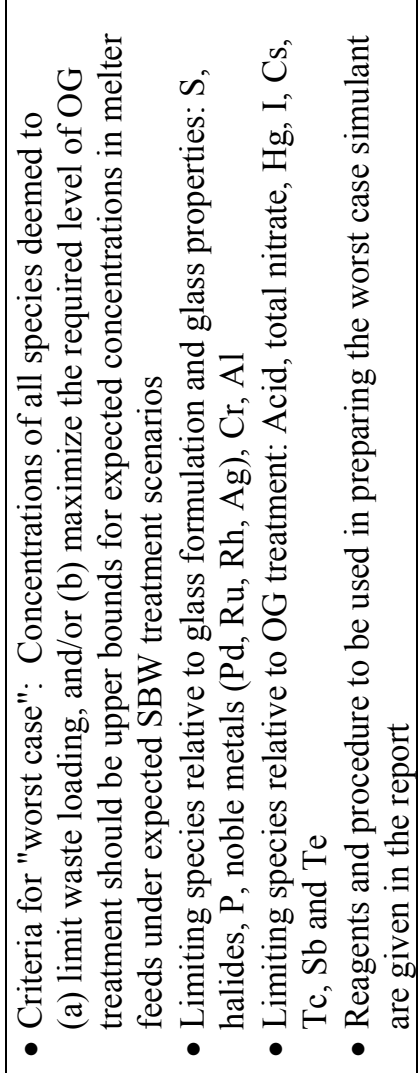 & 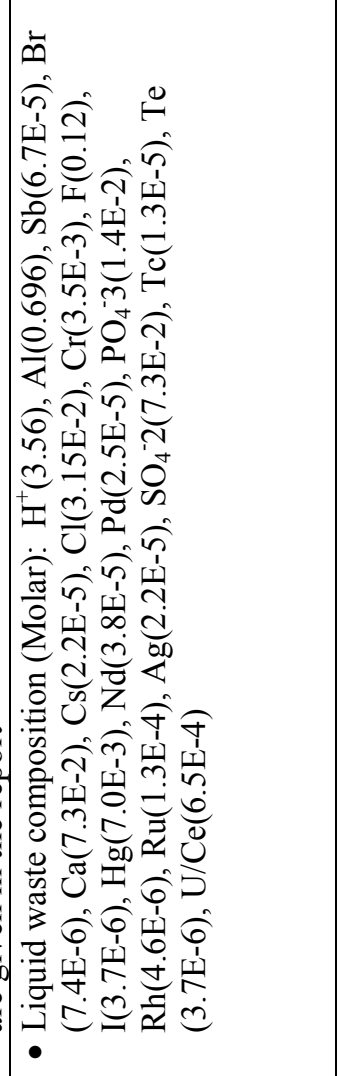 & 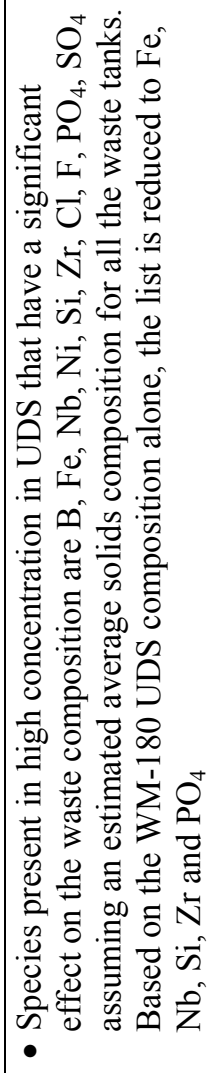 \\
\hline 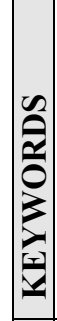 & & 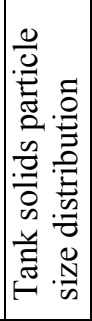 & 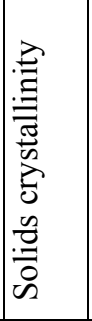 & 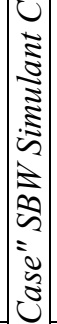 & 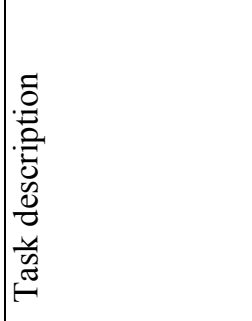 & 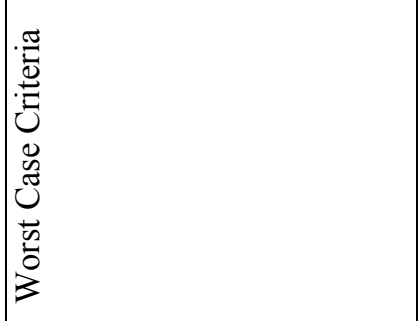 & 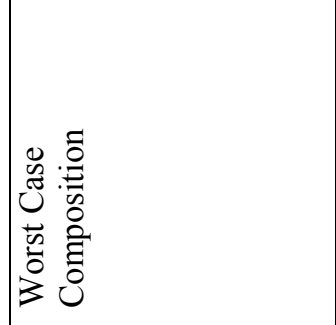 & 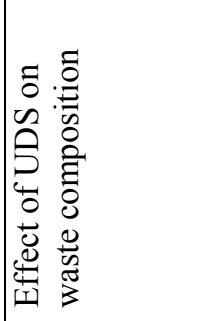 \\
\hline$\Theta$ & & 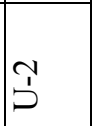 & $\hat{b}$ & & $i^{1}$ & $\vec{\prime}$ & $\stackrel{1}{1}$ & $i^{\prime}$ \\
\hline
\end{tabular}




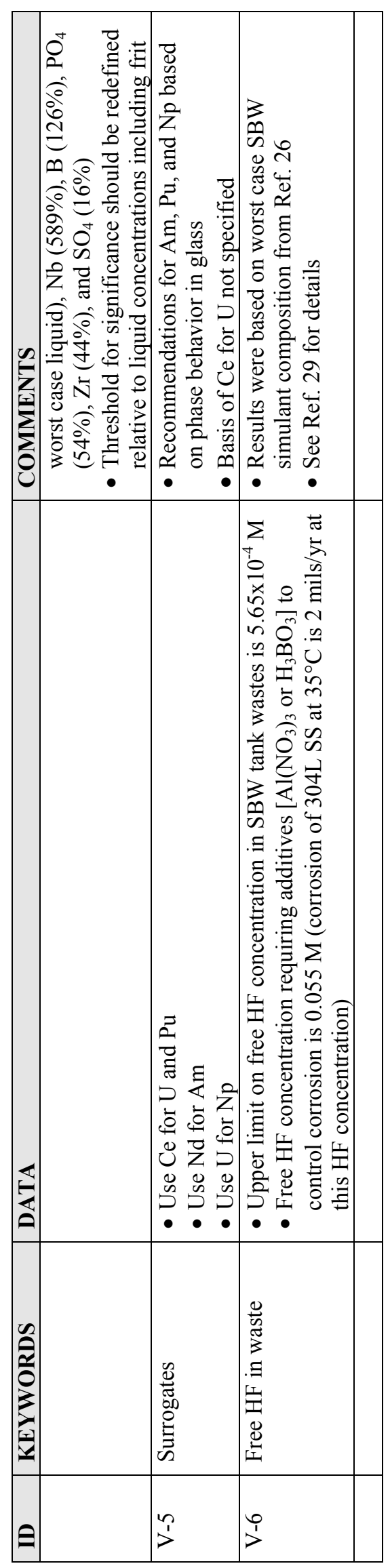




\subsection{DBEs Impacted by 2001 Tasks}

Many of the FY 2001 tasks generated results which impacted some DBEs. Table 2-2 identifies which DBEs were so-impacted. Columns in the table represent all 22 tasks completed in FY 2001 and column headings give references to the respective reports which describe them. Rows in the table represent the DBEs. For each DBE listed the column entries below the DBE name indicate which tasks impacted that DBE and provides the row IDs from Table 2-1 which contain the relevant information. 


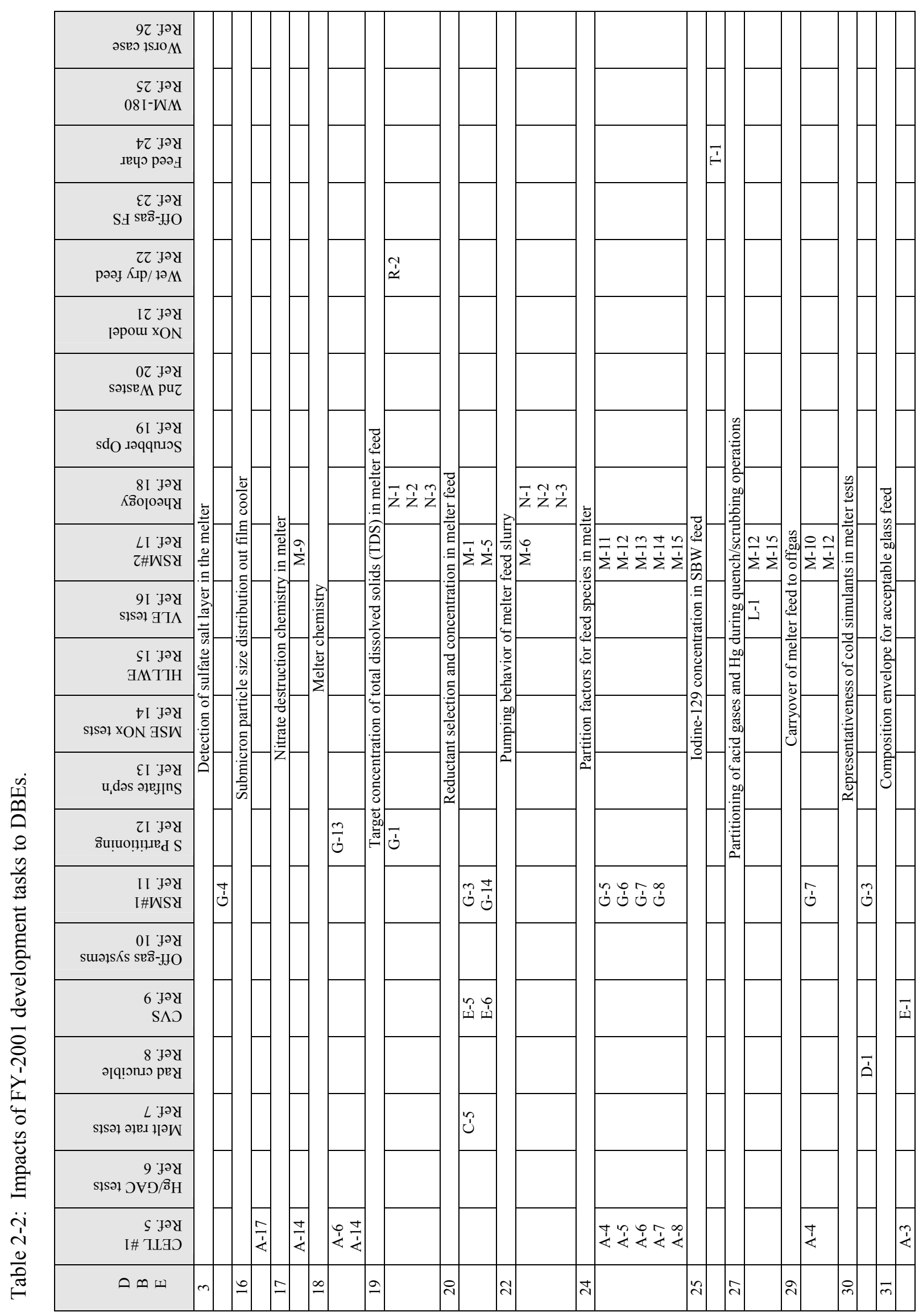




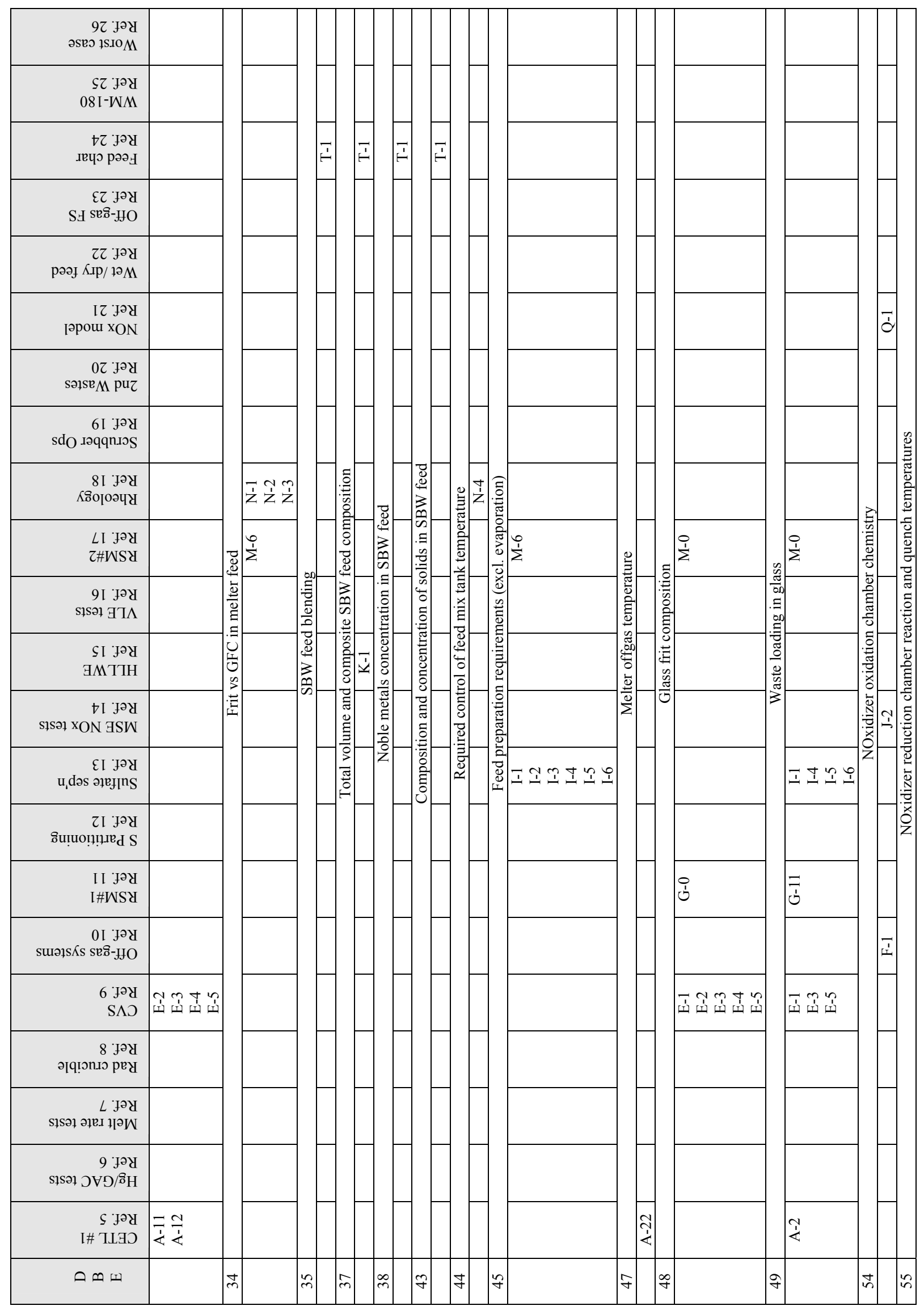




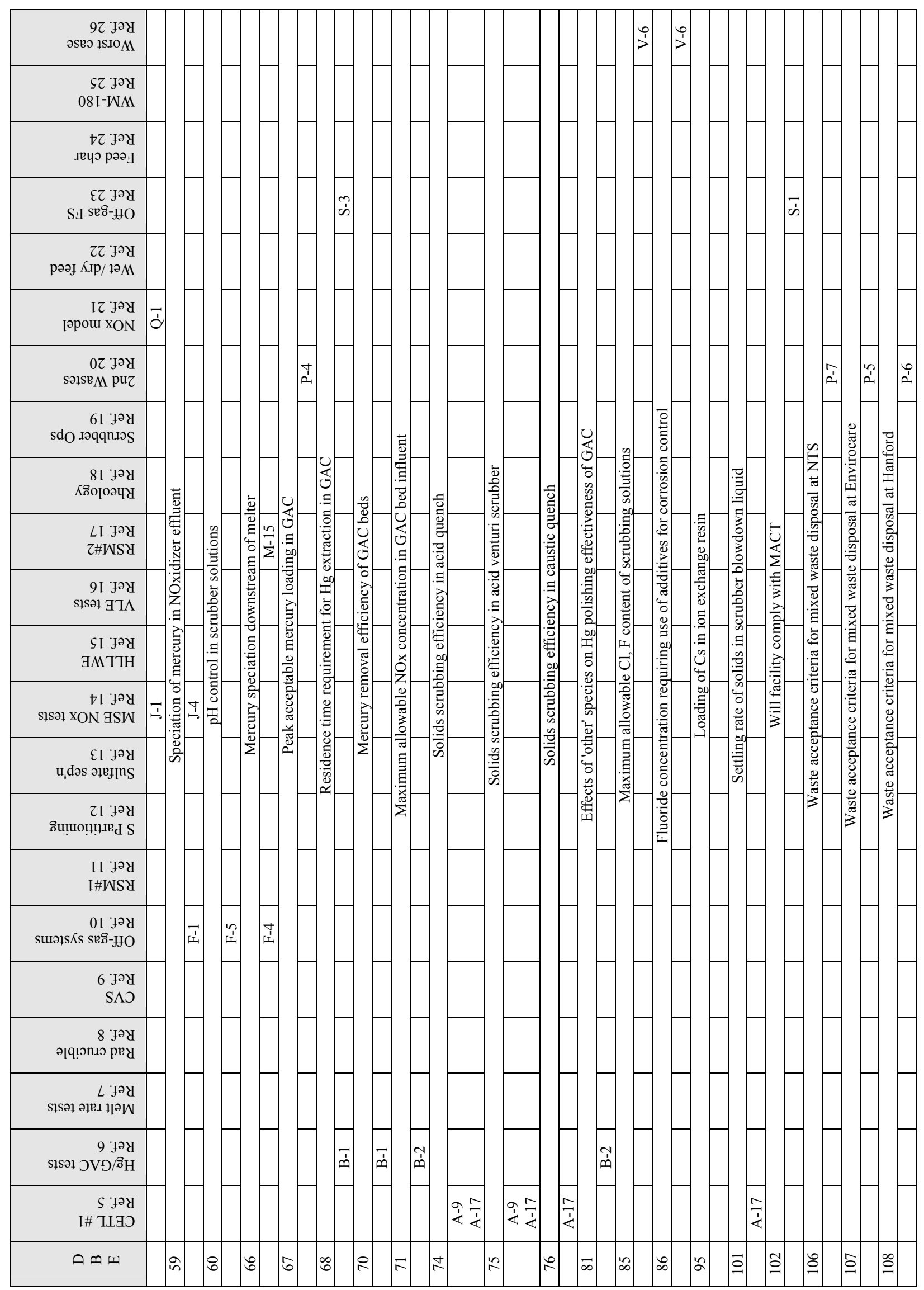




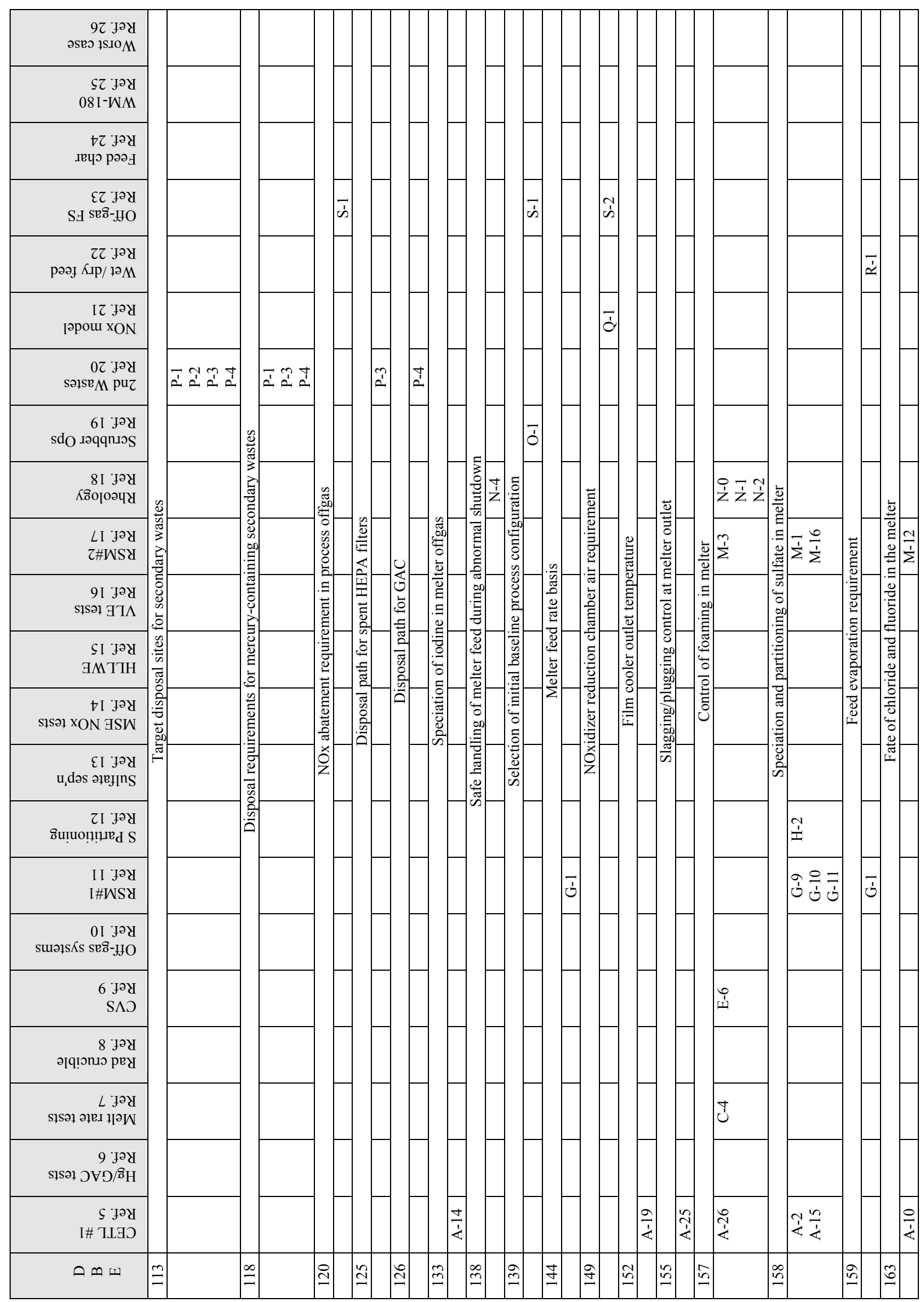




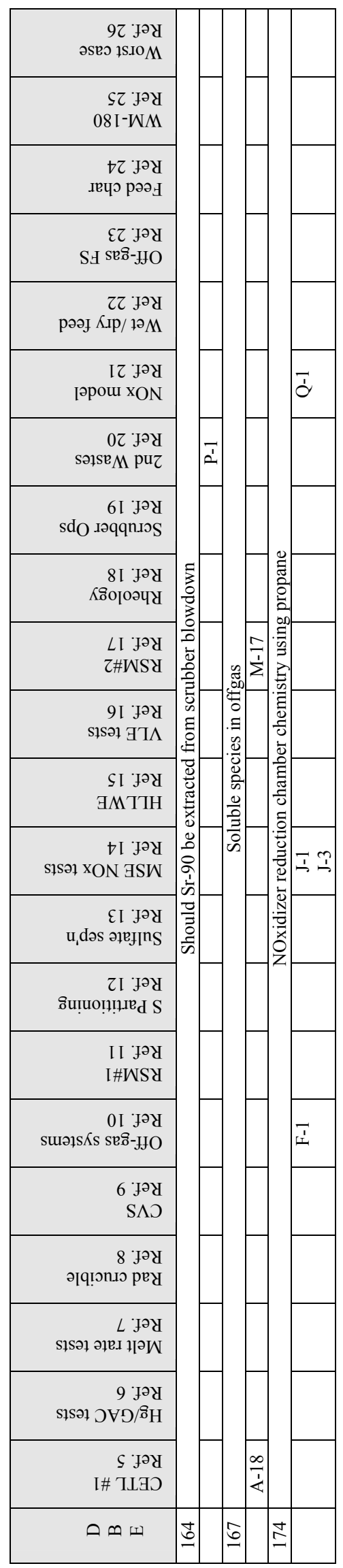




\section{IMPACTS OF FY 2001 WORK TO DBES}

This section provides a brief discussion of how the work performed in the last year affects Design Basis Elements (DBEs). Data that pertained to approximately 50 DBEs were obtained during the year. In many cases the new data substantiated earlier assumptions contained in the DBEs.

\section{DBE-3 Detection of Sulfate Salt Layer in the Melter}

Experience from FY 2001 crucible, research-, and pilot-scale melter tests suggests that formation of a segregated sulfate salt at some time during vitrification of SBW is likely to occur. Control of the growth and extent of the salt layer is necessary from several standpoints (safety, corrosion, removal and disposal of accumulated salt). Thus, unless the concentration of sulfate is reduced by preprocessing of the feed it will be necessary to monitor the formation and growth of any salt layer that forms on the surface of the glass in the melter. The method used to accomplish this in the pilot tests to date (manual probing of the melt with a refractory rod) is not viable for a production scale, remotely-operated melter. Therefore, a reliable, automated method for detecting the salt layer must be developed and demonstrated. A possible approach is to monitor electrical conductivity across the melt using a refractory probe. To be effective this approach would require a design that promotes preferential salt accumulation around the probe. This would ensure detection of the salt phase before development of a continuous layer across the surface of the melt and shorting of the electrodes.

\section{DBE-16 Submicron Particle Size Distribution Out Film Cooler}

Knowing the particle size distribution (PSD) of entrained solids in the melter offgas is necessary in defining requirements for design of equipment to remove the solids. Measurements of PSD made during the Clemson-1 test (Ref. 5) are the first measurements of solids in the offgas of melter tests of SBW surrogate waste. Based on SEM analysis of particulate samples from the Clemson-1 tests, three different particle shapes were identified, and particle sizes estimated for each, as well as for the aggregate. Additional data is needed to determine (a) the effects of feed and melter operating parameters on PSD of offgas solids, (b) the normal variation in PSD is during steady state operating conditions, and (c) the composition of the smaller particle fractions. It may also be necessary to characterize the behavior of "rod-like" particles with respect to removal in scrubbers, filters, etc. Such particles constituted roughly $25 \%$ of those collected in the Clemson- 1 test.

\section{DBE-17: Nitrate Destruction Chemistry in Melter}

Nitrates and nitric acid in the waste are mostly destroyed in the melter by reaction with sugar, resulting in $\mathrm{N}_{2}, \mathrm{~N}_{2} \mathrm{O}, \mathrm{NO}$ and $\mathrm{NO}_{2}$ in the melter offgas. Small amounts of nitric acid can volatilize and nitrates can be entrained in the offgas. All melter tests in which offgases were analyzed for nitrogen species can contribute to this DBE. However, interpreting experimental melter offgas data to derive nitrate destruction chemistry is complicated by several factors. Off-gas samples are taken and hence reflect conditions not at the melter outlet but at points downstream, usually the film cooler outlet. Reactions continue to occur, most notably the shift of $\mathrm{NO}$ to $\mathrm{NO}_{2}$ as the offgas is cooled from the melter outlet temperature or as the sample cools to room temperature, or oxidation and capture of NO on surfaces or in scrub solutions. Secondly, air in-leakage to the melter, which cannot be accurately measured, masks the amount of $\mathrm{N}_{2}$ produced from nitrate destruction. And finally, as experienced in pilot testing during FY 2001, offgas analyses may not include all nitrate destruction products or may not be capable of measuring the low concentrations of some species.

Data from the Clemson-1 test (Ref. 5) includes measurements of $\mathrm{NO}, \mathrm{NO}_{2}, \mathrm{HNO}_{3}, \mathrm{~N}_{2} \mathrm{O}$ and $\mathrm{N}_{2} \mathrm{O}_{4} / \mathrm{N}_{2} \mathrm{O}_{5}$ at the film cooler outlet (estimates of melter outlet composition were extrapolated from FC 
dilution). The $\mathrm{NO}$ to $\mathrm{NO}_{2}$ ratio seen in this test was 1:0.9. Data from this experiment could provide a basis for mass balance calculation of the amount of $\mathrm{HNO}_{3}$ and $\mathrm{N}_{2} \mathrm{O}$ in the melter offgas. The data shows that the concentration of $\mathrm{N}_{2} \mathrm{O}_{4}$ is small, and can either be neglected, or combined with $\mathrm{NO}_{2}$ since $\mathrm{N}_{2} \mathrm{O}_{4}$ is an intermediate in the absorption of $\mathrm{NO}_{2}$ by water.

Data from RSM-1 (Ref. 11) includes calculated $\mathrm{NO}, \mathrm{N}_{2} \mathrm{O}$ and total $\mathrm{NO}_{\mathrm{x}}$ concentrations in the melter offgas based on analysis of samples downstream of the film cooler. However poisoning of the $\mathrm{NO}_{\mathrm{x}}$ analyzer's catalytic reactor prevented obtaining $\mathrm{NO}_{2}$ (or total $\mathrm{NO}_{\mathrm{x}}$ ) concentrations. The $\mathrm{N}_{2} \mathrm{O}$ concentrations seen in RSM- 1 were typically $24 \%$ of the NO concentration; an order of magnitude higher than the Clemson-1 data shows. The reason for this large difference in the NOx chemistry is not known and may require additional testing.

$\mathrm{NO}_{2}$ measurement difficulties experienced in RSM-1 were overcome for the RSM-2 test which provided measurements of $\mathrm{NO}, \mathrm{NO}_{2}$, and $\mathrm{N}_{2} \mathrm{O}$ at the film cooler outlet (Ref. 17). The $\mathrm{NO}$ to $\mathrm{NO}_{2}$ ratio with sugar as reductant in this test was 1:0.2, which differs by more than a factor of four from the Clemson-1 data. The NO: $\mathrm{N}_{2} \mathrm{O}$ ratio for the two tests differed by a similar factor (1:0.017 vs 1:0.056 in Clemson-1 and RSM-2, respectively) but in the opposite direction. These results suggest significantly different nitrate destruction chemistry occurring in the Clemson and RSM melters.

\section{DBE-18: Melter Chemistry}

DBE-18 contains assumptions regarding the pyrolysis and oxidation of sugar in the melter and decomposition of carbonates that may be present in the waste. Clemson-1 offgas data (Ref. 5) shows nominal ratios of $\mathrm{CO}$ to $\mathrm{CO}_{2}$ and $\mathrm{H}_{2}$ to $\mathrm{CO}_{2}$ in the melter offgas of 0.096:1 and 0.086:1. These data could be used to update DBE-18, which presently shows a $\mathrm{CO}$ to $\mathrm{CO}_{2}$ ratio of $0.117: 1$ and a ratio of hydrogen to $\mathrm{CO}_{2}$ of $0.013: 1$. However, the large variation in the measured $\mathrm{CO}_{2}$ concentration $(99 \%)$ makes this questionable, especially in light of the offgas data from RSM-1 (Ref. 11) which show average ratios of 0.21 for $\mathrm{CO}$ to $\mathrm{CO}_{2}$ and $0.035 \mathrm{H}_{2}$ to $\mathrm{CO}_{2}$, and from RSM-2 (Ref. 17) which show corresponding ratios of 0.10 and 0.027 , respectively.

Data from Clemson-1, RSM-1, and RSM-2 could be used to provide a conservative basis for organics in the melter offgas, which are presently assumed to be zero. Clemson-1 data show an average 116 ppm THC in the melter offgas while the RSM-1 and RSM-2 data show 1140 and 700 ppm, respectively. The Clemson-1 data also includes analyses that identify many of the organic compounds present in the offgas.

\section{DBE-19: Target Concentration of Total Dissolved Solids (TDS) in Melter Feed}

The TDS concentration in the melter affects the melt rate and hence the melter size requirement. The higher the dissolved solids (or lower the water) in the waste, the higher the melt rate. However, high solids concentrations may cause problems in the feed system, such as precipitation, agglomeration and settling of solids in tanks and plugging in transfer lines. An engineering study was performed in FY-2001 (Ref. 22) that briefly discussed partial evaporation of SBW, but concluded that there was no clear benefit to partial evaporation. The study then did a more detailed evaluation of total evaporation (see DBE-159). Data from the RSM-1 (Ref. 11) test confirmed that the melt rate was limited by the water content of the feed.

Rheology studies (Ref. 18) showed that the present feed, without evaporation, has acceptable rheological properties. However, the rheology studies were performed with solids equivalent to a waste loading of $35 \%$ and not at lower waste loading. While questions remain regarding possible benefits from partial or complete evaporation of the melter feed, the data generated in FY-2001 support the present 
assumption that the TDS of the melter feed, assuming no evaporation, would be acceptable for a $35 \%$ waste loading. In RSM-2 tests, however, which were run at $20 \%$ waste loading using formulation "SBW-22", addition of GFCs to the SBW simulant resulted in gelling and required addition of either nitric acid or water to enable transport of the feed via the RSM-2 feed system.

The target concentration of TDS in the feed will depend upon whether GFCs or glass frit is used. The evaluation between frit and GFCs has yet to be performed and documented.

\section{DBE-20: Reductant Selection and Concentration in Melter Feed}

In work performed in the past year, criteria were defined for selection of a reductant (Ref. 7), followed by laboratory-scale slurry-fed melter tests at PNNL and melt rate furnace tests at CETL. These tests evaluated four reductants - starch, sugar, carbon and glycolic acid. The test results showed that only sugar met the reductant performance criteria (entry C-5 in Table 2-1). RSM-2 (Ref. 17) tests suggest that glycolic acid is unsuitable as the sole reductant in the feed. However, the results may also suggest that use of sugar and glycolic acid together may be superior to either alone (based on the observation that glycolic acid is more effective as a gas phase reductant while sugar is more effective in controlling redox in the glass (see entries M-2 and M-9 of Table 2-1).

The concentration of reductant in the melter feed affects several performance parameters, namely glass properties, foaming in the melter, glass melt rate, nitrate reduction, sulfate content of the glass and whether a salt layer forms and grows on the melt. While the test data shed some light on the relationships between reductant concentration and these performance parameters, it is and unclear regarding others. For example, crucible tests indicated that the sugar concentration (varied from 77 to $164 \mathrm{~g} / \mathrm{L}$ of SBW at a $35 \mathrm{wt} \%$ loading and SBW-2 frit) had little effect on salt formation (entry E-5 in Table 2-1). However, the data from RSM-1 tests showed increased reductant levels mitigated molten salt accumulation at similar waste loadings (entry G-11 in Table 2-1). RSM-2 tests showed that no salt layer was observed with the SBW-22 formulation with no sugar at all in the feed (entry M-1 in Table 2-1). The redox ratio at which metal oxides in the glass are reduced and form a separate molten or crystalline phase sets an upper limit for reductant concentration. There may also be a point at which glass durability is unacceptably compromised by too high a reductant concentration (and redox ratio). However, presumably there are lower limits on redox ratio (and corresponding reductant concentration in the feed) required to control foaming, melt rate, and sulfate layer formation and growth to within acceptable ranges.

Data from tests completed to date should be evaluated as a whole to (a) determine whether credible correlations can be identified between feed sugar concentration and the above performance measures, (b) decide what additional testing may be needed, and (c) understand the chemistry and attempt to formulate a credible model that might be tested against the data. Once valid correlations are in hand they can be used to optimize the reductant concentration.

\section{DBE-22: Pumping Behavior of Melter Feed Slurry}

Initial rheology studies (Ref. 18) determined viscosities and settling and mixing characteristics for simulated melter feeds made with four types of silica plus glass forming chemicals added to liquid SBW simulant. The testing confirmed that (a) addition of sugar, GFCs and particulate silica to the feed increased the "effective" viscosity (by a factor of nearly 2), and (b) the finer the solids the longer the settling time and the easier it would be to maintain a solid frit in suspension. Testing also indicated that addition of iron oxide may inhibit reactivity of the blended feed and that feed with solid frit will be erosive. 
Additional testing with actual frit for SBW-22 (or other formulations determined appropriate for the different SBW waste compositions) should be done using an actual mixing and feed system to determine parameters that ensure a reliable, homogeneous feed to the melter. The above observations and data could be used in scoping the testing program. Test data would be used to provide impeller size, speed, and position and minimum tank level required to provide a homogeneous feed. Additional information that is needed include erosion effects of feed on the expected materials of construction, the changes to feed rheology that occur over time as reactions proceed (particularly precipitation reactions), and a determination of whether frit should be used in place of GFCs.

\section{DBE-24 Partition Factors for Feed Species in Melter}

DBE-24 contains partition factors assumed in the mass balance for all nonvolatile and semivolatile species in the melter. Species entrained in the melter offgas may be particulate in the feed entrained in the offgas, solids crystallized from the feed and entrained in the offgas, molten glass splattered into the melter vapor space and carried into the offgas, or volatile species vaporized in the melter and then condensed as the offgas cools.

Tests at Clemson (entries A-4 through A-8 in Table 2-1) and Hanford (entries G-5 through G-8 and M-10 through M-14) contain melter DF factors, the reciprocal of partition factors. DF factors calculated from melter test data can contain considerable uncertainty because of the lack of closure in the mass balance. For Clemson-1 tests, the melter DF factors derived from glass analyses and feed measurements and reported in the Ref. 5 differ greatly (for some species by more than an order of magnitude) from those calculated on the basis of the quantities of individual species actually measured in the output from the melter (i.e., glass, scrub solution, and offgas solids). If the mass balance were completely closed then the two sets of DFs would agree. The fact that there are large discrepancies may be due to the lack of mass balance closure, analytical error, or measurement error and serves to underscore the large uncertainties in the reported DFs and the need for better measurements and (possibly) better mass balance closure.

From data collected in the RSM tests, "aerosol" and "total" DFs were calculated. Aerosol DFs were calculated by analysis of solids collected on filters only, while total DFs were calculated using analyses of scrub solutions and filtered solids data. Because equipment scale and configuration affect DF factors, many of the DF factors derived from RSM or even Clemson data will be different from those of a full-scale melter. For example, the RSM-1 and -2 data for Cs show a total DF of 3-5 and 9-49, respectively, and the Clemson data show a DF of 2, but data from the DWPF melter show a Cs DF of about 50 (Ref. 32).

Additional data are required to improve mass balance closure and reduce the ranges of between the upper and lower bounds for melter DFs, particularly for species that determine offgas treatment design requirements (e.g., Cs, Tc, Sr, Cl, F, TRU radionuclides). Data are also needed to extrapolate the effects of operating parameters and melter scale on melter DFs.

\section{DBE-25 Iodine-129 Concentration in SBW Feed}

The updated SBW composition (Ref. 24) shows an average ${ }^{129}$ I concentration of 5.5E-8 Ci/liter, and ${ }^{129} \mathrm{I}$ concentrations in different tanks of $1.3 \mathrm{E}-8$ to $9.9 \mathrm{E}-8 \mathrm{Ci} /$ liter. Historical analytical data for the

Tank Farm was reviewed in April, 2001 by Mike Swenson, who found ${ }^{129}$ I concentrations of $1.1 \mathrm{E}-8$ to 6.6 E-8 Ci/liter (see DBE titled "Iodine-129 concentration in SBW feed" in Appendix C of Ref. 28). The concentrations shown in Ref. 24 are thus consistent with the historical data.

DBE-27 Partitioning of Acid Gases and Hg During Quench/Scrubbing Operations 
Two tests provided additional understanding of partitioning of mercury during scrubbing that has significant implications for the treatment flowsheet. Mercury VLE data from the first of these tests (see entry L-1 of Table 2-1) indicates that the quantity of oxidized mercury $\left(\mathrm{HgCl}_{2}\right)$ that will partition to the gas phase is 10-100 times the amount predicted from thermodynamic considerations. However, even with this unexplainably high mole fraction of mercury in the gas phase, the portion partitioning to the liquid is much higher than was assumed in theoretical mass balance calculations. Based on this data alone, the mercury (if fully oxidized) should build up to much higher concentrations in the scrub than was indicated in the mass balance.

In the RSM-2 test (entry M-15 of Table 2-1), no mercury was found in the offgas downstream of the HEME. The CEM data from this test show that a significant portion (97\%) of the mercury detected in the offgas directly downstream of the melter was captured by the scrub system upstream of the HEME exit. Below $485^{\circ} \mathrm{C}$ thermodynamic calculations indicate that $\mathrm{HgCl}_{2}$ is the favored form for mercury if $\mathrm{Cl}$ is present in excess. However, the RSM-2 data clearly indicate elemental Hg as the dominant form. This may be because $\mathrm{Hg}$ oxidation kinetics become limiting as the temperature falls, preventing the predicted shift from elemental $\mathrm{Hg}$ to $\mathrm{HgCl}_{2}$. This possibility is consistent with results of other studies (see Ref. 27). Based on the preponderance of the elemental form of $\mathrm{Hg}$ one would expect poor mercury scrubbing efficiency. However, the RSM-2 data suggest that scrubbing efficiencies of $73-97 \%$ were achieved. A mechanism to explain the high apparent scrubbing efficiency is needed.

For the overall RSM-2 demonstration, $27 \%$ of the $\mathrm{Hg}$ fed to the melter was found in scrub solutions and $46 \%$ was found in acid flushes of the HEME. From this it may be conjectured that at least $63 \%$ of the mercury scrubbed from the offgas was elemental and insoluble (consistent with the speciation measurements). One explanation of the high scrubbing efficiency is that the combination of oxidizing conditions (high $\mathrm{NO}_{2}$ and chloride in the gas phase combined with a $\mathrm{HNO}_{3}$ scrub solution) together with effective liquid/gas contact in the HEME were sufficient to oxidize most of the $\mathrm{Hg}$, which was then dissolved (presumably as $\mathrm{HgCl}_{2}$ ) in the liquid on the HEME mesh. A second possibility, based on the apparently high fraction of insoluble $\mathrm{Hg}$ scrubbed, is that elemental $\mathrm{Hg}$ in the offgas condensed in the HEME and then formed particulate matter (through homogeneous or heterogeneous nucleation) which was collectable through intimate contact between the gas and liquid in the HEME mesh.

If the high fraction of detected mercury in the scrub liquids is representative of the mercury fraction that will be scrubbed in a production scale system, then alternative scrub processing methods should be evaluated. Otherwise, unless mercury is removed from the scrub, the grouted scrub purge may contain an excessive amount of leachable mercury. In addition, the volume of GAC required for $\mathrm{Hg}$ polishing may be lower than previously expected.

\section{DBE-29 Carryover of Melter Feed to Off-gas}

The carryover of melter feed to the offgas describes the fraction of the total input stream that is entrained in the offgas leaving the melter before it undergoes significant reaction and/or volatilization. Thus, it describes (a) the mass fraction of the non-volatile species in the feed which partitions to the offgas, and (b) the mass fraction of volatile and semivolatile species which partitions to the offgas in addition to that which would volatilize without any feed carryover. The carryover value therefore provides the default lower limit to the fraction of each species in the feed that is expected in the melter offgas.

Both the RSM and the Clemson-1 tests provided DF information for the melter. Entry A-4 in Table 2-1 gives a range of 10-28 for the overall DF for Clemson-1 and entries G-7 and M-13 give ranges of 1100-1230 and 58-1560 for the DF of non-volatile species. Both should be equivalent to the carryover of melter feed. Due to the large difference in these ranges we cannot confidently choose one or the other 
(or even an average) as "representative" of a production scale melter. The best we can do at this time is to use 10 as a lower bound and 1560 as an upper bound on the overall DF for carryover mass. Unfortunately this leads to a large range on the possible quantities of secondary waste that must be treated and disposed. Additional testing is needed to determine (a) whether melter design factors or poor data quality are responsible for the large disparity in the above data, and (b) better upper and lower bounds on the expected carryover range for a full-scale system.

\section{DBE-30 Representativeness of Cold Simulants in Melter Tests}

The first effort to compare glasses produced from simulants and from actual waste was made in FY 2001 (see Ref. 8). Radiologically cold and hot glasses were prepared in laboratory crucible melts using the WM-180 surrogate with two frit formulations, and also with actual WM-180 waste and the same two frit formulations. The compositions of the resultant cold and hot glasses were analyzed and found to be comparable. Leaching properties of the radioactive glasses were measured and were found superior to those of EA glass. XRD measurements of the radioactive glasses gave no evidence of crystallization. Similar measurements have been done on cold glasses in other testing programs (e.g., see entries A-11 and G-3 in Table 2-1) with similar conclusions, though this was not done here.

Thus, the data produced from this effort support the premise that the simulants are representative of real SBW from WM-180. However, additional data are needed to confirm this preliminary conclusion. Specifically, offgas measurements should be made with comparable setups for cold and hot feeds and the results should be compared. In addition it would be desirable to compare the behavior of noble metals and semivolatile radionuclides or their non-radioactive surrogates (e.g., non-radioactive Cs, and Rh for

${ }^{99} \mathrm{Tc}$ ) in cold and hot glasses. Finally, better estimates of the composition of UDS present in SBW should be made and simulated in non-rad testing.

\section{$\underline{\text { DBE-31 Composition Envelope for Acceptable Glass }}$}

Progress has been made in defining glass compositions that adequately immobilize SBW. Building on data gathered in previous years that relate glass properties to glass composition, a series of ten GFC formulations were defined and tested for WM-180 simulant (see entry E-0 in Table 2-1), leading to the recommendation to use the SBW-9 formulation in the RSM-1 and Clemson-1 tests. Data from these tests confirmed that the glass properties using this formulation were acceptable. In response to an update in the WM-180 composition, additional frit formulations were developed and tested that resulted in the recommendation of the SBW-22 formulation to be used in the RSM-2 test. Additional compositional variation studies will be required in order to define glass formulations that fully envelope the SBW composition range.

\section{DBE-34 Frit vs GFC in Melter Feed}

No tests using a glass frit have yet been performed. However, an evaluation of different forms of silica that could be used with other GFCs was done this past year (see entry N-0 in Table 2-1 or Ref. 18), and provides melter feed rheology data for the melter feed with GFCs. Similar tests (in addition to melter tests) are now needed using frit in place of GFCs.

\section{DBE-35 SBW Feed Blending}

The updated SBW composition report (Ref. 24) provides compositions of SBW in existing tanks as well as blended in future (new) tanks. Blending the SBW would produce an estimated $68 \mathrm{~m}^{3}$ less glass (through blending down of sulfur concentrations) and $27 \mathrm{~m}^{3}$ less grouted waste (see Attachment 3 ). In addition, a single, blended waste stream would require qualification of fewer glass formulations or the 
qualification of a narrower composition envelope. From these standpoints blending of SBW tank-by-tank processing would be desirable. However, the method(s) by which such a blending scheme could be accomplished have not been scrutinized and no programmatic decision or guidance has been provided.

\section{DBE-37 Total Volume and Composite SBW Feed Composition}

The updated SBW composition report (see entries T-0, T-1 in Table 2-1 or Ref. 24) provides the most recent estimates of the total volume and compositions of SBW that would be fed to the melter. These estimates are projections to specific future proposed startup dates for the vitrification facility, and as such, depend on INTEC Tank Farm management plans and projected generation rates of new wastes, as well as the vitrification startup date. While changes in Tank Farm management plans and waste generation operations will affect the composition of individual tanks and will be used to update the projected volumes and compositions, the effect on the average or blended composition is expected to be small. It is intended that the SBW composition report be periodically updated as wastes in the different tanks are evaporated, blended or new waste added, and new waste samples (both liquid and solids) are obtained and analyzed.

\section{DBE-38 Noble Metals Concentration in SBW feed}

The concentration of noble metals in the feed is of interest because of the possibility of their forming a separate molten phase on the bottom of the melt under reducing conditions. This, in turn, would likely lead to melter failure by shorting the electrodes. Noble metal concentrations in SBW are given in Ref. 24.

\section{DBE-44 Required control of feed mix tank temperature}

Once sugar is added to the SBW feed, temperature control is required to avoid initiating the reaction between sugar and nitric acid. One FY 2001 test showed that no observable reaction occurs below $50^{\circ} \mathrm{C}$ (see entry N-4 in Table $2-1$ ). On this basis is unlikely that any temperature control would be needed in the mix tank unless heating is required for blending or dissolution, or unless heat must be added or removed due to reactions between the waste and GFCs. We assume that a minimum $10^{\circ} \mathrm{C}$ safety margin will be maintained so that the feed tank temperature should be controlled to $<40^{\circ} \mathrm{C}$. The adequacy of this temperature margin will need additional verification under all expected feed compositions under carefully monitored test conditions.

\section{DBE-45 Feed Preparation Requirements (Excluding Evaporation)}

Feed preparation requirements include mixing requirements for homogenization of SBW liquid plus additives (frit plus reductant and [possibly] nitric acid-see entry M-6 in Table 2-1). It also includes the form and properties of the additives prior to mixing. The DBE presently assumes sugar will be added as a syrup (67 $\mathrm{wt} \%$ sugar solution), however tests to date have used granular sugar, and an analysis of process alternatives (see Attachment 3 ) recommends the use of granular sugar. Assuming use of granular sugar, testing will be needed to establish the mixing requirements to effect complete dissolution and blending. Acceptable forms of silica relative to mixing and settling requirements have been identified (Ref. 18). Testing may be required to establish that settling of frit does not occur in quiescent regions of the mix tank.

In a separate study (Ref. 13), removal of sulfate from the feed was demonstrated. Since the glass waste loading is limited by the sulfate concentration in the waste (Ref. 12), removal of sulfate would permit an increase in glass waste loading. Costs associated with additional unit operations and treatment and disposal of the radioactive $\mathrm{BaSO}_{4}$ waste stream need to be compared with the costs of making, 
storing, and disposing more glass. Additional discussion of sulfate removal from the feed is given in the above-referenced analysis of process alternatives.

\section{DBE-47 Melter Off-gas Temperature}

Although not a primary objective of the test, conditions were varied during the Clemson-1 melter test (Ref. 5) to achieve both "low" and "high" plenum temperatures (entry A-22 of Table 2-1). The target plenum temperature maintained throughout most of the test was $600^{\circ} \mathrm{C}$; the temperature was reduced to about $450^{\circ} \mathrm{C}$ for the low temperature tests and raised to $650^{\circ} \mathrm{C}$ for the high temperature test. Reducing the plenum temperature reduced the $\mathrm{NO}_{\mathrm{x}}$ concentration in the melter offgas by about $20 \%$ and the $\mathrm{SO}_{2}$ concentration by about $65 \%$. Lower plenum temperature means less air and steam are required in the film cooler resulting in reduced offgas flow. This reduces the offgas system size requirement. However, additional data from low plenum temperature melter tests is needed to (a) corroborate the above observations from Clemson-1, and (b) quantify "penalties" that could be associated with reduced plenum temperature (e.g., reduced melt rate, increased salt layer on melt, increased $\mathrm{H}_{2}, \mathrm{CO}$, and hydrocarbons in the offgas). Based on the experience of DWPF, the lower limit is set by flammability concerns, i.e., a high enough temperature is needed to ignite combustible gases in the melter to avoid flammability concerns in offgas equipment. This, together with other the issues identified through additional testing, would have to be considered.

\section{DBE-48 Glass Frit Composition}

Ten frit formulations were tested in the glass compositional variation studies (CVS) (entry E-0 of Table 2-1), using waste loadings of $25-45 \%$. Based on the results of this study, a waste loading of $30 \mathrm{wt} \%$ and a frit formulation, labeled "SBW-9", of $65 \mathrm{wt} \% \mathrm{SiO}_{2}, 15 \mathrm{wt} \% \mathrm{~B}_{2} \mathrm{O}_{3}, 5 \mathrm{wt} \% \mathrm{Li}_{2} \mathrm{O}, 10 \mathrm{wt} \%$ $\mathrm{Fe}_{2} \mathrm{O}_{3}$, and 5 wt \% CaO was recommended for testing in the RSM-1 and Clemson-1 tests using an early simulant for WM-180 SBW. Subsequent to this study, a revised simulant composition for WM-180 waste was developed, based on new sulfate measurements for the tank liquid (Ref. 25), that had a sulfate content $37 \%$ higher than had been used in the earlier simulant. Additional frit formulations were tested with the goal of retaining a higher amount of sulfate in the glass (Ref. 9) and minimizing the growth of a sulfate salt layer in the melter. The SBW-22 formulation that resulted from these efforts had the following composition: 67.95 wt \% $\mathrm{SiO}_{2}, 6.03$ wt $\% \mathrm{~B}_{2} \mathrm{O}_{3}, 6.11$ wt $\% \mathrm{Li}_{2} \mathrm{O}, 1.52$ wt $\% \mathrm{Fe}_{2} \mathrm{O}_{3}, 5.02$ wt $\% \mathrm{CaO}, 1.75$ wt $\% \mathrm{MgO}, 4.29$ wt $\% \mathrm{Na}_{2} \mathrm{O}, 4.88 \% \mathrm{~V}_{2} \mathrm{O}_{5}$, and $2.44 \mathrm{wt} \% \mathrm{ZrO}_{2}$. This formulation was used in the RSM-2 test (Ref. 17). No sulfate salt layer was observed in the melter during RSM-2 testing with the new formulation at a sugar concentration of $160 \mathrm{~g} / \mathrm{L}$ (entry M-1 in Table 2-1). On this basis the "preferred" formulation (as of this writing) is presumed to be SBW-22. However, glass composition optimization is not yet complete and will require completion of the composition variation study and evaluation of the range of waste compositions likely to be processed in the melter.

\section{$\underline{\text { DBE-49 Waste Loading in Glass }}$}

Glass formulation studies (entry E-0 of Table 2-1) performed in 2001 included melts with waste loadings from $25-45 \%$ and based on glass property results, recommended a waste loading of $30 \%$ for WM-180, based on the objective to minimize sulfate salt layer formation in the melter. One objective of the RSM-1 tests (Ref. 11) was to determine if the waste loading might be increased, and glasses were prepared using waste loadings of 30, 32 and $35 \mathrm{wt} \%$. Later on, new analyses of WM-180 waste showed a higher sulfur content than had previously been measured. Prior work had indicated that the sulfate content of the waste would limit the glass waste loading if an assumed requirement of the glass formulation is that no salt layer form in the melter (entry H-2 in Table 2-1). Thus, subsequent tests performed with the higher sulfate WM-180 surrogate (Ref. 25) used lower waste loadings. RSM-2 tests 
confirmed that salt layer did not form (entries M-1 and M-16 in Table 2-1) using waste simulant with 0.07 M sulfate and a waste loading of $20 \%$.

The results of studies performed during and before FY2001 suggest that the loading of SBW in glass is primarily determined by the allowable sulfur concentration. Current estimates are that between 0.8 and $1.0 \%$ of sulfur (on the basis of $\mathrm{wt} \%$ of $\mathrm{SO}_{3}$ targeted in the glass) would be the acceptable limit assuming most sulfur in the offgas is recycled back to the melter and that the accumulation of a molten salt layer in the melter is unacceptable. This translates into a loading of roughly $20 \mathrm{wt} \%$ for the current WM-180 waste composition. Since the total quantity of glass produced is inversely proportional to waste loading, reduction from $30-35 \%$ to $20 \%$ waste loading has significant negative impacts on the SBW vitrification project cost and schedule. Additional discussion of schemes utilizing increased waste loadings is given in Attachment 3.

\section{DBE-54 NOxidizer Oxidation Chamber Chemistry}

NOxidizer tests at MSE (entries F-1and J-2 in Table 2-1) demonstrated $>99.7 \%$ destruction efficiency of benzene-spiked feed. The stack THC analyzer for these tests registered below its detection limit. Kinetic modeling (Q-1 in Table 2-1) of the NOxidizer showed outlet $\mathrm{CO}$ and $\mathrm{H}_{2}$ concentrations equivalent to $99.9996 \%$ and $99.999 \%$ removal respectively.

\section{DBE-55 NOxidizer Reduction Chamber Reaction and Quench Temperatures}

Preliminary modeling of NOxidizer performance by the equipment vendor (entry S-2 of Table 2-1) shows a reduction chamber temperature of $2400^{\circ} \mathrm{F}\left(1316^{\circ} \mathrm{C}\right)$ and a quench temperature of $1665^{\circ} \mathrm{F}\left(907^{\circ} \mathrm{C}\right)$. Kinetic modeling (Row Q-1 of Table 2-1) shows a reduction temperature of $2314^{\circ} \mathrm{F}\left(1268^{\circ} \mathrm{C}\right)$, and a quench temperature of $1672^{\circ} \mathrm{F}\left(911^{\circ} \mathrm{C}\right)$. The kinetic modeling was based on natural gas rather than propane fuel. DBE-55 currently specifies a reduction temperature of $1200^{\circ} \mathrm{C}$ and a quench temperature of $820^{\circ} \mathrm{C}$.

In NOxidizer tests at MSE (Ref. 14) the quench temperature was one of three process variables studies relative to optimizing $\mathrm{NO}_{\mathrm{x}}$ destruction efficiency. The highest $\mathrm{NO}_{\mathrm{x}}$ destruction efficiencies were seen with (a) low quench temperature $\left(1600^{\circ} \mathrm{F}\right)$, low temperature difference between the quench and reoxidation stages $\left(50^{\circ} \mathrm{F}\right)$ and high oxygen in the NOxidizer effluent $(>4 \%)$, (b) low quench temperature $\left(1600^{\circ} \mathrm{F}\right)$, high temperature difference $\left(200^{\circ} \mathrm{F}\right)$ and low oxygen $(1.5 \%)$, and high quench temperature $\left(1800^{\circ} \mathrm{F}\right)$, low temperature difference $\left(50^{\circ} \mathrm{F}\right)$ and low oxygen $(1.5 \%)$. Thus it appears that high $\mathrm{NO}_{\mathrm{x}}$ destruction efficiencies can be achieved over a wide range of quench temperatures $\left(1600-1800^{\circ} \mathrm{F}\right)$ by adjusting other variables.

Based on additional information from the NOxidizer vendor, an air rate to the reduction chamber much greater than currently assumed is required to maintain burner stability (entry S-2 in Table 2-1). With a higher air rate, a higher fuel rate will be required to maintain reducing conditions, and the reduction chamber temperature will increase from that shown in the current mass balance (Ref. 28). It should be noted that quench water is added both in the reduction chamber and the quench chamber, and the "reduction chamber temperature" includes the cooling achieved by reduction chamber quench water.

\section{DBE-59 Speciation of Mercury in NOxidizer Effluent}

NOxidizer tests at MSE (entry J-4 of Table 2-1) confirmed the present assumption that mercury is reduced in the NOxidizer to elemental mercury. The tests showed greater than $99.8 \%$ of the mercury in the NOxidizer effluent as elemental. 


\section{$\underline{\mathrm{DBE}-60 \mathrm{pH} \text { Control in Scrubber Solutions }}$}

In the RSM-2 tests (entry F-5 in Table 2-1) the acid concentration of the initial scrubbing solution was adjusted to around 1. M Over the course of the tests the concentration gradually decreased to $\sim 0.6 \mathrm{M}$ suggesting that alkaline solids carried over from the melter to the scrub neutralized acids (such as $\mathrm{HNO}_{3}$ and $\mathrm{HCl}$ ) captured or formed in the scrub by absorption of acid gases as well as part of the initial acid in the scrub. Thus it is likely that a controlled addition of acid to the scrub will be required. The optimal $\mathrm{pH}$, however, has not been determined. If the acidity is high then most of the solids collected may likely dissolve, precluding a selective recycle of solids only. Selective recycle of solids may be desirable, given the apparent solubility of sulfate (see entry G-10 in Table 2-1).

\section{DBE-64 Air Addition to NOxidizer Oxidation Chamber}

The offgas treatment feasibility study (Ref. 23) includes a price quotation from the NOxidizer vendor along with the vendor's estimates of equipment requirements and flow rates. The vendor's estimate of airflow to the oxidation chamber confirms the present assumptions of the mass balance.

\section{DBE-66 Mercury Speciation Downstream of Melter}

(See discussion of DBE-27 Partitioning of Acid Gases and Hy During Quench/Scrubbing Operations)

\section{DBE-67 Peak Acceptable Mercury Loading in GAC}

Test data from Nucon (entry S-3 of Table 2-1), the supplier of Mersorb, shows a mercury loading of $23 \mathrm{gm} \mathrm{Hg}$ per gm carbon in the first section of a bed divided into 6 sections. The loading drops to 14 $\mathrm{gm} / \mathrm{gm}$ in the fifth section of $0.3 \mathrm{gm} / \mathrm{gm}$ in the final section. The Nucon tests were performed using an air stream. These loadings should be verified by testing a gas stream which simulates vitrification offgas, in conjunction with TCLP testing of the loaded carbon to determine whether it can be disposed without further treatment.

\section{DBE-68 Residence Time Requirement for $\mathrm{Hg}$ Extraction in GAC}

Test data from Nucon (entry S-3 of Table 2-1), the supplier of Mersorb, show a residence time of 10 seconds is required to avoid mercury breakthrough over the time required to process SBW (400 operating days). The Nucon tests were performed with an air stream. Small scale mercury removal tests using simulated vitrification offgas (entry B-0 of Table 2-1) were performed at residence times of 0.1 to 0.53 seconds and achieved 99\% removal of the $\mathrm{Hg}$ in the gas (entries B-0, B-1 in Table 2-1).

\section{DBE-70 Mercury Removal Efficiency of GAC Beds}

In five small-scale GAC bed tests (entries B-0, B-1 in Table 2-1), removal efficiencies varied between $99.1 \%$ and $99.6 \%$. Gas composition, residence time, and speciation of mercury were varied in these tests; however, the effects of these variables on mercury removal is not clearly evident from the resulting data. In addition, while the effluent concentrations from the tests were within MACT emissions limits, the inlet concentrations were approximately 100 times less than those indicated by the current mass balance. No data have been generated indicating how removal efficiency varies with inlet concentration. Vendor data based on removal of mercury from air (contained in Ref. 23) indicate that the removal of mercury is $100 \%$ until breakthrough, and the time to breakthrough varies with residence time. Additional testing and/or modeling is thus needed to clearly determine the effects of inlet mercury speciation, 
concentration, and residence time on mercury removal efficiency and time (or volume throughput) to breakthrough.

The effect of inlet $\mathrm{Hg}$ concentration on removal efficiency is also related to the question of scrubber efficiency in extracting $\mathrm{Hg}$ from the offgas. Mercury was not detected downstream of the HEME in the RSM-2 tests (entry M-15 in Table 2-1). If these data are representative then the high $\mathrm{Hg}$ scrubber inlet concentrations reported in the mass balance (attributable to low assumed $\mathrm{Hg}$ scrubbing efficiency) are eroneous and in need of adjustment.

\section{DBE-71 Maximum Allowable NOx Concentration in GAC Bed Influent}

The feed gas in small-scale GAC tests (entry B-0 in Table 2-1) included 990 ppmv NO, 97 ppmv $\mathrm{NO}_{2}$ and 1400 ppmv $\mathrm{N}_{2} \mathrm{O}$. Compared to the SBW vitrification process mass balance, the NO concentration in the test gas was $80 \%$ higher and the $\mathrm{NO}_{2}$ concentration several orders of magnitude higher. Hence it appears the upper limit of $\mathrm{NO}_{\mathrm{x}}$ in the $\mathrm{GAC}$ test bed influent is significantly above vitrification offgas normal levels. At this level the $\mathrm{NO}_{\mathrm{x}}$ concentrations used in the test did not appear to affect mercury removal efficiency over the duration of the tests (14-26 hours).

However, based on NOx concentrations in melter offgas determined from pilot testing (see entries A-14, G-13 in Table 2-1) potential concentrations of NOx in the offgas entering the GAC beds during NOxidizer upset conditions could be significantly higher than what was tested. Additional testing may thus be appropriate to determine the behavior of the $\mathrm{GAC}$ bed at $\mathrm{NO}_{\mathrm{x}}$ concentrations representative of such upset conditions (possibly as high as $2.4 \%$ ).

\section{DBE-74 Solids Scrubbing Efficiency in Acid Quench}

(See discussion of DBE-75 Solids Scrubbing Efficiency in Acid Venturi Scrubber)

\section{DBE-75 Solids Scrubbing Efficiency in Acid Venturi Scrubber}

Based on entry A-9 in Table 2-1 the nominal measured scrubber efficiency in the Clemson-1 test was $0-50 \%$. This number seems low, based on the authors' experience, but not inconceivable, depending on the size of the solids being collected. Hence, the more meaningful measurement from this test is probably the PSD in entry A-17. The efficiencies of industrial scrubbers are usually fairly well characterized as functions of the PSD. Rather than rely on the Clemson-1 measurement (which has a high uncertainty due to $83 \%$ closure on the mass balance (entry A-23 in Table 2-1) a more credible approach would be to corroborate the PSD measurements through additional testing and secure representative vendor performance data for candidate scrubber types.

\section{DBE-76 Solids Scrubbing Efficiency in Caustic Quench}

(See discussion of DBE-75 Solids Scrubbing Efficiency in Acid Venturi Scrubber)

\section{DBE-81 Effects of 'Other' Species on Hg Polishing Effectiveness of GAC}

Small-scale tests were performed (entry B-0 in Table 2-1) using a feed gas of wet air and a feed gas representative of vitrification offgas, containing $\mathrm{CO}, \mathrm{CO}_{2}, \mathrm{NO}_{\mathrm{x}}, \mathrm{SO}_{2}$ and $\mathrm{HCl}$ in addition to $\mathrm{N}_{2}, \mathrm{O}_{2}$ and $\mathrm{H}_{2} \mathrm{O}$. Results indicate no detrimental effect from these other species (entry B-2 in Table 2-1). 


\section{DBE-85 Maximum Allowable Cl, F Content of Scrubbing Solutions}

\section{Control)}

(See discussion of DBE-86 Fluoride Concentration Requiring Use of Additives for Corrosion

\section{DBE-86 Fluoride Concentration Requiring Use of Additives for Corrosion Control}

In association with Jerry Christian's work on developing simulants for a "worst case" SBW simulant he examined the issue of fluoride concentrations that would raise corrosion concerns (entry V-6 in Table 2-1). From corrosion tests for the Fluorinel Dissolution Process on 304L stainless steel and past determinations of fluoride complexation constants (Refs. 30,31) it was determined that a concentration of $0.055 \mathrm{M}$ free $\mathrm{HF}$ at $35^{\circ} \mathrm{C}$ would limit the long term corrosion rate to $2 \mathrm{mils} / \mathrm{yr}$ and the weld corrosion rate to an acceptably level. Using this information together with the composition information for "worst case" SBW (documented in Ref. 26), an expected "worst case" concentration of free HF in SBW is about $5.65 \times 10^{-4} \mathrm{M}$, which is well below the above the critical value of $0.055 \mathrm{M}$. Thus, it is safe to assume that there is no need for additives (such as $\mathrm{Al}\left(\mathrm{NO}_{3}\right)_{3}$ or $\mathrm{H}_{3} \mathrm{BO}_{3}$ ) in SBW feed to the melter process.

For downstream scrubber operations the data supplied by Dr. Christian may also be used to determine whether the same conclusion applies to scrub solutions. Based on mass balance calculations, the total concentration of fluoride in scrub liquors can be compared with the $0.055 \mathrm{M}$ threshold. Based on apparently high retention fractions of fluoride in the glass (entry A-10 in Table 2-1) it appears unlikely that scrub fluoride concentrations would reach this level. If they do, it would then be necessary to repeat the fluoride speciation calculations done for the SBW feed using the scrub liquor composition to determine whether the free HF concentration is below the threshold limit.

\section{DBE-101 Settling Rate of Solids in Scrubber Blowdown Liquid}

No explicit measurements of scrub solids settling rates were made. In principle these rates could be calculated from PSD data (entry A-17 in Table 2-1), assuming all solid particles are spherical and nonagglomerating. However, comments regarding observed particle morpology make questionable the accuracy of such calculations. In addition, analysis of scrub solutions suggest that a significant fraction of the solids are soluble, which further confounds the problem of calculating a settling rate. In summary, there is little data from the FY 2001 that sheds meaningful light on this DBE.

\section{DBE-102 Will Facility Comply with MACT?}

Requirements for offgas treatment are discussed in the Off-gas Feasibility Study (Ref. 23), and include MACT. MACT is a joint rule-making effort under the Clean Air Act and the Resource Conservation and Recovery Act to establish emission standards for hazardous waste combustor sources. The MACT standards reflect the maximum degree of reduction in emissions of hazardous air pollutants that is achievable, taking into account control costs, non-air related health and environmental impacts, and added energy requirements. One significant impact of MACT is the "derived" requirement for $\mathrm{NO}_{\mathrm{x}}$ removal. While $\mathrm{NO}_{\mathrm{x}}$ is not regulated under MACT, $\mathrm{NO}_{\mathrm{x}}$ removal is probably required in order to measure VOCs and SVOCs and thus demonstrate that they are within MACT limits. Ref. 27.

Implications of offgas measurements from RSM-1 , EV-16, and RSM-2 tests are discussed in DBE-106 Waste Acceptance Criteria For Mixed Waste Disposal at NTS 
Major waste acceptance criteria were captured and summarized for the NTS disposal site. These criteria deal with listed waste codes, RCRA metal content, free liquids, compressive strength requirement for solid wastes, container requirements, and specific radionuclide concentration limits (see entry P-7 in Table 2-1).

\section{DBE-107 Waste Acceptance Criteria For Mixed Waste Disposal at Envirocare}

Major waste acceptance criteria were captured and summarized for Envirocare. These criteria deal with listed waste codes, RCRA metal content, free liquids, compressive strength requirement for solid wastes, container requirements, and specific radionuclide concentration limits (see entry P-5 in Table 2-1).

\section{DBE-108 Waste Acceptance Criteria For Mixed Waste Disposal at Hanford}

Major waste acceptance criteria were captured and summarized for the Hanford disposal site. These criteria deal with listed waste codes, RCRA metal content, free liquids, compressive strength requirement for solid wastes, container requirements, and specific radionuclide concentration limits (see entry P-6 in Table 2-1).

\section{DBE-113 Target Disposal Sites for Secondary Wastes}

Herbst, Kirkham, and Losinski performed an evaluation of disposal sites for each of the secondary wastes (entries P-0 to P-4 in Table 2-1). The grouted scrub purge can be disposed of at Hanford as either a Category 3 waste, or if ${ }^{90} \mathrm{Sr}$ is removed, Category 1 waste. Because the mercury concentration in the grouted scrub is greater than $260 \mathrm{mg} / \mathrm{kg}$, a demonstration of treatment equivalency (to BDAT) will be needed to dispose this waste.

The vitrification facility has two sets of process offgas HEPA filters plus other heating, ventilation and air conditioning (HVAC) air filters. The evaluation recommends using washable filters to avoid having to dispose of highly contaminated upstream offgas HEPA filters. Otherwise these filters would require treatment (e.g., in the existing NWCF filter leach facility) prior to disposal. The downstream offgas HEPA filters are expected to be directly disposable at Envirocare. Additional information is needed to evaluate disposal of outlet HVAC filters.

Spent activated carbon could be disposed at Hanford, the Nevada Test Site or Envirocare. As with the grout, a treatment equivalency demonstration will be needed that is acceptable to the disposal site and regulators. The report recommends vitrifying spent ion exchange sorbent rather than dispose of it as a secondary waste.

\section{DBE-118 Disposal Requirements for Mercury-Containing Secondary Wastes}

To dispose of secondary wastes containing mercury two requirements (see entries P-1, P-3, and P-4 in Table 2-1) must be met: (a) The waste must pass the TCLP test for mercury, and (b) A demonstration of equivalency agreement with each disposal site must be negotiated. A demonstration of equivalency establishes that a treated RCRA waste will perform at least as well as the BDAT for that waste.

\section{DBE-120 NOx Abatement Requirement in Process Off-gas}

NOx abatement in the melter facility offgas will be required to a level negotiated with the State of Idaho, Department of Environmental Quality, Air Permitting Division (entry S-1 in Table 2-1). 
Reference 23 discusses specific requirements for NOx abatement in order to: (a) permit accurate analysis of VOCs and SVOCs, (b) avoid interference with $\mathrm{Hg}$ removal by activated carbon, (c) not exceed the State of Idaho significant NOx emission level, (d) comply with the precedent for removal of NOx set at other DOE high level waste facilites, i.e., the West Valley Demonstration Project, and (e) reduce plume visibility. The Feasibility Study concludes that if either a NOxidizer or SCR reactor is included in the flowsheet, all requirements for NOx abatement will be met.

\section{DBE-125 Disposal Path for Spent HEPA Filters}

(See discussion of DBE-113 Target Disposal Sites for Secondary Wastes)

$\underline{\text { DBE-126 Disposal Path for GAC }}$

(See discussion of DBE-113 Target Disposal Sites for Secondary Wastes)

\section{DBE-133 Speciation of Iodine in Melter Off-gas}

Concentrations of $\mathrm{HI}, \mathrm{I}_{2}$, and total I were reported for one pilot scale test (Clemson-1, see entry A-14 in Table 2-1). However, it has been noted ${ }^{d}$ that the EPA Method 0050 which was used has not been validated as being able to separate $\mathrm{HI}$ and $\mathrm{I}_{2}$. In addition, it will be noted from the reference entry in Table 2-1 that the HI and I2 concentrations $(0.096$ and $1.26 \mathrm{ppm})$ sum to only about half the total I concentration (2.6 ppm), raising questions about the accuracy of the measurements. Finally, Ref. 5 states the question of iodine speciation was not addressed in the test because a suitable analytical method to determine partition factors for iodine was lacking. Nonetheless it would be informative to compare the measured quantity of iodine in the offgas and glass (from the reported total I concentration) with the quantity input to the melter in the feed. (Ref. 5 states that the iodine in the feed was increased from the nominal level for SBW-9 simulant. However, the actual concentration was not reported.) This comparison might indicate the fraction of iodine that can be expected to be retained in the glass, the fraction that partitions to offgas solids, and the fraction that remains in the gas phase. Determining both the iodine concentration in the offgas and its speciation is crucial to ensuring that secondary wastes meet waste disposal criteria.

\section{DBE-138 Safe Handling of Melter Feed During Abnormal Shutdown}

To detect reactions between sucrose and nitric acid, simulated SBW was mixed with sugar, stirred, purged with argon and the purge gas analyzed (entry N-4 in Table 2-1). The experiment was run at ambient temperature for several days, and no $\mathrm{NO}$ or $\mathrm{NO}_{2}$ were detected. When the temperature was raised, no $\mathrm{NO}_{\mathrm{x}}$ was detected until the temperature reached $50^{\circ} \mathrm{C}$ and no appreciable amount until $80^{\circ} \mathrm{C}$. When the test was repeated at higher $\mathrm{HNO}_{3}$ concentration ( 3 vs $1 \mathrm{M}$ ) and the purge gas was analyzed for $\mathrm{CO}, \mathrm{CO}_{2}$ and $\mathrm{H}_{2}$ as well as $\mathrm{NO}_{\mathrm{x}}$, no reaction was seen until the temperature reached $80^{\circ} \mathrm{C}$. These experiments demonstrated that no sugar-nitric acid reactions occurred below $50-80^{\circ} \mathrm{C}$ that produce gaseous products.

A second evaluation of the rate of sucrose nitration in SBW feed at ambient temperature was performed. In this test, WM-180 feed simulant from the Clemson-1 test was stored four roughly four months and spectrally analyzed to detect the presence of a $\mathrm{C}-\mathrm{O}-\mathrm{N}-\mathrm{O}$ chemical bond using an FTIR instrument (entry A-23 in Table 2-1). Absence of such a bond would be evidence that nitration of the

\footnotetext{
d Lotus Notes memorandum from N.R. Soelberg to K.J. Perry on 7/5/01 titled "Speciation of Iodine in offgas".
} 
sugar (or any other organics present) had not occurred and this was, in fact, the case. This result provides assurance that a low temperature in the feed mixing tank during an abnormal shutdown would be sufficient to ensure that explosive products would not form by the action of $\mathrm{HNO}_{3}$ on sugar in the solution.

\section{DBE-139 Selection of Initial Baseline Process Configuration}

A starting baseline process was selected by consensus in a group of technical personnel supporting the INEEL high level waste program (entry S-1 in Table 2-1) Additional possible process variations were later described and documented in Attachment 3.

\section{$\underline{\text { DBE-144 Melter Feed Rate Basis }}$}

The melter feed rate will be determined by processing schedule requirements and melter sizing constraints. As part of an evaluation which determined the impacts of processing calcine in the SBW vitrification facility (Ref. 33), life-cycle costs were estimated for ten schedule/melter arrangements. The lowest cost arrangement of the ten that also completes SBW processing the soonest utilized a $4.5 \mathrm{~m}^{2}$ melter.

Glass melt rates were determined for the RSM-1 and the Clemson-1 tests with values ranging from 7.1-11.1 lbm/hr-ft2 for RSM-1 and an average rate of $3.0 \mathrm{lbm} / \mathrm{hr}-\mathrm{ft} 2$ for Clemson-1 (entries A-0 and G-1 in Table 2-1). These data are consistent with DWPF data that shows that a glass rate of about $6 \mathrm{lb} / \mathrm{hr}^{-\mathrm{ft}^{2}}$ is as high as can be achieved over long operating periods.

Assuming the glass volume of the "Total SBW" mass balance $\left(618 \mathrm{~m}^{3}\right.$, Ref. 28$)$, a glass rate of 6 $\mathrm{lbm} / \mathrm{hr}_{-} \mathrm{ft}^{2}$ (discounting the lower rate achieved in the EV-16 melter during the Clemson-1 test, and assuming the DWPF rate can be achieved with SBW), a $4.5 \mathrm{~m}^{2}$ melter, and glass specific gravity of 2.6 the required operating time would be 12,200 hours, or 2.54 years at 200 operating days/year. To process the entire volume of SBW in 12,200 hours would require a feed rate of $79 \mathrm{gal} / \mathrm{hr}$ or $6.3 \mathrm{~L} / \mathrm{hr}^{-\mathrm{ft}^{2}}$. The range of raw SBW simulant feed rates achieved in the RSM-1 test was $8.6-13.5 \mathrm{~L} / \mathrm{hr}^{-\mathrm{ft}^{2}}$, utilizing the SBW-9 glass formulation at $30 \mathrm{wt} \%$ waste loading. Since the waste loading for SBW-22 is only twothirds that of SBW-9 the equivalent range of processing rates using the SBW-22 formulation would be 5.7 to $9.0 \mathrm{~L} / \mathrm{hr}^{-\mathrm{ft}^{2}}$. Thus, the projected throughput requirement of $6.3 \mathrm{~L} / \mathrm{hr}-\mathrm{ft}^{2}$ in the production facility is within the range that has been achieved.

\section{DBE-149 NOxidizer Reduction Chamber Air Requirement}

The air rate to the NOxidizer reduction chamber assumed in the current mass balance may be low by a factor of 7.2 (entry S-2 in Table 2-1). If this much additional air is required it will significantly increase the fuel requirement and hence the flow rate through the remaining sections of the NOxidizer and downstream equipment. Kinetic modeling suggests that the flow rate of NOxidizer effluent would increase by a factor 4.7 over the present mass balance. Such a large change suggests re-evaluating the selection of the NOxidizer relative to other $\mathrm{NO}_{\mathrm{x}}$ abatement alternatives.

\section{DBE-155 Slagging/Plugging Control at Melter Outlet}

Pilot scale testing (Clemson-1) confirmed that solids accumulation in the melter offgas ducting and film cooler can be a significant problem (entry A-25 in Table 2-1). In this test solids obstructions in the offgas lines necessitated temporary shutdowns while to clear the offgas lines. Solids accumulation upstream of the film cooler and inside it were particularly problematic because the deposits were hard and difficult to remove, showing evidence of having been deposited in a molten state. As a result of 
experience from this test it was recommended that (a) the melter exit duct should be located on the top of the melter, and maximally distant from glass and cold cap surfaces and from the feed stream to minimize the carryover of feed and solids, (b) a "bayonet" style melter should be inserted into the melter offgas exit with coolant injection immediately inside the film cooler inlet, (c) use of elbows in offgas ducts upstream of the quench/scrubber operations should minimized and where needed, elbows should be "sweep" type (large radius of curvature), and (d) clean out ports in the off gas line upstream of the first quench would avoid the need to disassemble the piping during testing to remove deposits.

\section{DBE-157 Control of Foaming in Melter}

Foaming behavior was observed in a number of the tests conducted in FY 2001. In the Clemson-1 test only slight foaming was observed in the melt, and was apparently limited by use of a reducing agent (sugar at a concentration of $160 \mathrm{~g} / \mathrm{L}$ ) and by (unspecified) operating conditions (entry A-26 in Table 2-1). In melt rate tests at crucible scale foaming was so severe in batch type testing that a slurry-fed crucible test had to be developed whereby the feed was pumped into the crucible continuously (Ref. 7). In these incremental feeding tests foaming was observed at temperatures below $1000^{\circ} \mathrm{C}$ but not above (entry C-4 in Table 2-1). In research-scle testing of SBW-22 in RSM-2 excessive foaming was observed both in overly-reduced conditions (sugar concentration $>200 \mathrm{~g} / \mathrm{L}$ ) and overly-oxidized conditions (no sugar added - entry M-3 in Table 2-1). The first of these observations is consistent with glass formulation tests where it was noted that foaming intensity increased with sugar concentration during dryout of the simulated feed (entry E-6 in Table 2-1).

\section{DBE-158 Speciation and Partitioning of Sulfate in Melter}

An explanation of the observed behavior of sulfate in a melter feed was recently proposed ${ }^{\mathrm{e}}$. Alkalinitrates, -phosphates, -sulfates, -chromates, -molybdates, -hydroxides, etc. form a mutually miscible molten salt as the first liquid phase to form during feed-to-glass reactions in the cold-cap. The salt is low viscosity and reacts readily with other waste and additive materials. Alkali-nitrates react releasing nitrogen-containing gases and intermediate phases or the first glass forming melt, while the alkali-sulfate, -phosphate, and -chromate remain in a molten salt phase after the -nitrate has all reacted. This remaining salt is known to segregate from the glass melt although the concentration of sulfur (and other salt components) in the melt is well below the solubility limit in the bulk glass at the melt temperature.

A possible sequence leading to segregation of the above-described salt layer is (a) an aqueous component segregates from the cold cap before the water evaporates, (b) the molten salt mixture forms and then drains away from other dried feed material as the water evaporates, (c) a molten sulfate salt phase stays behind after the nitrates decompose, (d) the sulfate salt layer remains segregated and establishes equilibrium with the final glass-forming melt, (e) the equilibrium is dynamic with sulfur migrating between the salt layer to and from local areas of the melt having different equilibrium sulfur concentrations.

In addition to being incorporated into the glass melt or segregating to a molten salt layer, sulfur in the feed may partition to the offgas by fuming of sulfuric acid or by reduction of $\mathrm{SO}_{4}{ }^{-}$to $\mathrm{SO}_{2}$. It may also precipitate from the glass melt as metal sulfides which eventually settle to the bottom of the melter. The fate of sulfur from the melter feed is of primary interest since both growth of a molten salt layer and precipitation of metal sulfides are unacceptable from an operations standpoint (see DBE-3 Detection of

\footnotetext{
${ }^{\mathrm{e}}$ This mechanism was discussed in a presentation by John Vienna of PNNL at the Tanks Focus Area coordination meeting held at the INEEL December 3-6, 2002.
} 
Sulfate Salt Layer in the Melter). It has been found that the speciation and partitioning of sulfur during vitrification of SBW depends on a number of physical and chemical parameters. Among these are the sulfur content, reductant type and concentration, and acid and nitrate concentrations in the feed. In addition the feed rate, offgas flow rate (including sweep gas), and frit composition have been studied in various tests and found to influence the fate of feed sulfur to varying degrees.

Two glass formations were developed and tested during FY 2001 with the objective of preventing the formation and/or growth of a salt phase in the melter. These formulations were labeled SBW-9 and SBW-22. SBW-9 was selected from among several formulations on the basis of its having produced a salt-free glass (entry E-5 in Table 2-1). However, subsequent research-scale melter tests using this formulation were not salt-free (entries A-15, C-3, G-11 in Table 2-1). An additional concern with SBW-9 in these tests was an increase in the feed sulfur concentration over what had been assumed during initial tests of SBW-9 (see DBE-49 Waste Loading in Glass). The inability of the SBW-9 formulation to block salt formation led to testing and development of the SBW-22 formulation and adoption of a lower waste loading in the glass. Tests of SBW-22 have been completed in the SFMRF (at SRS) and the RSM (at PNNL). A partial test of SBW-22 was also performed in the EV-16 (Clemson). Preliminary results ${ }^{\mathrm{f}}$ from these tests indicate that at $20 \%$ waste loading most of the sulfur in the feed was incorporated in the glass with no residual salt layer but with $5-10 \%$ of the feed sulfur still carried over to the scrub (entry M-16 of Table 2-1) The resulting sulfur content of the glass was approximately $1 \mathrm{wt} \%$ (as $\mathrm{SO}_{3}$ ). The EV-16 melter was the largest scale tested to date but was abbreviated (due to the September terrorist attacks). Therefore, additional testing is needed at this scale (or larger) to fully demonstrate that the SBW-22 is truly "salt-free".

While the SBW-22 results demonstrate that partitioning of sulfur to a molten salt can be avoided by reducing the waste loading and possibly by tailoring of the frit, it has not been determined that this is the wisest course to pursue. For example, to reduce storage and disposal costs of the glass product it may be desirable to volatilize sulfur to $\mathrm{SO}_{2}$ (and thus limit the growth of a salt layer) rather than attempt to dissolve all the feed sulfur in the glass and eliminate the salt layer entirely. Experimental studies conducted during FY 2001 have shed light on how different operating conditions and process inputs influence sulfur partitioning between the various phases discussed above. The information that was gleaned may be of use in directing further development of methods to control sulfate salt layer formation and/or growth in a melter without reducing waste loading.

In the initial CSM sulfur partitioning tests at PNNL with SBW-9 the only tests where no salt layer was observed were those using either $150 \%$ of the nominal sugar concentration or $240 \%$ of the nominal free acid (entry H-2 in Table 2-1). In these tests it was noted also that (a) the only test where $100 \%$ of the feed sulfur was dissolved in the glass was that where the reductant concentration was $0 \mathrm{~g} / \mathrm{L}$, (b) a 10 -fold increase in the purge gas flow gave a slightly larger salt layer and reduced the $\% \mathrm{~S}$ retention in the glass from 73 to $67 \%$, (c) with $67.5 \mathrm{~g} / \mathrm{L}$ of sugar in the feed (50\% of baseline) the $\% \mathrm{~S}$ retention increased from 73 to $96 \%$, (d) doubling the $\mathrm{S}$ concentration in the feed resulted in a $\% \mathrm{~S}$ retention of $46 \%$ and a significant salt layer. Another significant result from this test was that nominal measured $\mathrm{SO}_{2}$ concentrations were below $2 \mathrm{ppm}$ in the offgas. When sufficient $\mathrm{SO}_{2}$ was spiked into the sweep gas to yield a nominal $90 \mathrm{ppm}$ in the offgas the measured $\mathrm{SO}_{2}$ concentration of the offgas did not increase. This result, together with the fact that significant $\mathrm{SO}_{2}$ concentrations in melter offgas were not observed in other tests (see entries G-11 and H-2 in Table 2-1), may indicate that volatilized sulfur from the melter (under the redox conditions tested) is present primarily in forms other than $\mathrm{SO}_{2}$.

\footnotetext{
${ }^{\mathrm{f}}$ These results were reported by John Vienna at the Tanks Focus Area coordintation at the INEEL on Dec 3-6, 2001. They had not been documented as of $2 / 5 / 02$.
} 
In the Clemson-1 test using the EV-16 melter the measured sulfur partitioning was approximately $57 \%$ to the glass, $12 \%$ to the scrub solution and solids, $28 \%$ to the gas phase, and $3 \%$ to the salt layer (entry A-15 in Table 2-1).

In summary, based on various FY 2001 testing, the following tentative conclusions may be drawn:

(a) $\quad 0.8-1.0 \mathrm{wt} \% \mathrm{SO}_{3}$ appears be the practical upper limit of sulfur concentration in glass from SBW;

(b) Waste loading will have to be adjusted according to the concentration of sulfur in the feed if the objective is to confine all sulfur to the glass;

(c) Even at $20 \%$ waste loading some sulfur will probably partition to the offgas and scrub liquor for WM-180 waste;

(d) Addition of a reductant (sugar) to the feed reduces the $\% \mathrm{~S}$ retained by the glass and increases the $\% \mathrm{~S}$ which is volatilized;

(e) From the data in hand we cannot yet define a set of conditions in a large melter which will ensure that a salt layer will either not form or (if formed) not grow beyond a prescribed extent (albeit the SBW-22 formulation in RSM-2 appears to have satisfied the former condition at a research-scale);

(f) The trending data from testing to date could provide guidance in determining a set of conditions that will lead to i) absence of a salt layer and incorporation of most of the sulfur in the glass melt, ii) partitioning of most of the sulfur to the offgas (assuming either that scrub liquor is not recycled to the melter or that the majority of sulfur in the offgas is nonscrubbable and leaves the system in the gas phase), or iii) development of a steady state salt layer in the melter that can be tolerated. Whichever scenario is most acceptable from a risk and cost basis could then be pursued.

\section{DBE-159 Feed Evaporation Requirement}

In an engineering evaluation of feed evaporation, Wendt and Haefner (Ref. 22) determined that evaporating the liquid SBW to dryness would result in a savings in capital equipment of about $\$ 1$ million out of a total equipment cost of $\$ 30$ million, and would increase the glass rate by $50 \%$. However, because of the uncertainties in how the evaporation would be done and whether the product would have acceptable properties, the study did not recommend changing the baseline flowsheet to include feed evaporation. Test data that addresses some of these uncertainties, together with several evaporation schemes, are discussed in the Attachment 3. The two drivers for reconsidering feed evaporation are cost and schedule. Attachment 3 indicates that evaporation, along with other pretreatment schemes, can offer significant savings in reducing the lifecycle cost and schedule for vitrifying SBW.

\section{DBE-163 Fate of Chloride and Fluoride in the Melter}

According the mass balance reported for the Clemson- 1 test, $98.5-100+\%$ of $\mathrm{Cl}$ and $\mathrm{F}$ fed to the melter were found in the glass (entry A-10 in Table 2-1). However, the same test indicates $2.6 \mathrm{ppm} \mathrm{Cl}$ and $0.07 \mathrm{ppm}$ F measured in the offgas (entry A-14 in Table 2-1)as well as in the sulfate salt taken from the melter (table 5.11 in Ref. 5). In light of significant over-recoveries of $\mathrm{Cl}$ and $\mathrm{F}$ in the glass, ranging from $131-459 \%$ and the fact that chloride concentrations in glass were not reported from other tests (except RSM-2 where some chloride measurements in the glass were obtained), the $98.5-100 \%$ figures must be viewed with some skepticism. Nonetheless, on the basis of the Clemson-1 data it is presumed that a high fraction of $\mathrm{Cl}$ and $\mathrm{F}$ would be retained in the glass and that the chloride in the melter offgas would be below the 75 ppmv MACT limit after suitable corrections for water vapor and oxygen (the 
nominal correction to the $2.6 \mathrm{ppm}$ total $\mathrm{Cl}$ in the offgas is roughly $1 /(1-0.362) \times(11.5 / 7)=2.6$ giving a value of $6.7 \mathrm{ppmv}$ used for determining MACT compliance).

\section{DBE-164 Should Sr-90 be Extracted from Scrubber Blowdown?}

Removing ${ }^{90} \mathrm{Sr}$ from scrubber blowdown would permit disposal of the grouted blowdown waste as Hanford Category 1 (or NRC Class A) rather than Hanford Category 3 (or NRC Class C). For this reason Herbst, Kirkham and Losinski (entry P-1 in Table 2-1) recommend removing ${ }^{90} \mathrm{Sr}$ from the scrub. Whether ${ }^{90} \mathrm{Sr}$ should be removed depends largely on the conditions required for ${ }^{137} \mathrm{Cs}$ removal. Removal of strontium by ion exchange requires neutral or alkaline conditions. Test data is needed of the behavior of the scrub solution when it is neutralized and made alkaline. If heavy precipitation occurs, processing the solids may more than offset the savings from reduced disposal costs. If no precipitation occurs, the sorbent presently selected for cesium removal may also remove ${ }^{90} \mathrm{Sr}$. Testing the cesium sorbent is needed to determine its performance at different levels of $\mathrm{pH}$ and sodium concentration in light of information from the cesium sorbent vendor which conflicts with historical test data from Hanford (Ref. 34) regarding the effect of sodium on the performance of the cesium sorbent.

\section{DBE-167 Soluble Species in Off-gas}

Information regarding soluble species in the offgas can be gleaned from analysis of scrub solids and solutions from Clemson-1 (entry A-18 of Table 2-1) and RSM-2 (entries M-10 through M-14 and M-17 of Table 2-1). Based on analysis of scrub solid and liquid samples from Clemson-2 tests, dissolved species include $\mathrm{B}, \mathrm{Cs}, \mathrm{Li}, \mathrm{K}, \mathrm{SO}_{4}$ and $\mathrm{Na}$, while species found in the solid phase include $\mathrm{Al}, \mathrm{Ca}, \mathrm{Ce}, \mathrm{Cu}$, $\mathrm{Fe}, \mathrm{P}, \mathrm{Si}$, and $\mathrm{Zn}$. $\mathrm{Ca}, \mathrm{Fe}$ and $\mathrm{Zn}$ partition to solids and liquid in approximately a 3:1 ratio, $\mathrm{Cr}$ in 1:2 ratio, $\mathrm{Cu}$ and $\mathrm{Ni}$ in a 3:2 ratio, and $\mathrm{Ru}$ in a 1:1 ratio. XRD analyses of solids filtered from the scrub solution in the Clemson- 1 tests indicate that major compounds include $\mathrm{SiO}_{2}, \mathrm{~K}_{2} \mathrm{NaAlF}_{6}$, and $\mathrm{CaF}_{2}$. The data thus indicate that $\mathrm{K}, \mathrm{Na}, \mathrm{Ca}, \mathrm{Fe}, \mathrm{Zn}, \mathrm{Cr}, \mathrm{Cu}, \mathrm{Ni}$, and $\mathrm{Ru}$ form both soluble and insoluble species in the offgas.

Samples of scrub liquid and undissolved solids filtered from the scrub were analyzed in RSM-2 tests. Soluble species included $\mathrm{B}, \mathrm{Ca}, \mathrm{Cl}, \mathrm{K}, \mathrm{Na}$ and $\mathrm{SO}_{4}$, and insoluble species included $\mathrm{Fe}, \mathrm{Si}$, Ti, and Zr.

\section{DBE-174 NOxidizer Reduction Chamber Chemistry Using Propane}

NOxidizer tests at MSE (entry J-1 of Table 2-1) demonstrated 94-96\% $\mathrm{NO}_{\mathrm{x}}$ destruction efficiency from a simulated offgas containing up to $40,000 \mathrm{ppm} \mathrm{NO}_{\mathrm{x}}$ and a NOxidizer fueled by propane. A matrix of thirteen tests was designed to determine the effects of three parameters $-T_{\text {quench }},\left(T_{\text {reoxidation }}-T_{\text {quench }}\right)$, and $\left[\mathrm{O}_{2}\right]_{\text {exit }}(\mathrm{T}=$ temperature, []$=$ concentration $)-$ on $\mathrm{NO}_{\mathrm{x}}$ destruction efficiency. The highest $\mathrm{NO}_{\mathrm{x}}$ destruction efficiencies were seen with (a) low quench temperature $\left(1600^{\circ} \mathrm{F}\right)$, low temperature difference $\left(50^{\circ} \mathrm{F}\right)$ and high oxygen $(>4 \%)$, (b) low quench temperature $\left(1600^{\circ} \mathrm{F}\right)$, high temperature difference $\left(200^{\circ} \mathrm{F}\right)$ and low oxygen $(1.5 \%)$, and high quench temperature $\left(1800^{\circ} \mathrm{F}\right)$, low temperature difference $\left(50^{\circ} \mathrm{F}\right)$ and low oxygen $(1.5 \%)$.

Kinetic modeling (see entry Q-1 of Table 2-1 and Ref. 21) provides more detail of the reduction chamber reactions, although this modeling was based on natural gas rather than propane because of the availability of kinetic mechanisms for natural gas. Based on $4.96 \% \mathrm{NO}_{\mathrm{x}}$ in the NOxidizer feed, the model shows $99.94 \% \mathrm{NO}_{2}$ destruction in the reduction stage, $85 \% \mathrm{NO}$ destruction in the reduction stage, $14 \%$ destruction of $\mathrm{NO}$ in the quench and reoxidation stages, and a slight gain of $\mathrm{NO}_{2}$ in the quench and reoxidation stages such that the overall destruction $\mathrm{NO}_{2}$ efficiency is $99.95 \%$. 


\section{STATUS OF SBW VITRIFICATION PROCESS}

During FY 2001, a baseline flowsheet for vitrification of SBW was defined, and a database (the TBDB) was developed and populated that contains a mass balance for the flowsheet, the basis for the mass balance, and plans for obtaining data needed to validate the flowsheet basis. The flowsheet consists of three primary systems - the feed system, the melter and the offgas treatment system. This section examines the FY 2001 work from a process viewpoint in contrast to the low level discussion of the individual DBEs in Section 3. In this higher level context, the following subsections summarize the FY 2001 work in light of (a) progress toward obtaining the data needed for each of the three primary systems listed above, (b) insights gained that suggest additional development, not envisioned in the present database, is needed, and (c) major data needs that have not been addressed.

\subsection{Feed System}

The major equipment in the feed system includes (a) an SBW storage tank and pumps, (b) a sugar solution storage tank and pumps, (c) glass frit storage and transfer equipment, (d) melter feed mix tanks and associated pumps and (e) melter feed tanks and associated pumps. The function of the feed system is to deliver a homogeneous feed of waste, glass forming components and reductant to the melter at the rate required to meet the treatment schedule.

\subsubsection{Feed Rheology, Feed Reactions and Frit Versus Glass Forming Components}

Initial feed rheology studies found no gelling or caking to occur during feed mixing, and RSM-1 and other melter tests experienced no feed line plugging during the tests. No settling or segregation of feed solids was noted in any test. Thus, within the parameters of the tests, i.e, WM-180 simulant and glass forming components equivalent to a waste loading of about $35 \%$, transfer of a homogeneous feed to the melter has been verified. However, tests of the RSM mixing and feed system are needed at the new baseline waste loading of $20 \%$. Use of alkaline glass forming components such as $\mathrm{CaO}$ and $\mathrm{Li}_{2} \mathrm{O}$ resulted in neutralization of the SBW, precipitation of solid and gelatinous species, and the release of heat during the RSM-2 test. In this test, which used a 20\% waste loading and the SBW-22 formulation with higher alkaline fraction, additional acid was needed in the feed in order to prevent gelling.

The rheology studies found the melter feed to be very abrasive and chemically aggressive; these results will dictate material design requirements for the transfer, mix and storage equipment. An evaluation of several forms of silica resulted in the recommendation to use -400 mesh silica.

No evaluation of frit versus glass forming chemicals has yet been performed. This evaluation is needed to further define the number and size of storage vessels for these materials, to better define feed rheology, to better determine temperature and chemical control requirements of feed and mix tanks, and to confirm glass melt rate, glass properties and other characteristics of the glass melt and melter operation.

It was shown (Ref. 18) that no reaction between sugar and nitric acid in the waste occurs below $50^{\circ} \mathrm{C}$. Confirmation tests of this limiting temperature are needed to establish for the full scale process the temperature and cooling requirements of the melter feed mix tanks and melter feed tanks.

\subsubsection{Frit Formulation and Feed Mixing}

Frit formulation relates primarily to glass quality and will be discussed in Section 4.2.1; however, the frit formulation(s) sets requirements for the feed system. Progress has been made determining glass property/composition relationships through CVS work. These relationships should be used to determine 
whether a single or multiple frit formulations would be required to process waste from the different INTEC Tank Farm tanks. The CVS models should also be used to evaluate potential benefits of feed mixing (i.e., pre-blending the liquids from all SBW tanks in the tank farm) relative to glass formulation; i.e. reduced glass volume, a single frit formulation, or increased margin in the envelope of feed composition.

\subsubsection{Reductant Type and Form}

Sugar was shown to be the only reductant, of four tested, which met requirements for not affecting glass product properties (entry C-5 in Table 2-1), being able to reduce iron in the melter without final inclusion in the glass, and not adversely affecting the feed transport properties. In contrast to the baseline assumption of $67 \mathrm{wt} \%$ sugar solution added to SBW, all melt tests to date have used granular sugar as the reductant. As discussed more fully in the Attachment 3, use of granular sugar has advantages of reducing the amount of water in the feed and avoiding the need to heat the sugar syrup to keep it pumpable, and is consistent with the test data. Thus granular sugar is recommended.

\subsubsection{Feed Pretreatment}

The baseline flowsheet assumes no feed pretreatment. However, one of the major results of this past year's development testing is the finding that the maximum glass waste loading is only about $20 \%$, limited by the amount of sulfate in the waste feed. Tests this year have also demonstrated that $>80 \%$ of the sulfate could be precipitated from an SBW simulant by the addition of barium nitrate, and that the resulting precipitate could be separated from the liquid waste (Ref. 13). Peeler and Vienna (Ref. 9) estimate that if the waste sulfate concentration did not limit waste loading, the glass formulation would be constrained by the sodium content and the waste loading would increase to $38 \%$. Thus sulfate precipitation offers a means of greatly reducing the volume of glass by nearly a factor of 2 with associated savings in equipment costs, glass storage facility costs, and glass disposal costs.

Other feed pretreatment steps offer additional process and cost benefits. The total melter feed is approximately $50 \%$ water, and the melter offgas is more than $70 \% \mathrm{H}_{2} \mathrm{O}$. Evaporating the feed to dryness would reduce the melter offgas by a factor of more than 3, resulting in significant savings by downsizing the needed offgas equipment. In addition the melt rate would double (Ref. 22). Though no evaporation tests of SBW were performed in the past year results from earlier tests provide a preliminary basis for evaluation of evaporation schemes. These studies are cited and evaporation schemes discussed in Attachment 3.

A third pretreatment scheme which offers potential cost savings is to remove nitrates by crystallization. Combined with sulfate precipitation, this scheme has the potential of reducing the feed rate by $91 \%$ and the product glass volume by $70 \%$ (see Attachment 3 ).

The potential savings offered by pretreatment schemes provide incentive for further evaluation and testing of these schemes.

\subsection{Melter and Canister Filling System}

The function of the melter and canister filling system is to produce from the feed waste a vitrified product that meets all disposal requirements. Progress was made in the paste year determining the limiting waste loading in the glass, developing glass formulations that result in glass meeting both operating and disposal requirements, and characterizing the melter offgas. However, all data obtained to date is strictly applicable only to a WM-180 simulant waste feed. 


\subsubsection{Glass Waste Loading, Glass Formulation and Control of Salt Layer}

Glass formulation studies in the first half of the year (Ref. 9) resulted in the recommendation of a formulation called "SBW-9" and a waste loading of $30 \mathrm{wt} \%$. Using a formulation very similar to SBW-9 and varying waste loadings between $30 \%$ and $35 \%$, RSM-1 tests produced glasses that met all processing and disposal requirements. However, in tests performed in the EV-16 melter at the Clemson Environmental Laboratory using the SBW-9 formulation and a waste loading of 30\%, a salt layer was observed on the melt during the demonstration. This result, along with an updated WM-180 surrogate formulation (Ref. 25) that showed a $40 \%$ higher sulfate concentration in the waste, led to development of additional glass formulations. The objective of these later formulations was to incorporate all feed sulfate in the glass. To achieve this objective a new glass formulation ("SBW-22") and a waste loading of 20\% were recommended. The RSM-2 tests, which used the higher-sulfate waste formulation, the SBW-22 formulation, and the recommended $20 \%$ waste loading resulted in no salt layer accumulation and yielded glass with acceptable properties.

The tests performed this past year thus showed that for WM-180 waste, with a sulfate concentration of $0.07 \mathrm{M}$, limiting the waste loading to $20 \%$ (or less) is one method to control salt layer accumulation. A glass formulation was developed that captured $>90 \%$ of the feed sulfate in the glass. However, several issues regarding waste loading remain. Glass formulations for wastes other than WM180 have not been developed. Schemes have been proposed to reduce the sulfate concentration in the feed and hence permit higher waste loadings, i.e., feed blending and feed pretreatment, but surrogates for the waste from these schemes have not been tested. Feed blending would reduce the sulfate concentration in the waste to the level of the surrogate in tests early in the year, for which a waste loading of $30 \%$ was recommended. Feed pretreatment has the potential of increasing the waste loading to the $35-40 \%$ range. Another alternative that has been discussed to increase waste loading is to allow a limited sulfate salt layer to develop and restrict its growth by volatilizing sulfur. Some of the test data suggests that such an approach may be feasible. Based on the sizable economic benefits from increasing the waste loading, further consideration of these alternative process schemes is recommended.

\subsubsection{Melter Scale-Up}

Melter tests were performed in the past year in the EV-16 melter, the Research-Scale Melter (RSM), the slurry fed melt rate furnace (SFMRF) and the centimeter-scale melter (CSM). The EV-16 melter has a chamber 18 -in by 18 -in, with a design depth of 16 -in. The nominal glass volume in the EV16 melter is $3 \mathrm{ft}^{3}$. The RSM chamber has a diameter of 6-in and a nominal glass depth of 3-in, equating to a glass volume of about $0.05 \mathrm{ft}^{3}$. The SFMRF and CSM both utilize crucibles. The SFMRF crucible typically contains $5 \mathrm{~kg}$ or $0.07 \mathrm{ft}^{3}$ of glass. The CSM tests with 1-1.5 inch diameter melt surfaces are typically used to obtain between 10 and 50 gm of glass.

Past experience at other DOE vitrification facilities as well as budget limitations has dictated the use of different subscale melters to obtain data for the design of vitrification facilities for INEEL waste. While the data obtained has been useful in preparing mass balances, feasibility designs and initial cost estimates, future tests will be needed to determine the effects of scale on melter performance parameters. Knowledge of such will be necessary before a full size design can be formulated with confidence.

\subsubsection{Melter Operating Parameters}

Glass melt rates determined from the RSM-1 and the EV-16 tests were generally consistent with data from existing, full-scale melters at DOE sites, and provide a basis for determining the required melter size for a given treatment schedule or processing schedule for a given melter size. The melt rate for a dried feed should be determined as part of an evaluation of pretreatment schemes. 
The melter plenum temperature has a significant impact on offgas equipment sizing requirements, since the melter offgas must be cooled by adding air and steam in the film cooler. The RSM-1 tests were run with plenum temperatures significantly lower than presently assumed in the baseline mass balance $\left(536^{\circ} \mathrm{C}\right.$ compared to $\left.650^{\circ} \mathrm{C}\right)$, and the Clemson- 1 tests included periods targeting a plenum outlet temperature of $450^{\circ} \mathrm{C}$ with no apparent deleterious effects. Additional offgas, melt rate, and processability data are needed to establish the minimum plenum temperature required to allay flammability, melt viscosity, and throughput concerns. However, based on the advantages of operating at lower temperature and the offgas data from the Clemson- 1 test, it is recommended that the baseline plenum temperature be changed to $500^{\circ} \mathrm{C}$.

\subsubsection{Melter Partition Factors and Reactions}

Data was obtained from RSM-1, RSM-2 and Clemson-1 tests relative to partitioning of semivolatile and nonvolatile species between glass and offgas. Off-gas data from these tests also provides a basis for mass balance assumptions regarding reactions that occur in the melter, producing $\mathrm{CO}, \mathrm{CO}_{2}$, $\mathrm{NO}, \mathrm{NO}_{2}, \mathrm{SO}_{2}, \mathrm{HCl}, \mathrm{HF}, \mathrm{HI}$ and $\mathrm{H}_{2}$. Partitioning data is needed to determine the requirements for offgas treatment, to confirm that the baseline process flow scheme will produce secondary wastes that can be disposed and offgas that meets emission standards, and to evaluate options for processing scrub wastes.

The partition factor data have large uncertainties. Part of the uncertainty is due to incomplete mass balance closure. For example, based on the steady state portion of the Clemson- 1 test, $98.5 \%$ of the nominal $\mathrm{Cl}$ in the feed was found in the glass, and $32 \%$ was found in the scrub solution. The partition factor (fraction of input mass leaving the offgas) for $\mathrm{Cl}$ based on the scrub would thus be $32 \%$, but based on the glass it would be only $1.5 \%$. For some species, the concentration found in the offgas is near or below the detection limit, and use of a detection limit to calculate a species partition factor can introduce large uncertainty. Finally, the effect of scale or melter configuration on the partition factors is unknown and result in misleading results. For example, the DF (inverse of the partition factor) for cesium was found to be 1.5-4.9 in the Clemson-1 tests, 3-5 in the RSM-1 test, and 9-49 in the RSM-2 test. However, data for large-scale melters typically shows Cs DFs of 80-100 (for example, see Ref. 32).

In spite of the large uncertainties in the data, the database should be updated to reflect findings from the RSM and Clemson tests using the most conservative values relative to offgas system design. The numeric changes to specific factors may depend on the direction of future mass balances, but the following should be considered:

- $\mathrm{SO}_{3}$ in the offgas would be absorbed by quench and scrub solutions producing $\mathrm{H}_{2} \mathrm{SO}_{4}$, affecting the acidity of the solutions which in turn will determine their effectiveness in removing other species from the offgas. Measurable $\mathrm{SO}_{3}$ was seen in the RSM-2 data.

- Considerably less $\mathrm{SO}_{2}$ was seen in the RSM-2 offgas than the other melter tests, and may be because of the use of the SBW-22 formulation of GFCs, although extremely low levels of $\mathrm{SO}_{2}$ were also noted in CSM testing with other formulations. Based on RSM-2 results indicating $5-10 \%$ of sulfur from the feed was recovered in the scrub, the extent of reaction of sulfate to $\mathrm{SO}_{2}$ in the mass balance model should be reduced from $14 \%$ to around $6 \%$.

- Concentrations of HI and $\mathrm{I}_{2}$ were measured in RSM-2 melter offgas. The quality of this data should be assessed. Depending on the results of this assessment it may be appropriate to use the RSM-2 HI and $\mathrm{I}_{2}$ concentrations as a basis for specifying reactions producing these species in the mass balance model. The model presently assumes all I in the offgas is present as NaI. 
- Appreciable concentrations of $\mathrm{N}_{2} \mathrm{O}$ were seen in some tests. Appropriate reactions producing $\mathrm{N}_{2} \mathrm{O}$ should be added to the mass balance model.

- Partition factors for semi-volatile and nonvolatile species in the model should be updated based on the recent data. However, for species with poor mass balance closure or poor agreement with DWPF and other large-scale data, partition factors based on large-scale data may be preferable.

- Particle-size distribution data from Clemson-1 offgas solids can be used to refine calculations of solids scrubbing efficiencies used in the mass balance until better PSD data is obtained.

- Concentrations of $\mathrm{HNO}_{3}$ in the melter offgas were measured in the Clemson-1 tests, and should be used as a basis for volatilization of $\mathrm{HNO}_{3}$ in the melter in future mass balances.

- Appreciable concentrations of $\mathrm{Cl}_{2}$ were seen in some tests. Appropriate reactions producing $\mathrm{Cl}_{2}$ should be added to the mass balance model.

\subsection{Off-Gas Treatment System}

\subsubsection{Film Cooler}

The function of the film cooler is to prevent deposition of solids in the offgas exiting the melter plenum in offgas piping. Air and/or steam is added in the film cooler to cool the offgas and entrained solids to a temperature below that which solids would stick to walls of piping and equipment. Appreciable deposition of solids in offgas piping was seen in the Clemson-1 tests with blockage in a duct connecting the melter plenum to the film cooler. To avoid this the film cooler needs to be close-coupled with (i.e., inserted into) the melter offgas exit. Deposits downstream of the film cooler were generally of a friable, powder-like consistency, and adhered very loosely to the pipe walls. Additional tests of alternative configurations (e.g., smaller piping to increase gas velocity) are needed to demonstrate a design that adequately prevents solids deposition in offgas piping.

\subsubsection{Off-gas Quench and Scrub System}

The primary functions of the offgas quench and scrub system are to cool the offgas to saturation temperature, to remove radionuclides to the extent that further processing of the offgas can be done out of cell, and to process or treat the resulting scrub solution and solids.

\subsubsection{Off-gas Quench and Scrub}

The offgas treatment system of RSM and Clemson downstream of the film cooler differs from the baseline flowsheet. The RSM system includes an ejector venturi scrubber (EVS) and high efficiency mist eliminator (HEME), the Clemson system includes a quench chamber, air atomized scrubber, cyclone separator, packed bed and mist eliminator. The baseline flowsheet has a quench column, venturi scrubber and HEME. Considerable review and evaluation of offgas treatment systems has been performed in the past year (Refs. 19, 23). Final selection of unit operations, particularly for offgas scrubbing, is dependent on better definition of the contaminants in the melter offgas. Data gained in the past year contributes to filling this data gap.

\subsubsection{Soluble and Insoluble Species}

The baseline flowsheet includes separation of solids captured in the quench and scrub liquids, with recycle of these solids to the melter. The mass balance assumes chemical species are either totally soluble 
or insoluble. Information regarding soluble and insoluble species in the scrub was obtained from analysis of scrub solids and solutions from Clemson-1 (Ref. 5) and RSM-2 (Ref. 17) tests. These analyses should be used to update the baseline lists of soluble and insoluble species (see discussion for DBE 167). Besides shifting some species from one group, soluble or insoluble, to the other, the scrub solids and liquid analyses along with XRD analyses indicate that some elemental species partition between both soluble and insoluble solids. Sensitivity studies are needed to determine the impacts of species partitioning between soluble and insoluble solids. These studies will determine whether additional test data should be obtained to better determine partition factors, the range of these factors, and how different process parameters such as melter plenum temperature or scrub $\mathrm{pH}$ affect the partition factors.

\subsubsection{Scrub Liquids and Solids Treatment}

The baseline system of scrub treatment includes several untested systems, including solids separation, $\mathrm{pH}$ adjustment of scrub purge, removal of cesium by ion exchange, and grouting of the cesium-free scrub purge. In addition, recycle scrub has not been included in the feed simulant used in any melter test to date. Insights gained from experiments this past year include the following:

- Data from Clemson-1 showed that a large fraction ( $>50 \%)$ of the fraction of solids collected in the scrub are less than 1 micron in diameter. This finding would preclude separation of solids by settling.

- Analysis of RSM-2 samples, the only melter test which included mercury in the feed, showed no mercury in the HEME effluent gas. Experiments that determined mercury VLE data at scrub conditions confirmed that a very high fraction of mercury in the melter offgas would be captured by the scrub. While questions remain regarding the speciation of mercury in the offgas and scrub, the data suggests that higher-than-expected mercury scrubbing efficiency may necessitate removal of mercury from the scrub.

- Undocumented tests of neutralization of simulated scrub solution showed significant precipitation. Assuming this was not an artifact of the test procedure it suggests that filtration will be required upstream of the cesium ion exchange column. Further testing is needed to establish that the observed precipitation is representative of the actual scrub liquid. Analysis of the composition and quantity of solids should be performed to determine if they could be recycled to the melter or require a different disposal path.

- Although no tests were performed this past year of the proposed cesium sorbent, some data was recently received from earlier tests performed at Hanford on a similar waste stream. The data shows that increasing sodium concentration in the waste decreases cesium removal efficiency. The sodium concentration expected in the SBW vitrification plant scrub solution is much higher than the waste tested at Hanford.

- Significant levels of organics $(\sim 1 \mathrm{~g} / \mathrm{l})$ were seen in the scrub solution of RSM-2 tests. The effect of these organics on grouting the scrub purge will need to be determined.

Partly because of these test results and partly because of identified uncertainties in the baseline scrub treatment system, modifications and alternative processes have been proposed for scrub treatment. These include:

- Adding steps to remove mercury by electrochemical reduction and amalgamate the resulting elemental mercury to the baseline scrub treatment system. 
- Adding a step to precipitate mercury from the scrub purge.

- Removing strontium in addition to cesium from the scrub purge.

- Using a moving bed with continual replacement of sorbent to remove cesium and continual bleed of the loaded sorbent to the melter.

- Treating the scrub purge by evaporation to produce a dry solid waste. Purge from the downstream caustic scrubber would also be treated by evaporation. This alternative would eliminate recycle of scrub to the melter, ion exchange to remove cesium (and strontium), and the grouting step.

An evaluation of scrub treatment alternatives is needed, followed by testing to confirm the performance of those that offer the greatest benefits.

\subsubsection{Off-gas Solids Filtration}

The evaluation of secondary wastes (Ref. 20) recommended replacing the in-cell HEPA filters with washable HEPA filters. Some development testing of washable filters has been performed at SRS.

Review of the data from this program is recommended. It may be desirable to commission additional parametric testing to determine the feasibility of washable filters in the SBW vitrification process. The alternative to washable filters is the conventional fabric HEPA filters that must be treated for disposal in the NWCF filter leach facility.

\subsubsection{NOx Abatement}

Requirements for NOx abatement were identified (Ref. 23) and calculations performed to estimate the maximum allowable NOx concentrations at the stack. Tests have confirmed that the NOxidizer will reduce effluent NOx concentrations well below the allowable limit (Ref. 14).

Information from the NOxidizer vendor, however, shows that a much higher rate of air to the reduction chamber will be required than is presently assumed. Based on the higher air rate, the NOxidizer effluent rate will be 6-8 times the inlet rate, compared to the baseline mass balance of 1.7 times. The increased offgas volume will have significant implications for the size of downstream equipment and also the volume of spent carbon waste. Given that alternative NOx abatement technologies were ranked almost equal to the NOxidizer in past NOx abatement technology evaluations (Ref. 23), testing of SCR technology is recommended.

\subsubsection{Acid Gas Removal}

The caustic quench and scrub step cools the NOxidizer effluent and removes acid gases, including, $\mathrm{HCl}, \mathrm{HF}, \mathrm{HI}$, and $\mathrm{SO}_{2}$. No data was obtained in melter tests this past year regarding offgas compositions downstream of scrubbing units. As discussed in Attachment 3, the need for acid gas removal has not been established. Thus it is recommended that in future melter tests, samples of gas downstream of HEPA filters be taken and analyzed in order to determine whether additional acid gas removal would be required.

\subsubsection{Mercury Removal}

Tests were performed using small-scale GAC beds $\left(0.4-2 \mathrm{~cm}^{3}\right)$ to determine the effects of feed gas composition, form of mercury and residence time on mercury removal efficiency (Ref. 6). While the 
effluent concentrations from the tests were within MACT emissions limits, the inlet concentrations were approximately 100 times less than the current mass balance concentration. Additional melter tests that include mercury in the feed are needed to better establish the mercury concentration downstream of scrubbing equipment. Then, additional testing at appropriate feed concentrations and a larger range of residence times is needed to clearly determine the effects of inlet mercury speciation and residence time on mercury removal efficiency. 


\section{REFERENCES}

1. Consent Order and Settlement Agreement between DOE and the State of Idaho Regarding Spent Nuclear Fuel and Nuclear Waste Issues, October 17, 1995.

2. DOE, Idaho High-Level Waste \& Facilities Disposition Draft Environmental Impact Statement, DOE/EIS-0287D, December 1999.

3. Tank Focus Area, Assessment of Selected Technologies for the Treatment of Idaho Tank Waste and Calcine, PNNL-13268, August 2000.

4. A. Olson, J. Murphy, K. Perry, Pre-Decisional Sodium Bearing Waste Technology Development Roadmap, INEEL/EXT-2000-01299, September 2000.

5. K. J. Perry, R. R. Kimmitt, N. R. Soelberg, R. D. Tillotson, A. N. Olson, Test Results from SBW-FY-01-PS-01 Vitrification Demonstration of Sodium Bearing Waste Simulant Using WM-180 Surrogate, INEEL/EXT-0101073, August 2001.

6. J. A. Del Debbio, T.T. Watson, R. J. Kirkham, Removal of Mercury from SBW Vitrification Off-Gas by Activated Carbon, INEEL/EXT-01-01227, September, 2001.

7. J. A. McCray, D. L. Griffith, R. R. Kimmitt, D. D. Siemer, Status of Melt Rate Testing and Reductant Selection for SBW Vitrification, INEEL/EXT-01-01223, September, 2001.

8. L. G. Olson, Radioactive Crucible Scale Glass Melts Using INTEC Tank WM-180 Sodium-Bering Waste, INEEL/EXT-01-01020, September, 2001.

9. D. K. Peeler, Glass Formulation Development for INEEL Sodium-Bearing Waste (FY2001 WM-189), WSRCTR-2001-00295, September 21, 2001.

10. D. W. Marshall, FY-2001 Accomplishments in Off-Gas Treatment Technology Development, INEEL/EXT-0101302, September, 2001.

11. R. W. Goles, J. M. Perez, B. D. MacIsaac, D. D. Siemer, J. A. McCray, Test Summary Report INEEL SodiumBearing Waste Vitrification Demonstration RSM-01-1, PNNL-13522, May, 2001.

12. J. G. Darab, D. D. Graham, B. D. MacIsaac, R. L. Russell, H. D. Smith, J. D. Vienna, D. K. Peeler, Sulfur Partitioning During Vitrification of INEEL Sodium Bearing Waste: Status Report, PNNL-13588, July, 2001.

13. C. M. Nitzel, Separation of Barium Sulfate Precipitate from Liquid Sodium-Bearing Waste Simulant, August, 2001.

14. MSE Technology Applications, Inc., John Zink NOxidizer Propane-Fired Performance Assessment and Mercury Emission Speciation, PTP-81, February, 2001.

15. J. A. Nenni, ETS Process Parameter and Outlet Stream Predictions for WM-185 Feed, INEEL Interoffice Memorandum, January 9, 2002.

16. R. J. Kirkham, Mercury Scrubbing Vapor Liquid Equilibrium (unpublished report) 
17. R. W. Goles, J. A. Del Debbio, R. J. Kirkham, B. D. MacIsaac, J. A. McCray, D. D. Siemer, N. R. Soelberg, Test Summary Report INEEL Sodium-Bearing Waste Vitrification Demonstration RSM-01-2, PNNL-13869, May, 2002.

18. R. Russell, H. Smith, Summary Report for Rheology Testing of INEEL Sodium Bearing Waste (SBW) Simulant and Melter Feed, March, 2001.

19. D. R. Marshall et al, Evaluation of Scrubber Operations for Treatment of Idaho Waste Vitrification Facility Off-gas, INEEL/EXT-01-00952, September, 2001.

20. A. K. Herbst, R. J. Kirkham, S. J. Losinski, Secondary Waste Cosiderations for Vitrification of Sodium Bearing Waste at the Idaho Nuclear Technology and Engineering Center FY-2001 Status Report, INEEL/EXT-01-01172, September, 2001.

21. R. A. Wood, Modeling $N O_{x}$ Destruction Options for INEEL Sodium Bearing Waste Vitrification, INEEL/EXT-01-01220, September, 2001.

22. D. S. Wendt, D. R. Haefner, Wet vs. Dry SBW Vitrification Feed Evaluation, EDF-2860, October 11, 2001.

23. R. A. Wood, D. Tyson, B. Bonnema, C. Olsen, A. P. Pinto, D. Wendt, S. Reese, B. Raivo, Feasibility Study for the Idaho Waste Vitrification Facilities Off-gas Treatment for Sodium-Bearing Waste, INEEL/EXT-0100995.

24. C. M. Barnes, Feed Composition for the Sodium-Bearing Waste Treatment Process, INEEL/EXT-200001378, Revision 1, July, 2001.

25. J. D. Christian, Composition and Simulation of Tank WM-180 Sodium-Bearing Waste at the Idaho Nuclear Technology and Engineering Center, INEEL/EXT-2001-00600, May, 2001.

26. J. D. Christian, "Worst Case" Simulant for INTEC Sodium-Bearing Waste Vitrification Tests, INEEL/EXT01-01219.

27. N. R. Soelberg, et al, Sodium Bearing Waste Vitrification Test Results, paper presented at IT3'02 Conference, May 13-17, 2002, New Orleans, LA.

28. Dean Taylor, Charles Barnes, Lance Lauerhass, INEEL SBW Vitrification Process, INEEL/EXT-0101139, September 2001.

29. J. D. Christian, Technical Baseline Database for SBW Vitrification: Fluoride Concentration Requiring Use of Additives for Corrosion Control, INEEL Interoffice Memorandum to D. D. Taylor, September 24, 2001, JDC-04-01.

30. R. R. Hammer, A Determination of the Stability Constants of a Number of Metal Fluoride Complexes and Their Rates of Formation, ENICO-1004, August, 1979.

31. J. A. Murphy, Determination of the Zirconium Fluoride Stability Constants by Direct Measurement of Equilibrium Hydrofluoric Acid Using the Amperometric Response of Titanium and Hafnium Electrodes, WINCO-1098, May 1992.

32. N. E. Bibler, T. L. Fellinger, S. L. Marra, R. J. O'Drisscoll, J. W. Ray, Tc-99 and Cs-137 Volatility from the DWPF Production Melter during Vitrification of the First Macrobatch at the Savannah River Site, 
33. S. O. Bates, B. D. Raivo, J. J. Quigley, S. M. Berry, W. H. Landman, S. L. Palmer, T. M. Hipp, Feasibility Study for Vitrification of Calcine in the Idaho Waste Vitrification Facility, INEEL/EXT-01-00978, September, 2001.

34. L. A. Bray, K. J. Carson, R. J. Elovick, D. E. Eakin, HWVP Transuranic Process Waste Treatment by Ion Exchange, HWVP-90-1.2.2.04.04A, February, 1990.

35. C. M. Barnes, Feed Composition for the Sodium-Bearing Waste Treatment Process, INEEL/EXT2000-01378, Revision 0, October 2000. 
ATTACHMENT 1 
Table A-1: Complete list of Design Basis Elements (DBEs) in technical baseline for SBW vitrification.

\begin{tabular}{|c|c|}
\hline DBE ID & DBE Name \\
\hline 2 & Fate of sulfur in NOx abatement \\
\hline 3 & Detection of sulfate salt layer in the melter \\
\hline 15 & Disposition/handling of noble metals in melter \\
\hline 16 & Submicron particle size distribution out film cooler \\
\hline 17 & Nitrate destruction chemistry in melter \\
\hline 18 & Melter chemistry \\
\hline 19 & Target concentration of total dissolved solids (TDS) in melter feed \\
\hline 20 & Reductant selection and concentration in melter feed \\
\hline 21 & No secondary liquid waste streams \\
\hline 22 & Pumping behavior of melter feed slurry \\
\hline 23 & Flammability limits on $\mathrm{H} 2, \mathrm{CO}$, and unburned $\mathrm{HCs}$ in offgas \\
\hline 24 & Partition factors for feed species in melter \\
\hline 25 & Iodine-129 concentration in SBW feed \\
\hline 26 & Volatilities of radionuclides (excluding Cs, Tc-99, and I-129) in melter \\
\hline 27 & Partitioning of acid gases and $\mathrm{Hg}$ during quench/scrubbing operations \\
\hline 28 & Dioxins/Furans in offgas system \\
\hline 29 & Carryover of melter feed to offgas \\
\hline 30 & Representativeness of cold simulants in melter tests \\
\hline 31 & Composition envelope for acceptable glass feed \\
\hline 32 & What tank farm solids will be coprocessed with SBW? \\
\hline 34 & Frit vs GFC in melter feed \\
\hline 35 & SBW feed blending \\
\hline 36 & Evaporation limit for SBW \\
\hline 37 & Total volume and composite SBW feed composition \\
\hline 38 & Noble metals concentration in SBW feed \\
\hline 39 & Corrosion of melter components \\
\hline 40 & Canister fill height measurement \\
\hline 41 & Canister closure method \\
\hline 43 & Composition and concentration of solids in SBW feed \\
\hline 44 & Required control of feed mix tank temperature \\
\hline 45 & Feed preparation requirements (excl. evaporation) \\
\hline 46 & Steam/air ratio in film cooler \\
\hline 47 & Melter offgas temperature \\
\hline 48 & Glass frit composition \\
\hline 49 & Waste loading in glass \\
\hline 50 & Melter air rate \\
\hline 51 & Processing pressure in melter \\
\hline 52 & Pressure drops through offgas system components \\
\hline 53 & NOxidizer reduction chamber chemistry using kerosene \\
\hline 54 & NOxidizer oxidation chamber chemistry \\
\hline 55 & NOxidizer reduction chamber reaction and quench temperatures \\
\hline 56 & NOxidizer refractory changeout frequency \\
\hline 57 & Disposal path for spent NOxidizer refractory \\
\hline 58 & Composition of spent NOxidizer refractory \\
\hline 59 & Speciation of mercury in NOxidizer effluent \\
\hline
\end{tabular}




\begin{tabular}{|c|c|}
\hline DBE ID & DBE Name \\
\hline 60 & pH control in scrubber solutions \\
\hline 62 & Off-gas system corrosion control \\
\hline 63 & Off-gas flow control system \\
\hline 64 & Air addition to NOxidizer oxidation chamber \\
\hline 65 & Mercury retention and speciation in the melter \\
\hline 66 & Mercury speciation downstream of melter \\
\hline 67 & Peak acceptable mercury loading in GAC \\
\hline 68 & Residence time requirement for $\mathrm{Hg}$ extraction in $\mathrm{GAC}$ \\
\hline 69 & Maintenance and reliability issues for GAC columns \\
\hline 70 & Mercury removal efficiency of GAC beds \\
\hline 71 & Maximum allowable NOx concentration in GAC bed influent \\
\hline 72 & Process requirements for sulfide precipitation of $\mathrm{Hg}$ \\
\hline 73 & Electrolytic reduction of oxidized mercury \\
\hline 74 & Solids scrubbing efficiency in acid quench \\
\hline 75 & Solids scrubbing efficiency in acid venturi scrubber \\
\hline 76 & Solids scrubbing efficiency in caustic quench \\
\hline 77 & Species removal efficiencies in knockout drum \\
\hline 78 & Species removal efficiencies in HEME \\
\hline 79 & Species removal efficiencies in upstream HEPA filter bank \\
\hline 80 & Species removal efficiencies in downstream HEPA filter bank \\
\hline 81 & Effects of 'other' species on Hg polishing effectiveness of GAC \\
\hline 82 & Removal efficiencies for dioxins/furans in GAC column \\
\hline 83 & Maximum acceptable undissolved solids content of scrubbing solutions \\
\hline 84 & Maximum acceptable dissolved solids content of scrubbing solutions \\
\hline 85 & Maximum allowable $\mathrm{Cl}, \mathrm{F}$ content of scrubbing solutions \\
\hline 86 & Fluoride concentration requiring use of additives for corrosion control \\
\hline 87 & Required corrosion control additives \\
\hline 88 & Particulate removal efficiency in WESP \\
\hline 89 & Hg removal efficiency in WESP \\
\hline 90 & NOx removal efficiency in WESP \\
\hline 91 & Liquid/gas ratio in scrubbers and quench operations \\
\hline 92 & Catalytic oxidizer operating parameters \\
\hline 93 & Scrubbing temperatures \\
\hline 94 & Solids removal efficiency in demister \\
\hline 95 & Loading of Cs in ion exchange resin \\
\hline 96 & Choice of target disposal site for grouted waste \\
\hline 97 & Waste loading of scrubber blowdown in grout \\
\hline 98 & Grout formulation for scrubber blowdown \\
\hline 99 & Thermochemical heat release during grouting of scrubber blowdown \\
\hline 100 & Maximum allowable solids loading in HEPA filters \\
\hline 101 & Settling rate of solids in scrubber blowdown liquid \\
\hline 102 & Will facility comply with MACT \\
\hline 103 & Glass canister size \\
\hline 104 & Waste acceptance criteria for mixed waste disposal at WIPP \\
\hline 105 & Waste acceptance criteria for waste disposal at Yucca Mountain \\
\hline 106 & Waste acceptance criteria for mixed waste disposal at NTS \\
\hline
\end{tabular}




\begin{tabular}{|c|c|}
\hline DBE ID & \begin{tabular}{|c|} 
DBE Name \\
\end{tabular} \\
\hline 107 & Waste acceptance criteria for mixed waste disposal at Envirocare \\
\hline 108 & Waste acceptance criteria for mixed waste disposal at Hanford \\
\hline 109 & Glass durability requirement \\
\hline 110 & Glass homogeneity requirement \\
\hline 111 & Glass cooling requirement \\
\hline 112 & Melter feed homogenization requirement \\
\hline 113 & Target disposal sites for secondary wastes \\
\hline 114 & Melter selection \\
\hline 115 & Choice of melter pilot test facility \\
\hline 117 & Target disposal site for glass \\
\hline 118 & Disposal requirements for mercury-containing secondary wastes \\
\hline 120 & NOx abatement requirement in process offgas \\
\hline 122 & Radioactive process streams to be recycled to melter \\
\hline 123 & Should Cs-137 be extracted from scrubber blowdown \\
\hline 124 & Glass formulation for scrub purge ion exchange sorbents \\
\hline 125 & Disposal path for spent HEPA filters \\
\hline 126 & Disposal path for GAC \\
\hline 127 & Selection and performance of Cs-137 ion exchange sorbent \\
\hline 128 & Composition of ion exchange sorbent \\
\hline 129 & Preheating requirements for HEPA filters \\
\hline 130 & GAC TCLP performance \\
\hline 131 & $\mathrm{H} 2$ generation mechanisms in grout \\
\hline 132 & Gas generation in Cs sorbent \\
\hline 133 & Speciation of iodine in melter offgas \\
\hline 134 & Destruction/removal efficiency (DRE) for ammonia in thermal/catalytic oxidation units \\
\hline 135 & Destruction/removal efficiency (DRE) for dioxins/furans in thermal/catalytic oxidation units \\
\hline 136 & Destruction/removal efficiency (DRE) for hydrocarbons and PICs in thermal/catalytic oxidation units \\
\hline 137 & Effects of recycled scrub on melter and glass \\
\hline 138 & Safe handling of melter feed during abnormal shutdown \\
\hline 139 & Selection of initial baseline process configuration \\
\hline 140 & Scrub purge recycle/blowdown ratio \\
\hline 141 & Melter/Off-gas System Stream Factor \\
\hline 144 & Melter feed rate basis \\
\hline 145 & Composition of air \\
\hline 146 & Acid scrub make-up composition \\
\hline 147 & Caustic scrub make-up composition \\
\hline 148 & NOxidizer fuel selection and fuel composition \\
\hline 149 & NOxidizer reduction chamber air requirement \\
\hline 150 & Selection of quench and scrub components in offgas treatment system \\
\hline 151 & Chemicals included in mass balance calculations \\
\hline 152 & Film cooler outlet temperature \\
\hline 153 & Pressure control air requirement \\
\hline 155 & Slagging/plugging control at melter outlet \\
\hline 157 & Control of foaming in melter \\
\hline 158 & Speciation and partitioning of sulfate in melter \\
\hline 159 & Feed evaporation requirement \\
\hline
\end{tabular}




\begin{tabular}{|c|l|}
\hline DBE ID & \\
\hline 160 & HgCl2 scrubbing efficiency in acid quench and venturi scrubber \\
\hline 162 & SBW vitrification process is operationally safe against identified safety concerns \\
\hline 163 & Fate of chloride and fluoride in the melter \\
\hline 164 & Should Sr-90 be extracted from scrubber blowdown \\
\hline 165 & Wash flow for HEME \\
\hline 166 & Operating temperature in HEME \\
\hline 167 & Soluble species in offgas \\
\hline 168 & Operating temperature in demister \\
\hline 169 & Caustic scrub purge rate \\
\hline 170 & Scrub cooler outlet temperatures \\
\hline 171 & Removal of particulate matter in the GAC beds \\
\hline 172 & Removal efficiency for iodine in GAC \\
\hline 173 & Conditioning of scrub purge prior to radionuclides extraction \\
\hline 174 & NOxidizer reduction chamber chemistry using propane \\
\hline 175 & Treatment and disposal path for spent Cs-137 IX resin \\
\hline
\end{tabular}




\section{ATTACHMENT 2}




\section{MASS BALANCES FROM RSM-1, EV-16, RSM-2}

The information in this attachment was prepared for the paper "Sodium Bearing Waste Vitrification Test Results", N.R. Soelberg et al, presented at the IT3'02 Conference, May 13-17, 2002, New Orleans, LA. It summarizes the mass balance/partitioning data obtained from the RSM-1, EV-16, and RSM-2 test series, described in the body of this report. The tables below (labeled "Table 10, Table 11, and Table 12", as in the referenced paper) were prepared using data supplied from several sources. The data used from each test, and their sources, are indicated in the table below:

\begin{tabular}{|c|c|c|c|}
\hline TEST & DATA USED & SOURCE & DATA DESCRIPTION \\
\hline RSM-1 & Appendix C & Ref. 11 of main report & $\begin{array}{l}\text { Additive data for SBW feed } \\
\text { simulant }\end{array}$ \\
\hline$"$ & Table 4.3 & " & SBW simulant composition \\
\hline$"$ & $\begin{array}{l}\text { Spreadsheet } \\
\text { "PaprTbl.xls" }\end{array}$ & R. W. Goles (PNNL) & Glass composition data \\
\hline EV-16 & Table 3.1 & Ref. 5 of main report & SBW simulant composition \\
\hline$"$ & Table 5.12 & " & Off-gas flow rates \\
\hline$"$ & $\begin{array}{l}\text { Table } 5.16 \\
\text { Table } 5.17 \\
\text { Table } 5.18 \\
\text { Table } 5.19\end{array}$ & $"$ & Off-gas composition data \\
\hline$"$ & Table 6.2 & $"$ & $\begin{array}{l}\text { Feed species mass partitioning } \\
\text { data in glass and offgas } \\
\text { treatment streams }\end{array}$ \\
\hline$"$ & Table 6.3 & $"$ & $\begin{array}{l}\text { Feed species mass partitioning } \\
\text { data in offgas sample streams }\end{array}$ \\
\hline RSM-2 & $\begin{array}{l}\text { Spreadsheet } \\
\text { "RSM-2 Process Rates.xls" }\end{array}$ & R. W. Goles & $\begin{array}{l}\text { Melter feed and glass } \\
\text { production rates }\end{array}$ \\
\hline " & $\begin{array}{l}\text { Spreadsheet } \\
\text { "GlsComp.xls" }\end{array}$ & R.J. Kirkham (INEEL) & Glass composition data \\
\hline$"$ & $\begin{array}{l}\text { Spreadsheet } \\
\text { "RSM feed Data.xls" }\end{array}$ & R.J. Kirkham & SBW simulant composition \\
\hline$"$ & $\begin{array}{l}\text { Spreadsheet } \\
\text { "rsms spread sheet scrubber } \\
\text { data.xls" }\end{array}$ & R.J. Kirkham & $\begin{array}{l}\text { Feed species mass partitioning } \\
\text { data in offgas scrubber streams }\end{array}$ \\
\hline
\end{tabular}

The values in the tables below were generated in a single spreadsheet, "MB Calcs.xls". Due to differences in assumptions and interpretation of uncertainties in tabulated test data, the mass balance numbers in the tables here differ in many cases from those in the published reports referenced in the body of the current report. However, while absolute values may differ, data trends should be similar.

In the column headings of the tables "OG smpl" indicates data obtained from offgas sampling (as opposed to scrub system liquid/solid streams); "\% in scrub", "\% as gas" and "\% on TF" indicate the fractions of feed captured in scrub streams, on total filter samples, and in gas sample impingers, respectively; "MB\%" = overall mass balance closure. In Table 10 the MB\% value is the sum of the first three column values, and in Tables 11 and 12 it is the ["\% in glass"] value plus the greater of ["\% in scrub"] and ["\% on TF" + "\% as gas"] values. Blanks in the tables indicate values for which data was not supplied in the data sources. 


\begin{tabular}{|c|c|c|c|c|c|c|c|c|c|c|c|c|c|c|c|c|c|c|c|c|c|c|}
\hline \multirow{5}{*}{ 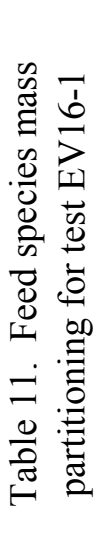 } & \multirow{5}{*}{$\mid$} & $\stackrel{\circ}{\stackrel{0}{\Sigma}}$ & $\infty$ & & $\stackrel{\infty}{\infty}$ & $\stackrel{n}{2}$ & $\bar{m}$ & $\bar{\infty}$ & 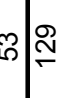 & 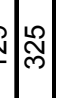 & & $\bar{\sigma}$ & $\bar{\infty}$ & $\hat{\imath}$ & $\mid$ & $\Phi \bar{\infty}$ & $\bar{v}$ & $\infty$ & & ப) & & $\infty$ \\
\hline & & $\begin{array}{ll}0 & 0 \\
\pi & 0 \\
0 & 0 \\
0\end{array}$ & & & & & 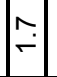 & & & $\mid$ & & & & & & & $\infty$ & & & $\stackrel{\leftrightarrow}{\stackrel{\circ}{*} .}$ & & \\
\hline & & $\begin{array}{c}u \\
\vdash \\
\delta \\
\circ \\
\circ \\
\end{array}$ & ¿ & & 임 & 品. & & 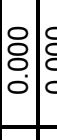 & : & & $\left|\begin{array}{l}\infty \\
\vdots \\
0 \\
0 \\
0\end{array}\right|$ & ¿ & : & @o & 吕 & $\stackrel{\sim}{\leftarrow}$ & & $\stackrel{\sim}{\longrightarrow}$ & 임 & & : & $\stackrel{\sim}{*}$ \\
\hline & & $\begin{array}{l}\cong \\
\stackrel{0}{0} \\
\circ \\
\circ\end{array}$ & - & & $\begin{array}{l}0 \\
0 \\
0\end{array}$ & 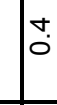 & $\approx$ & $\dot{m}$ & 仓े & $\dot{A}$ & ¿. & 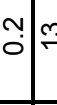 & $=\mid \begin{array}{lll}0 \\
\dot{N}\end{array}$ & $\stackrel{0}{\circ}$ & 芯 & $\stackrel{\bullet}{\rightarrow}$ & $\stackrel{S}{\mathrm{v}} \stackrel{\circ}{\rightarrow}$ & $\stackrel{m}{-}$ & $\mid$ & $=5$ & $\dot{\mathrm{b}}$ & $\begin{array}{l}0 \\
\\
\end{array}$ \\
\hline & & 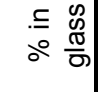 & $\infty \approx$ & & $\infty$ & R & $\infty$ & $\stackrel{\infty}{\curvearrowright}$ & m্য় & vi & $\infty:$ & $\bar{\sigma} \bar{\gamma}$ & $=\infty \infty$ & 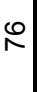 & |ొ్లి & $2 \frac{\infty}{2}$ & $=0$ & $\infty$ & $\bar{n}$ & ळ/ & $\left.\right|_{\infty}$ & $\widetilde{\sigma}$ \\
\hline
\end{tabular}

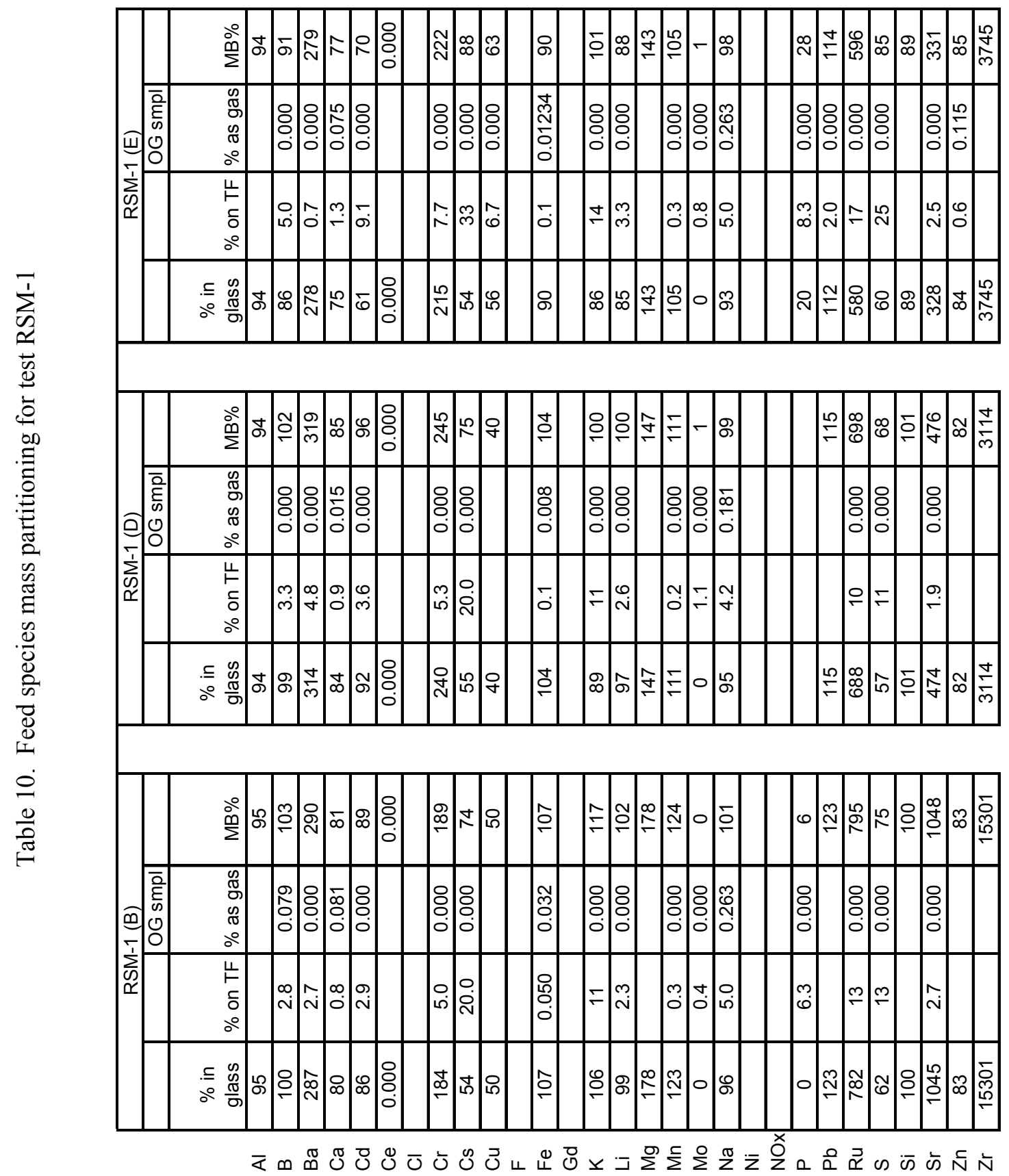


Table 12. Feed species mass partitioning for test RSM-2

\begin{tabular}{|c|c|c|c|c|c|}
\hline & \multicolumn{5}{|c|}{ RSM-2 (2) } \\
\hline & & & OG & $\mathrm{mpl}$ & \\
\hline & $\begin{array}{c}\% \text { in } \\
\text { glass }\end{array}$ & $\begin{array}{l}\% \text { in } \\
\text { scrub }\end{array}$ & $\begin{array}{c}\text { \% on } \\
\text { TF }\end{array}$ & $\begin{array}{c}\% \text { as } \\
\text { gas }\end{array}$ & $\mathrm{MB} \%$ \\
\hline $\mathrm{Al}$ & 84 & 0.8 & 0.3 & 0.000 & 85 \\
\hline B & 83 & 4.6 & 3.8 & 0.000 & 87 \\
\hline $\mathrm{Ba}$ & 359 & 7.4 & 1.3 & 0.13 & 366 \\
\hline C & & 1.7 & & 132.8 & 133 \\
\hline $\mathrm{Ca}$ & 68 & 1.3 & 0.4 & 0.004 & 69 \\
\hline $\mathrm{Cd}$ & 62 & 7.4 & 1.9 & 0.000 & 69 \\
\hline $\mathrm{Ce}$ & 0 & 0.0 & & & 0 \\
\hline $\mathrm{Cl}$ & 83 & 19.9 & & 13.1 & 103 \\
\hline Co & 0 & 0.0 & & & 0 \\
\hline $\mathrm{Cr}$ & 299 & 6.6 & 2.5 & 0.000 & 305 \\
\hline Cs & 80 & 9.9 & 11.1 & 0.003 & 91 \\
\hline $\mathrm{Cu}$ & 101 & 10.9 & 1.5 & 0.002 & 112 \\
\hline $\mathrm{F}$ & & 51.9 & & 123.4 & 123 \\
\hline $\mathrm{Fe}$ & 116 & 0.6 & 0.1 & 0.000 & 117 \\
\hline $\mathrm{Hg}$ & 0 & 23.1 & 0.68 & 71.5 & 72 \\
\hline I & & 11.1 & & 106.5 & 107 \\
\hline $\mathrm{K}$ & 104 & 7.8 & 7.3 & 0.000 & 112 \\
\hline $\mathrm{Li}$ & 96 & 3.4 & 2.2 & 0.000 & 99 \\
\hline $\mathrm{Mg}$ & 114 & 1.9 & 0.0 & 0.008 & 116 \\
\hline $\mathrm{Mn}$ & 54 & 0.7 & 0.3 & 0.000 & 55 \\
\hline Mo & 135 & 8.3 & 3.5 & 0.007 & 143 \\
\hline $\mathrm{Na}$ & 90 & 5.5 & 6.0 & 0.000 & 96 \\
\hline $\mathrm{Ni}$ & 494 & 11 & 0.1 & 0.000 & 504 \\
\hline NOx & & & & 98 & 98 \\
\hline $\mathrm{P}$ & 114 & 2.5 & 0.5 & 0.000 & 117 \\
\hline $\mathrm{Pb}$ & 102 & 2.4 & 0.7 & 0.000 & 104 \\
\hline $\mathrm{Ru}$ & 756 & 9.8 & 4.9 & 0.000 & 765 \\
\hline$S$ & 104 & 10.4 & 6.7 & 0.432 & 114 \\
\hline $\mathrm{Si}$ & 101 & 0.2 & & & 102 \\
\hline $\mathrm{Sr}$ & 100 & 0.000 & & & 100 \\
\hline $\mathrm{Ti}$ & 5367 & 12.8 & 0.0 & 0.000 & 5380 \\
\hline $\mathrm{Zn}$ & 61 & 2.5 & 1.4 & 0.104 & 63 \\
\hline $\mathrm{Zr}$ & 93 & 0.018 & 0.013 & 0.000 & 93 \\
\hline V & 87 & 1.4 & 0.2 & 0.000 & 88 \\
\hline
\end{tabular}

\begin{tabular}{|c|c|c|c|c|}
\hline \multicolumn{5}{|c|}{ RSM-2 (3) } \\
\hline \multicolumn{7}{|c|}{$\begin{array}{c}\text { OG smpl } \\
\text { in } \\
\text { glass }\end{array}$} & $\begin{array}{c}\text { \% in } \\
\text { scrub }\end{array}$ & $\begin{array}{c}\text { \% on } \\
\text { TF }\end{array}$ & $\begin{array}{c}\text { as } \\
\text { gas }\end{array}$ & MB\% \\
\hline 77 & 0.1 & 0.2 & 0.000 & 77 \\
\hline 89 & 2.9 & 0.7 & 0.3 & 92 \\
\hline 253 & 4.4 & 6.6 & 0.040 & 260 \\
\hline 0 & 3.0 & & 0.000 & 0 \\
\hline 75 & 0.2 & 0.1 & 0.000 & 75 \\
\hline 54 & 3.5 & 1.0 & 0.000 & 57 \\
\hline 109 & & & & 109 \\
\hline 80 & 6.6 & & 0.000 & 86 \\
\hline 0 & & & & 0 \\
\hline 269 & 3.2 & 0.6 & 0.000 & 272 \\
\hline 95 & 5.7 & 2.0 & 0.003 & 101 \\
\hline 89 & 15.2 & 0.5 & 0.000 & 104 \\
\hline & 43.7 & & 334.1 & 334 \\
\hline 115 & 0.0 & 0.1 & 0.0 & 115 \\
\hline 0 & 16.1 & 0.50 & 165.6 & 166 \\
\hline 0 & 28.8 & & 0.000 & 0 \\
\hline 100 & 3.5 & 1.2 & 0.000 & 103 \\
\hline 99 & 1.1 & 0.3 & 0.000 & 100 \\
\hline 115 & 0.3 & 0.1 & 0.000 & 115 \\
\hline 51 & 0.2 & 0.1 & 0.000 & 51 \\
\hline 143 & 4.9 & 0.6 & 0.000 & 148 \\
\hline 102 & 2.3 & 1.0 & 0.000 & 104 \\
\hline 251 & 16 & 0.1 & 0.000 & 268 \\
\hline 0 & & & 77 & 77 \\
\hline 110 & 0.8 & 0.1 & 0.000 & 111 \\
\hline 104 & 1.1 & 0.2 & 0.000 & 105 \\
\hline 92 & 8.6 & 2.9 & 0.000 & 101 \\
\hline 105 & 5.0 & 2.0 & 0.452 & 110 \\
\hline 100 & 0.0 & & & 100 \\
\hline 105 & & & & 105 \\
\hline 4697 & 2.6 & & & 4699 \\
\hline 66 & 1.3 & 0.6 & 0.073 & 68 \\
\hline 110 & 0.0 & 0.004 & 0.000 & 110 \\
\hline 107 & 0.2 & 0.1 & 0.000 & 107 \\
\hline & & & & \\
\hline
\end{tabular}

\begin{tabular}{|c|c|c|c|c|}
\hline \multicolumn{5}{|c|}{ RSM-2 (4) } \\
\hline & & \multicolumn{2}{|c|}{ OG smpl } & \multirow[b]{2}{*}{$\mathrm{MB} \%$} \\
\hline $\begin{array}{l}\% \text { in } \\
\text { glass }\end{array}$ & $\begin{array}{l}\% \text { in } \\
\text { scrub }\end{array}$ & $\begin{array}{c}\text { \% on } \\
\text { TF }\end{array}$ & $\begin{array}{c}\% \text { as } \\
\text { gas }\end{array}$ & \\
\hline 77 & 0.4 & $\mathrm{NM}^{*}$ & NM & 78 \\
\hline 89 & 4.7 & NM & NM & 94 \\
\hline 253 & 3 & NM & NM & 256 \\
\hline 0 & 3.1 & NM & NM & 3 \\
\hline 75 & 0.6 & NM & NM & 76 \\
\hline 54 & 8.6 & NM & NM & 62 \\
\hline 109 & 0.00 & NM & NM & 109 \\
\hline \multirow[t]{2}{*}{80} & 5.4 & NM & NM & 85 \\
\hline & 0.00 & NM & NM & 0.00 \\
\hline 269 & 4.7 & NM & NM & 273 \\
\hline 95 & 8.7 & NM & NM & 104 \\
\hline \multirow[t]{2}{*}{89} & 11.8 & NM & NM & 100 \\
\hline & 107.7 & NM & NM & 108 \\
\hline \multirow[t]{3}{*}{115} & 0.3 & NM & NM & 115 \\
\hline & 19.2 & NM & NM & 19 \\
\hline & 32.2 & NM & NM & 32 \\
\hline 100 & 5.6 & NM & NM & 105 \\
\hline 99 & 2.1 & NM & NM & 101 \\
\hline 115 & 0.9 & NM & NM & 116 \\
\hline 51 & 0.4 & NM & NM & 52 \\
\hline 143 & 7.3 & NM & NM & 150 \\
\hline 102 & 3.8 & NM & NM & 105 \\
\hline \multirow[t]{2}{*}{251} & 12 & NM & NM & 263 \\
\hline & 0.41 & NM & NM & 0.4 \\
\hline 110 & 1.6 & NM & NM & 111 \\
\hline 104 & 2.4 & NM & NM & 106 \\
\hline 92 & 13.0 & NM & NM & 105 \\
\hline 105 & 8.9 & NM & NM & 114 \\
\hline 100 & 0.1 & NM & NM & 100 \\
\hline 105 & 0.0 & NM & NM & 105 \\
\hline 4697 & 6.5 & NM & NM & 4703 \\
\hline 66 & 1.2 & NM & NM & 68 \\
\hline 110 & 0.0 & NM & NM & 110 \\
\hline 107 & 0.6 & NM & NM & 107 \\
\hline
\end{tabular}


Table 12. (cont'd)

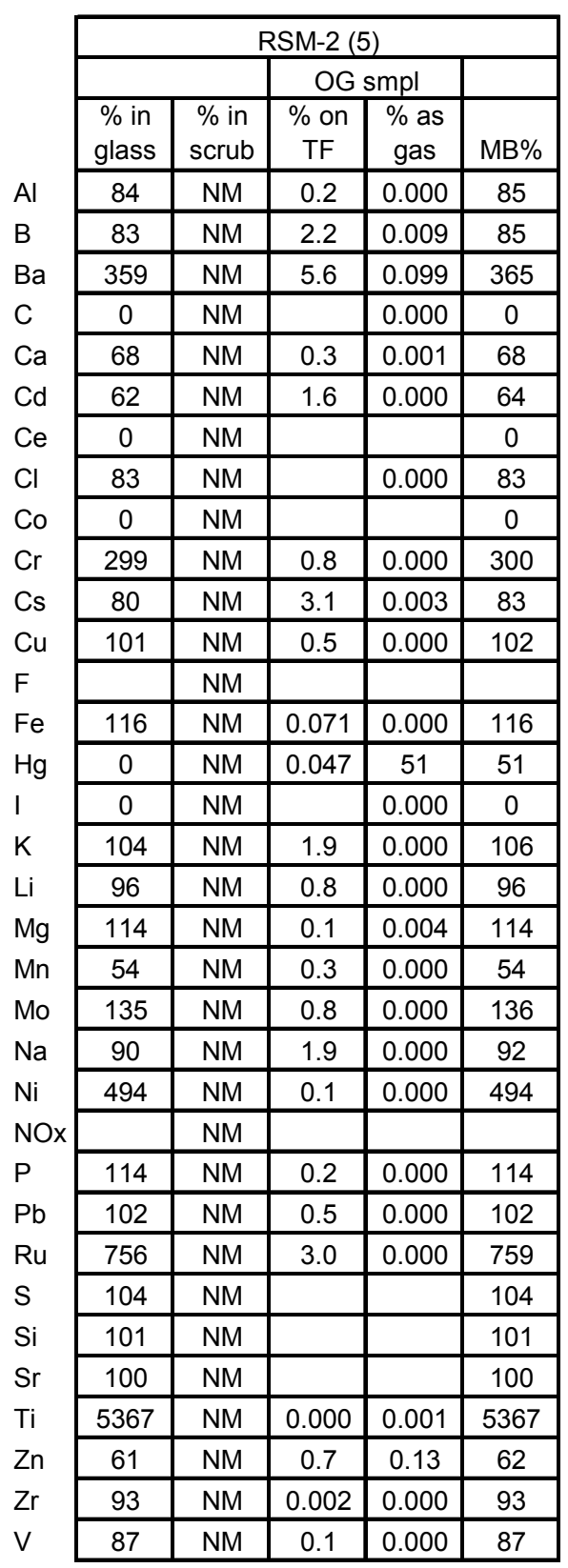

\begin{tabular}{|c|c|c|c|c|}
\hline \multicolumn{5}{|c|}{ RSM-2 (6) } \\
\hline & & \multicolumn{2}{|c|}{ OG smpl } & \\
\hline $\begin{array}{l}\% \text { in } \\
\text { glass }\end{array}$ & $\begin{array}{c}\% \text { in } \\
\text { scrub }\end{array}$ & $\begin{array}{c}\% \text { on } \\
\text { TF }\end{array}$ & $\begin{array}{c}\% \text { as } \\
\text { gas }\end{array}$ & $\mathrm{MB} \%$ \\
\hline 83 & 0.9 & 1.7 & 0.059 & 85 \\
\hline 80 & 6.0 & 3.0 & 2.5 & 86 \\
\hline 300 & 7.0 & 7.6 & 0.0228 & 308 \\
\hline & & & 0.000 & 0 \\
\hline 68 & 1.3 & 1.2 & 0.0659 & 69 \\
\hline 52 & 6.2 & 1.8 & 0.16 & 58 \\
\hline 99 & & & & 99 \\
\hline 54 & 46.8 & & 0.000 & 100 \\
\hline 0 & & & & 0 \\
\hline 325 & 6.1 & 2.5 & 0.43 & 331 \\
\hline 87 & 8.6 & 2.3 & 0.38 & 95 \\
\hline 92 & 32.5 & 1.3 & 0.12 & 125 \\
\hline & 52.3 & & 14 & 14 \\
\hline 113 & 0.5 & 1.3 & 0.0426 & 114 \\
\hline 0 & 46.1 & 0.8 & 15 & 46 \\
\hline & 20.2 & & 0.000 & 0 \\
\hline 111 & 6.0 & 1.5 & 0.069 & 117 \\
\hline 98 & 2.8 & 1.4 & 0.13 & 100 \\
\hline 108 & 1.8 & 1.2 & 0.11 & 109 \\
\hline 92 & 1.2 & 2.8 & 0.069 & 95 \\
\hline 160 & 6.0 & 0.9 & 0.090 & 166 \\
\hline 96 & 4.3 & 1.8 & 0.050 & 101 \\
\hline 486 & 34.3 & 0.28 & 0.010 & 520 \\
\hline & 3.7 & & 95.19 & 95 \\
\hline 102 & 1.8 & 1.0 & 0.000 & 104 \\
\hline 94 & 2.3 & 2.6 & 0.13 & 97 \\
\hline 49 & 33.9 & 1.7 & 0.000 & 83 \\
\hline 99 & 8.3 & 2.8 & 2.7 & 108 \\
\hline 100 & 0.1 & & & 100 \\
\hline 96 & & & & 96 \\
\hline 5320 & 11.6 & 0.0 & 0.001 & 5332 \\
\hline 64 & 2.2 & 2.6 & 0.72 & 67 \\
\hline 130 & 0.0 & 0.5 & 0.000 & 130 \\
\hline 101 & 0.6 & 0.4 & 0.013 & 102 \\
\hline
\end{tabular}




\section{ATTACHMENT 3}


Date: $\quad$ November 5, 2001

To: $\quad$ T. T. Nichols

MS 5218

6-9173

From:

C. M. Barnes

MS 3625

6-0864

Subject: $\quad$ EVALUATION OF SBW VITRFICATION PROCESS ALTERNATIVES

Reference: D. Taylor, C. Barnes, L. Lauerhass, INEEL SBW Vitrification Process, INEEL/EXT01-01139, September, 2001.

The mass balance for SBW vitrification will provide the basis for the conceptual design. A baseline flow scheme was defined in a value-engineering session held in mid FY 2001. During the valueengineering session, some variations to the baseline flowsheet were suggested but not evaluated. Also in the value-engineering session, some unit operations in the baseline flow scheme were defined more by function than equipment type, leaving room for later evaluations to provide additional flowsheet detail. FY 2001 end-of-year reports of vitrification testing and development also contain several recommendations for changes to the baseline flowsheet. This letter contains the results of a review of 33 process variations of the baseline, in order to determine (1) if test data is needed to evaluate the alternative (2) whether modeling can be of benefit evaluating the alternatives, and (3) for those that can be evaluated with presently available data and models, which alternatives would have the greatest impact on the mass balance.

A list of process these 33 alternative schemes is given in Table 1.

The process alternatives were initially screened relative to the questions

1. What data are needed to evaluate differences between the alternative and the baseline, and are these data available?

2. Can the Visual Basis/Excel mass balance model be used to evaluate differences between the alternative and the baseline?

3. Can the ASPEN PLUS mass balance model be used to evaluate differences between the alternative and the baseline?

Following this initial screening, the Visual Basic/Excel simulator was used to generate mass balances for those alternatives for which it was deemed appropriate. Results from the mass balances such as the glass rate, secondary waste compositions and rates, and internal stream flowrates were used to evaluate the alternatives.

The Technical Baseline Database (TBDB) is a repository of the baseline flow scheme, mass balance and basis information for the flow scheme and mass balance. The TBDB, documented as of August 2001 in the above reference, is a living document that will be updated as results from additional testing are received and additional modeling is performed. Results from this evaluation, once appropriately reviewed, will be incorporated into the TBDB. 
Table 1. Process Alternatives Baseline

No SBW evaporation

No sulfate removal from feed No SBW feed blending

Liquid sugar reductant

Glass frit

Film cooler

Spray quench tower*

Venturi scrubber*

HEME*

Single Scrub Tank

No HEME wash water tank

Standard HEPA filters*

No $\mathrm{Hg}$ removal from scrub, all $\mathrm{Hg}$ removed by GAC

Split of acid scrub blowdown between recycle and secondary waste

Solids settling in acid scrub tank, filter on purge upstream of neutralization

Cs removal by IX from acid scrub purge

Neutralization of acid scrub by caustic

Cs IX using Ionsiv IE-95

Caustic quench/scrub in single unit operation

GAC bed upstream of final HEPAs $\mathrm{NO}_{\mathrm{x}}$ abatement using a noxidizer

\section{$\underline{\text { Alternative }}$}

1. SBW partial evaporation

2. SBW total evaporation

3. SBW denitration

4. SBW absorption on silica gel

5. Barium sulfate precipitation

6. Feed blending from multiple Tank Farm tanks

7. Granular sugar feed

8. Alternative reductant

9. Multiple glass forming components

10. Alternative melter off-gas cooling

11. Ejector venturi scrubber

12. Submerged bed scrubber

13. Steam atomized scrubber

14. Wet electrostatic precipitator

15. Cascaded acid scrub with multiple tanks

16. HEME wash water tank

17. Washable HEPA filters

18. Hg removal from scrub by electrolytic reduction

19. Hg removal from scrub by sulfide precipitation

20. Hg removal from scrub by ion exchange (enhancements to $\mathrm{Hg}$ oxidation in the off-gas and $\mathrm{Hg}$ scrubbing from the off-gas would be considered for any of the above $\mathrm{Hg}$ removal schemes)

21. Total recycle of scrub purge (may require $\mathrm{Hg}$ removal or other treatment)

22. No recycle of scrub purge

23. No settling designed into scrub tank, filtration on total scrub flow (will require additional tank or tanks)

24. Filter downstream of neutralization

25. No treatment of acid scrub purge

26. Removal of both $\mathrm{Cs}$ and $\mathrm{Sr}$ from scrub

27. Removal of Cs and Sr downstream of combining acid and caustic scrub purge streams 28. Neutralization with other neutralizers (to reduce $\mathrm{Na}$ concentration in IX feed and to reduce volume of grouted waste)

29. Cs IX using other sorbents

30. Partial water quench only, no scrub

31. Quench and scrub in separate steps

32. GAC bed downstream of final HEPAs

33. $\mathrm{NO}_{\mathrm{x}}$ abatement using SCR

* Alternatives for the in-cell off-gas solids removal operations may be evaluated as grouped combinations rather than single unit operation replacements 
T. Nichols

November 5, 2001

Page 3

\section{CONCLUSIONS}

1. Pretreatment schemes have the potential for large savings, hundreds of millions of dollars, in Idaho Waste Vitrification Facility (IWFV) costs. These pretreatment schemes include

a. Barium sulfate precipitation followed by partial SBW evaporation with crystallization and separation of nitrate precipitates.

b. Barium sulfate precipitation without evaporation

c. SBW absorption on silica gel followed by evaporation to dryness

d. Partial evaporation of SBW, resulting in a slurry feed.

The magnitude of the potential savings estimated for these schemes justifies funding experiments to better quantify the expected improvements in such parameters as glass waste loading, frit formulation, melt rate, and melter off-gas rate. This additional test data would then be used in an evaluation that would more thoroughly select the recommended pretreatment process from the above four alternatives.

2. Two alternatives, replacing the film cooler with an evaporative cooler or replacing the noxidizer with an SCR reactor, have the potential for significant reductions in off-gas flowrates. If feed pretreatment is not incorporated into the baseline flowsheet, testing of these alternatives is recommended.

3. Five schemes $(15,18,19,21$ and 22 in Table 1) should be evaluated using an ASPEN Plus model. Scrub composition data from RSM-2 and, if available, Clemson-2 should also be used in these evaluations.

4. Four additional changes to the baseline are recommended - replacing the sugar solution feed with granular sugar, blending SBW feed, changing the melter plenum temperature to $500^{\circ} \mathrm{C}$ and removing strontium from the acid scrub purge.

5. Unless new data is obtained that would suggest otherwise, no further evaluation is recommended of total denitration (scheme $3 \mathrm{~b}$ in Table 1), chilling the air feed to the film cooler (10a), Hg removal by ion exchange (20), no treatment of acid scrub purge (25) or GAC downstream of final HEPA filter (32).

\section{INITIAL SCREENING}

\section{Melter Feed Evaporation (Alternatives 1-4)}

Alternatives 1-4 relate to partially or totally evaporating the feed to the melter. The four alternatives listed are representative of at least twenty permutations or variations of evaporation schemes, in which the variables include (a) the number of streams combined prior to the evaporation (out of the set: SBW, scrub recycle, reductant, one or more of the glass forming components), (b) degree of denitration (none, partial, total) (c) type of denitration (thermal, organic reductant, electrolytic, rotary kiln, fluidized bed), (d) number of process steps (separate denitration or combined with evaporation, removal and separate treatment of precipitated solids, etc.) (e) degree of evaporation, and (f) type of evaporator.

Test data and previous evaluations related to SBW evaporation and denitration schemes are contained in the following reports: 
(1) D. S. Wendt, D. R. Haefner, "Wet Vs. Dry SBW Vitrification Feed Evaluation," EDF-2860, October $11,2001$.

(2) R. J. Kirkham, A. K. Herbst, "Suitability of Silica Gel to Process INEEL Sodium Bearing Waste," September, 2000.

(3) R. J. Kirkham, "Sodium Bearing Waste Solidification by Evaporation," RJK-6-98, September 29, 1998.

(4) J. A. McCray, "Report on Freeze Crystallization and Evaporation/Precipitation Testing for SodiumBearing Waste Treatment," JAM-11-98, September 30, 1994.

(5) J. A. McCray, J. Pao, "High Temperature Evaporation/Precipitation Tracer Study Results," JAM-495/JHP-3-95, June 30, 1995.

(6) E. P. Wagner, "Evaluation of Evaporation/Crystallization as Treatment for Sodium Bearing Liquid Waste," EPW-04-94, November 7, 1994.

(7) R. D. Adams, "Evaporation/Precipitation Process for SBW Treatment Planning Estimate," RDA-0394, October 27, 1994.

(8) J. Pao, "Laboratory Simulation of Liquid Waste Evaporation," JHP-05-00, June 27, 2000.

(9) D. W. Marshall, J. Pao, "FY-98 Idaho Nuclear Technology and Engineering Center Low Activity Waste Preconditioning Development Program Status Report," DWM-02-98/JHP-01-98, September 24, 1998.

(10) J. Pao, "Comparison of High Temperature and Organic-Reductant Thermal Denitration of INTEC Low Activity Waste in a Bench Scale Rotary Reactor," JHP-04-98, December 24, 1998.

(11) D. W. Marshall, "Optional Denitration Processes for Conditioning Low-Activity Wastes at the Idaho Nuclear Technology \& Engineering Center," DWM-05-98, December, 1998

(12) D. T. Hobbs, Electrolytic Treatment of ICCP Sodium-Bearing Waste Simulant, WSRC-RP-941300, December, 1994.

(13) D. D. Siemer, SAIC/Studsvik Calcination Test: Conclusions, DDS-08-00, August 29, 2000.

(14) Tank Focus Area, "Technical Review of the Applicability of the Studsvik, Inc. THOR ${ }^{\mathrm{sm}}$ Process to INEEL SBW," September, 2000.

(15) W. H. Landman, "Solidification of SBW for EIS Supporting Studies," Conference Note, September 29, 1998.

Benefits from feed evaporation include an increase in the glass melt rate, a reduction in the melter heat requirement and a reduction in the off-gas flowrate. Wendt and Haefner ${ }^{1}$ estimate a $50 \%$ increase in the glass rate for a dry feed compared to the baseline SBW composition. The increase in the glass rate would allow either for a 33\% reduction in the processing schedule or, if the schedule were kept the same, a lower feed rate resulting in capital savings due to a smaller melter and smaller off-gas equipment. If the feed rate were kept the same as the baseline, the melter off-gas flowrate would be reduced by more than $60 \%$, with corresponding reductions in downstream flowrates. The heat required to evaporate and superheat the water in SBW to the melter plenum temperature of $650^{\circ} \mathrm{C}$ is approximately $330 \mathrm{~kW}$, more than twice as great as the estimated melter electrode power requirement of $160 \mathrm{~kW} .{ }^{\mathrm{a}}$ Wendt and Haefner ${ }^{1}$ also estimate that the dry feed scheme equipment costs are about $\$ 1$ million less that the baseline wet feed, out of a total plant equipment cost of about $\$ 30$ million, due to savings in the feed system costs.

The major concerns or risks of feed evaporation relate to the transport, storage, handling and mixing of the concentrated SBW, either as sludge or "dry" solids. At a high degree of concentration, the concentrated SBW has been observed to "set up" upon cooling. ${ }^{3}$ If evaporated with the alkaline glass

\footnotetext{
${ }^{\text {a }}$ Heat to evaporate and superheat waste is based on the baseline mass balance feed rate of 100 gallons per hour. The melter electrode power is taken from the SBW Vitrification Feasibility Study, which is based on a feed rate of $104 \mathrm{gal} / \mathrm{hr}$.
} 
T. Nichols

November 5, 2001

Page 5

forming components (GFCs) or a reductant, sufficient neutralization may occur to cause the precipitation of gelatinous aluminum hydroxide compounds.

The above benefits, as well as the amount of information currently available, justify leaving at least one feed evaporation scheme in the set to be further evaluated. In the following discussion, a rationale is developed for defining which evaporation schemes to retain and which to eliminate from further consideration.

As a result of road mapping efforts for SBW vitrification in late FY-00, the Tank Focus Area (TFA) sent an independent review team to the Studsvik treatment facility in Irwin TN to evaluate the applicability of the Studsvik process for evaporation and denitration of SBW. In their report, ${ }^{14}$ the TFA review team stated that the dry product that would be produced by the Studsvik process may be suitable as an interim storage waste and dry feed for the vitrification facility. However, they recommended that DOE-ID not pursue further steam reforming initiatives for treating SBW. The rationale for eliminating the Studsvik steam reforming process applies equally to other total denitration methods, including calcination and rotary kiln denitration. All of these processes involve large equipment operating at relatively high temperatures $\left(\geq 500^{\circ} \mathrm{C}\right)$. The cost of the denitration equipment does not justify the relatively small reduction in mass feed rate to the melter. ${ }^{\mathrm{b}}$ In addition, denitration in a calciner or rotary kiln requires the addition of significant quantities of other materials such as aluminum nitrate that would add to the melter feed mass flowrate and the glass rate.

Proof of principle tests were performed ${ }^{12}$ on a low temperature denitration method, electrolysis, using an SBW simulant. However, this alternative is rejected due to (a) low denitration efficiencies (55-68\%), (b) the explosion hazard of producing hydrogen gas at the cathode, (c) the potential for metals and metal hydroxide films plating out on the electrodes, (d) additional processing steps required due to the ammonia gas produced, and (e) the lack of data available for this process.

In the present baseline mass balance, the acid scrub recycle rate is determined by the buildup of chloride in the scrub. Total solids (dissolved plus undissolved solids) in the scrub are much lower than in SBW, hence the water content is higher $(95+\%$ compared to $\sim 65 \%$ for $\mathrm{SBW})$. The scrub recycle rate is only about $5-10 \%$ of the fresh SBW rate, hence separate evaporation of the scrub would result in only small benefits that would likely not be justified by added equipment costs. However, because of the high water content of the recycle relative to SBW, it makes sense to combine the scrub with SBW prior to evaporation. If the evaporation were to the point of dryness, combining the scrub would eliminate any liquid feed to the melter.

The question of whether to combine other melter feeds, i.e., the reductant or some or all of the GFCs prior to evaporation is less easily answered. The benefit of combining all melter feeds prior to evaporation relates to mixing. If GFC and sugar are combined with the liquid feeds, the final concentrate could be expected to be more homogeneous than if added after evaporation of the SBW. Adding the alkaline GFCs $\left(\mathrm{Li}_{2} \mathrm{O}, \mathrm{CaO}\right.$ and $\left.\mathrm{Na}_{2} \mathrm{O}\right)$ to the liquid $\mathrm{SBW}$ would result in a partial neutralization of SBW, which would reduce the amount of nitrate removed (as nitric acid) in the evaporation. Adding sugar prior to evaporation has the advantage of destroying, at evaporation temperatures, all the nitric acid. If sugar is not added, the nitric acid removed in evaporation would be recovered as concentrated nitric acid as LET\&D bottoms. If no use can be found for this acid, it would need to be processed into a separate waste form. Destroying the nitric acid by the addition of sugar prior

\footnotetext{
${ }^{\mathrm{b}}$ Nitrate associated with nitric acid in the feed can be removed by evaporation or reduction with sugar. Nitrate in excess of that associated with acid amounts to about $15-20 \mathrm{wt} \%$ of SBW, or $10-13 \mathrm{wt} \%$ of the total melter feed.
} 
T. Nichols

November 5, 2001

Page 6

to evaporation would eliminate this waste stream. However, it would tie the evaporation more closely to vitrification off-gas system, as noncondensibles from the evaporator condenser would need to be added into the melter off-gas upstream of the noxidizer.

The following table summarizes the screening of the remaining potentially viable SBW evaporation schemes. It should be noted that the primary reason several of the schemes were screened out is lack of data. One partial-evaporation scheme and one total-evaporation scheme are retained. Others that are screened out at this time may be worth reconsidering at a later time if additional test data is obtained.

Table 2. Screening decisions for SBW evaporation schemes Scheme

\begin{tabular}{ll}
\hline Feed & Degree \\
SBW \& Scrub Recycle & Partial \\
SBW \& Scrub Recycle & Total \\
SBW, Recycle \& GFC & Partial \\
SBW, Recycle \& GFC & Total \\
SBW, Recycle \& Sugar & Partial \\
SBW, Recycle \& Sugar & Total \\
SBW, Recycle, Sugar \& & Partial \\
GFC & \\
SBW, Recycle, Sugar \& & Total \\
GFC
\end{tabular}

$\underline{\text { Screening Decision and Basis }}$

Retain based on results of McCray's evaporation tests and evaluations $\mathrm{s}^{4-7}$

Reject based on lack of data and potential problems with properties of solid product

Reject as this option reduces the amount of acid removed by evaporation

Retain based on Kirkham's SBW silica gel absorption tests

Reject based on lack of data and potential problems with properties of solid Reject based on lack of data and potential problems with properties of solid Reject based on lack of data and potential problems with properties of solid Reject based on lack of data and potential problems with properties of solid

A final question needing an answer in order to define the retained partial evaporation scheme is, "To what extent should the feed be evaporated?".

$\mathrm{McCray}^{4}$ evaporated an SBW simulant in increments of approximately $20 \%$ by volume. At the end of each incremental evaporation, the solution was cooled, and if precipitates formed, they were collected. The simulant McCray used had concentrations of $0.53 \mathrm{M} \mathrm{Al}^{+3}, 1.17 \mathrm{M} \mathrm{Na}^{+}, 5.5 \mathrm{M} \mathrm{NO}_{3}^{-}$, as well as lower concentrations for 20 other species. No precipitation was observed until his third increment. Hence the onset of precipitation was somewhere between $37 \%$ and $53 \%$ volume reduction. The concentration of $\mathrm{Al}^{+3}$ in the current "total" SBW composition is $4 \%$ higher than McCray's simulant, $\mathrm{Na}^{+}$ is $30 \%$ higher, and nitrate $8 \%$ higher. WM-1 80 has an $\mathrm{Al}^{+3}$ concentration $25 \%$ higher than McCray's and $\mathrm{Na}^{+}$concentration $76 \%$ higher. Comparing the concentrations of the present waste streams to McCray's results suggests that a volume reduction of 10-25\% could be achieved before the onset of precipitation. Test results from Marshall and $\mathrm{Pao}^{\mathrm{c}}$ lead to a similar conclusion.

\footnotetext{
${ }^{c}$ D. Marshal and J. Pao evaporated an SBW LAW simulant, essentially diluted SBW. They achieved about 70\% volume reduction before precipitates formed. However, when the results are adjusted to present SBW concentrations, the degree of concentration achievable appears to be closer to $10-15 \%$.
} 
T. Nichols

November 5, 2001

Page 7

Evaporation only to the point of precipitation would avoid problems due to solids in the evaporator equipment for the process scheme of evaporation of SBW and scrub recycle only. However, if the reductant and/or GFC were added, much of the nitric acid would decompose or react, the solution $\mathrm{pH}$ would increase, and precipitation would be likely. Thus for the scheme in which one or both of these other components is added prior to evaporation, it is likely that even less concentration than the above estimate could be achieved prior to precipitation.

The melter feed in the baseline mass balance contains approximately $15 \mathrm{wt} \%$ undissolved solids and 50 wt \% water. ${ }^{\mathrm{d}}$ The process basis for the DWPF SME is concentration to $50 \mathrm{wt} \%$ total solids. ${ }^{4}$ Nearly all the solids in the DWPF feed are undissolved, since Savannah River sludge has been washed prior to entering the DWPF process. Ideally the degree of evaporation to a slurry would depend on rheological property limits for transferring the slurry from the evaporator through melter feed tanks and into the melter. One DWPF mass balance ${ }^{\mathrm{e}}$ shows the following limits for SME concentrate:

\begin{tabular}{|c|c|c|}
\hline & Minimum & Maximum \\
\hline Yield stress, dynes $/ \mathrm{cm}^{2}$ & 25 & 150 \\
\hline Viscosity, $\mathrm{cp}$ & 10 & 49 \\
\hline Density, $\mathrm{g} / \mathrm{cm}^{3}$ & 1.33 & 1.45 \\
\hline Solids content, wt $\%$ & 40 & 50 \\
\hline
\end{tabular}

A more recent report ${ }^{\mathrm{f}}$ of DWPF operation shows the density of SME concentrate in the range 1.39-1.47 $\mathrm{g} / \mathrm{cm}^{3}$. Feed solids content of up to $59 \%$ have also been reported. ${ }^{\mathrm{g}}$ Until these target properties can be better defined, the DWPF maximum limits provide a reasonable starting target concentration. Based on a $50 \%$ total solids content, the degree of concentration would be about $50-60 \%$.

Process simulation can help determine the benefits of partial evaporation, however, testing would be required to validate major assumptions in the mass balance. Testing would be needed to more clearly define the degree of evaporation and to determine the glass melt rate for concentrated feeds.

\section{Barium Sulfate Precipitation (Alternative 5)}

Recommendations of the waste loading of SBW (as oxide) in glass have decreased from 36\% (April, $1999)^{\mathrm{h}}$ to $35 \%(\text { July, } 1999)^{\mathrm{i}}$ to $30 \%(2001)^{\mathrm{j}}$ to $20 \%(2001)^{\mathrm{k}}$ as more and more data is collected. Data has shown that the waste loading is limited by the sulfate content of the SBW. Removal of sulfate from the feed thus has the potential for greatly reducing the glass volume, which in turn would reduce storage, shipping and other costs. Removal of sulfate from the feed would also benefit the off-gas and scrub system by reducing the amount of $\mathrm{SO}_{2}$ in the off-gas.

\footnotetext{
${ }^{\mathrm{d}}$ Solids from the insoluble frit components in the total melter feed vary between $13 \%$ and $21 \%$ for the four mass balance cases in Reference 2, while the total water from SBW, recycle and sugar amounts to 48-50\% depending on feed case.

${ }^{\mathrm{e}}$ Basic Data Report, DWPF Sludge Plant, DPSP 80-1033, Rev. 9, September, 1982.

${ }^{\mathrm{f}}$ J. E. Occhipinti, J. T. Carter, R. E. Edwards, R. S. Beck, D. C. Iverson, DWPF Radioactive Operations - Year Two, WSRCMS-98-00108, 1998.

g J. M. Perez, Jr. et. al, High Level Waste Melter Study Report, PNNL-13582, July, 2001.

${ }^{\text {h }}$ D. K. Peeler, J. D. Vienna, Waste Loading Estimates for INEEL HAW, WSRC-RP-99-00349, April $22,1999$.

i J. D. Vienna, et.al, Glass Formulation Devalopment for INEEL Sodium-Bearing Waste, PNNL-12234, July, 1999.

${ }^{j}$ D. K. Peeler, T. B. Edwards, I. A. Reamer, R. J. Workman, J. D. Vienna, J. V. Crum, M. J. Schweiger, Glass Formulation Development for INEEL Sodium-Bearing Waste (FY-2001 WM-180), WSRC-TR-2001-00295, September 21, 2001

k J. D. Vienna, "SBW-22," e-mail to K. J. Perry, July 12, 2001.
} 
T. Nichols

November 5, 2001

Page 8

Data regarding barium sulfate precipitation is found in the following reports:

(16) S. K. Fiskum, D. E. Kurath, B. M. Rapko, "Development and Demonstration of a Sulfate Precipitation Process for Hanford Waste Tank 241-AN-107," PNWD-3050, BNFL-RPT-029, August, 2000.

(17) C. M. Nitzel, "Separation of Barium Sulfate Precipitate from Liquid Sodium-Bearing Waste Simulant,"August, 2001.

(18) D. D. Siemer, unpublished results of barium sulfate precipitation tests, March 3, 2001, July 3, 2001, July 17, 2001

The above reports show that $60-90 \%$ of the sulfate in a waste can be removed by precipitation as barium sulfate. Adding barium to an alkaline waste such as Hanfords' results in precipitation of barium carbonate as well as barium sulfate. ${ }^{16}$ However the acidity of SBW will prevent carbonate formation. Using test surrogates spiked with radionuclides Siemer ${ }^{18}$ showed that about $1-2 \%$ of the plutonium and $2-3 \%$ of strontium in the initial test sample was contained in the sulfate precipitate. The Hanford tests ${ }^{16}$ showed that the sulfate precipitate contained only $0.02 \%$ of the ${ }^{137} \mathrm{Cs}$ in the feed, less than $1 \%$ of the ${ }^{60} \mathrm{Co},{ }^{154} \mathrm{Eu}$ and ${ }^{155} \mathrm{Eu}$, but $10 \%$ of the ${ }^{99} \mathrm{Tc}$. Additional test data may be needed to determine the radionuclide concentrations in the precipitate to determine its disposal site. Nitze ${ }^{17}$ demonstrated that the precipitate could be separated from the waste solution by either settling or filtration.

Sufficient data is available to develop an initial mass balance for a barium sulfate precipitation scheme. Because of the benefits of removing sulfate from the feed, this process alternative is retained for further evaluation.

\section{SBW Feed Blending (Alternative 6)}

Based on tank farm planning documents updated as recently as May 31, 2001, SBW from five different tanks would be blended in new tanks in 2010 , providing a homogeneous liquid feed to the melter. A feasibility study ${ }^{1}$ for the new tank farm is presently being completed. However, because of uncertainties regarding whether a new tank farm would be constructed, the SBW Vitrification report ${ }^{\mathrm{m}}$ contained mass balances for three individual SBW tanks as well as the blended total SBW. At present, one tank (WM180 ) is full and no changes to its composition are expected prior to either transfer to a new tank or processing in the vitrification facility. Waste presently in several other tanks, along with other waste that will be generated until 2005 , will be evaporated and make up the remaining vitrification facility feed.

In September 2001, tank farm management plans were changed in order to fill a second tank in FY-02. According to these revised plans, ${ }^{\mathrm{n}}$ tank WM-189 will be filled in January, 2002 and WM-188 in June, 2006. Besides the SBW waste in these three tanks, about 100,000 gallons will be present in other tanks in 2010 .

The SBW vitrification mass balances ${ }^{\mathrm{m}}$ show that the total glass produced from 865,000 gallons in WM180 , WM-188 and WM-189 is $619 \mathrm{~m}^{3}$ and the total grout is $494 \mathrm{~m}^{3}$. The glass and grout volumes produced from 960,000 gallons of a blended waste are $618 \mathrm{~m}^{3}$ and $521 \mathrm{~m}^{3}$ respectively. Prorating the glass and grout volumes produced from the three tanks up to the total volume of SBW shows that

\footnotetext{
${ }^{1}$ K. Childs, et. al, Idaho Waste Vitrification Facility Project Waste Collection Tank Facility Feasibility Study Report (draft), September 10, 2001.

${ }^{m}$ D. Taylor, C. Barnes, L. Lauerhass, INEEL SBW Vitrification Process, INEEL/EXT-01-01139, September, 2001.

${ }^{\mathrm{n}}$ C. B. Millet, Excel file PEMP 2002 HLLWE Case-shortfile2, September 26, 2001.
} 
T. Nichols

November 5, 2001

Page 9

blending would result in about $68 \mathrm{~m}^{3}$ less of glass and $27 \mathrm{~m}^{3}$ less of grout. While these volume differences contain uncertainties because of uncertainties in projected waste compositions and other mass balance assumptions, they do suggest that blending offers significant savings.

A comparison of compositions of waste in WM-180, WM-188 and WM-189 is shown in Table 2, expressed as concentrations in a tank compared to the average. For a few species, concentrations in each of the 3 tanks exceed the average because concentrations in the remaining waste are less than the average.

Table 2. SBW Composition Variation WM-180/ WM-188/ WM-189/

Average Average Average

$\begin{array}{llll}\mathrm{H}+ & 0.44 & 1.42 & 1.02 \\ \mathrm{NO} 3 & 0.94 & 1.10 & 1.13 \\ \mathrm{Al} & & & \\ \mathrm{B} & 1.24 & 1.06 & 1.16 \\ \mathrm{Ca} & 0.70 & 1.26 & 1.50 \\ \mathrm{Cr} & 0.96 & 1.17 & 1.39 \\ \mathrm{Cs} & 0.75 & 1.35 & 1.44 \\ \mathrm{Fe} & 0.58 & 1.81 & 1.17 \\ \mathrm{Hg} & 1.04 & 1.22 & 1.22 \\ \mathrm{~K} & 0.58 & 1.46 & 0.68 \\ \mathrm{Na} & 1.25 & 0.96 & 1.29 \\ \mathrm{U} & 1.42 & 0.89 & 1.20 \\ \mathrm{PO} 4 & 0.76 & 1.14 & 1.22 \\ \mathrm{SO} 4 & 2.00 & 0.61 & 0.94 \\ & 1.45 & 0.90 & 1.12 \\ \mathrm{U}-235 & & & \\ \mathrm{U}-238 & 0.82 & 1.26 & 1.20 \\ \mathrm{~Np}-237 & 0.73 & 1.32 & 1.24 \\ \mathrm{Pu}-238 & 0.23 & 1.85 & 1.11 \\ \mathrm{Pu}-239 & 0.97 & 1.27 & 1.05 \\ \mathrm{Am}-241 & 1.20 & 1.22 & 0.87 \\ \mathrm{Sr}-90 & 0.49 & 1.83 & 0.88 \\ \mathrm{Tc}-99 & 0.29 & 1.95 & 0.93 \\ \mathrm{Cs}-137 & 0.81 & 1.71 & 0.72 \\ & 0.55 & 1.76 & 0.90\end{array}$

Test data is needed to more accurately determine the effects of composition on glass loading, the need for multiple glass frits, effects on scrub composition, melter separation factors, and other mass balance assumptions. However, based on the differences in waste volumes between processing the SBW tank waste separately or blended, and judgement that variations in feed composition of the magnitude shown in Table 2 will affect design requirements and costs for many equipment items of the vitrification process, it is recommended that until data is obtained that shows these effects do not more than offset any incremental costs associated with blending, blending be assumed for the baseline flowsheet. Because mass balances prepared for the SBW Vitrification ${ }^{\mathrm{m}}$ report include cases both with and without blending, no additional mass balances are needed to evaluate this alternative. 
T. Nichols

November 5, 2001

Page 10

\section{Granular Sugar Feed (Alternative 7)}

In the present mass balance, the reductant is fed as $67 \mathrm{wt} \%$ sugar solution. Heating is required to keep the viscosity of this syrupy solution sufficiently low to pump. The water present in the sugar solution amounts to about $8-10 \%$ of the total water in the melter feed, assuming no feed evaporation. Melter tests to date have used granular rather than dissolved sugar. If the feed is evaporated to dryness, a granulated sugar feed is recommended to keep the feed as flowable solids and eliminate reactions that may occur in feed storage in the liquid phase between sugar and nitrate in the waste. Cost differences between equipment to process liquid and granular sugar are expected to be small. However the benefit appears to be in the direction of granular sugar due to (a) eliminating the need to replace the sugar feed system when revamping the vitrification facility for calcine, (b) elimination of the need to heat the stored sugar, (c) reducing the amount of water fed to the melter, and (d) aligning the design basis more with melter tests. Hence it is recommended that granular sugar be assumed for the baseline flowsheet. This decision can be revisited during conceptual design as details of the sugar feed system are determined.

\section{Alternative Reductants (Alternative 8)}

The use of sugar as the reductant in the melter is based on test data contained in the following report: J. A. McCray, D. L. Griffith, R. R. Kimmitt, D. D. Siemer, Status of Melt Rate Testing and Reductant Selection for SBW Vitrification, INEEL/EXT-01-01223, September, 2001.

The above report found that activated carbon, glycolic acid and corn starch did not meet the requirements set for the reductant, but sugar did. The report concluded that "sugar will likely be the preferred reductant." However, additional testing was recommended. At this time there is no basis for generating mass balances with alternative reductants. If these additional tests are performed, results from these additional tests could provide the basis for evaluating different reductants for the SBW vitrification process.

\section{Glass Forming Components (Alternative 9)}

The glass "frit" formulation in the baseline mass balance is based on test data contained in the following report:

(20) D. K. Peeler, T. B. Edwards, I. A. Reamer, R. J. Workman, J. D. Vienna, J. V. Crum, M. J. Schweiger, Glass Formulation Development for INEEL Sodium-Bearing Waste (FY-2001 WM180), WSRC-TR-2001-00295, September 21, 2001.

The "frit" formulation planned for future tests contains nine components - $\mathrm{B}_{2} \mathrm{O}_{3}, \mathrm{CaO}, \mathrm{Fe}_{2} \mathrm{O}_{3}, \mathrm{Li}_{2} \mathrm{O}$, $\mathrm{MgO}, \mathrm{Na}_{2} \mathrm{O}, \mathrm{SiO}_{2}, \mathrm{~V}_{2} \mathrm{O}_{5}, \mathrm{ZrO}_{2}{ }^{\circ}$ In $\mathrm{SBW}$ surrogate melter tests to date, glass-forming components (GFCs) have been used rather that a prepared glass frit. Different compositions consisting of oxides, hydroxides or carbonates of $\mathrm{Si}, \mathrm{B}, \mathrm{Li}, \mathrm{Fe} \mathrm{Ti}, \mathrm{Ca}$ and $\mathrm{Ba}$ were evaluated in determining the recommended composition. Melter tests planned for FY-02 will include fritted glass formers, and the results from these tests will provide a basis for selecting either frit or GFCs. Frit has been assumed for the baseline flowsheet to minimize the number of feed storage tanks and additional water present as hydrates in

\footnotetext{
${ }^{\circ}$ J. D. Vienna, Excel spreadsheet "SBW-22 comps," attached to e-mail "SBW-22", J. D Vienna to K. J. Perry, July 12, 2001.
} 
T. Nichols

November 5, 2001

Page 11

GFCs. Apart from this difference in water content, mass balance simulations of these two alternatives would not show differences, hence will not be performed in this evaluation.

\section{Alternative Melter Off-gas Cooling (Alternative 10)}

The baseline design uses a film cooler to prevent particulate and molten solids in the melter off-gas from depositing on the walls of the off-gas piping. Air and/or steam are added in the film cooler to cool molten particulate in the melter off-gas. The air added in the film cooler adds a significant fraction to the total off-gas rate. Barnes ${ }^{\mathrm{p}}$ calculated that a reduction in melter plenum temperature from $650^{\circ} \mathrm{C}$ to $500^{\circ} \mathrm{C}$ would result in a $20-30 \%$ reduction in all downstream flowrates. Peurrung ${ }^{\mathrm{q}}$ calculated that replacing a film cooler with evaporative cooling would reduce the downstream flowrate for the Hanford low-level waste vitrification facility by $57 \%$.

The melter plenum temperature is related to the feed composition, the feed rate, the melt rate and the cold cap coverage. For the DWPF melter, the vapor space above the cold cap was kept at a temperature between $650^{\circ} \mathrm{C}$ and $800^{\circ} \mathrm{C}$ to provide sufficient heat for evaporation and melting. ${ }^{r}$ Recent optimization resulting in dropping the minimum plenum temperature of the DWPF melter to $490^{\circ} \mathrm{C} .{ }^{\mathrm{s}}$ The target plenum temperature for FY-01 tests with SBW surrogate at the Clemson Environmental Technologies Laboratory ${ }^{\mathrm{t}}$ was $600^{\circ} \mathrm{C}$, and varied between $450^{\circ} \mathrm{C}$ for a low feed flowrate to about $650^{\circ} \mathrm{C}$ for a high feed flowrate. In the Clemson tests, the "high" feed rate was $87 \%$ greater than the "low" feed rate. Future design studies should include optimization of melter plenum temperature relative to melter and off-gas system costs, and additional melter tests should provide data to establish the minimum required plenum temperature.

Process variations to the baseline flowsheet include two alternatives. Changing the air to steam ratio or chilling the film cooler air could result in small reductions in the off-gas flowrate. A larger reduction could be achieved by replacing the film cooler with an evaporative cooler. The Studsvik process uses an evaporative cooler to cool off-gas from the reformer. Another evaporative cooler design, called the "transpiring wall reactor" is somewhat similar in design to a film cooler, except that water replaces the air or steam used to maintain a clean fluid boundary layer to protect walls of a reactor from solids deposition. The transpiring wall reactor ${ }^{\mathrm{u}}$ was developed to prevent molten salts that precipitate in supercritical water oxidation reactors from depositing on the reactor wall.

Mass balances are presented in a later section of this report that better quantify potential benefits of these alternatives. However, test data would ultimately be required to demonstrate the feasibility of any evaporative cooler design and confirm its expected performance.

\footnotetext{
${ }^{\mathrm{p}}$ C. M. Barnes, "Mass Balance Sensitivity Analysis and Process Alternatives," CMB-11-01, September 27, 2001

${ }^{q}$ L. M. Peurrung, T. J. Deforest, J. R. Richards, "Process System Evaluation - Consolidated Letter Reports. Volume 1 Alternatives for the Off-Gas Treatment System for the Low-Level Waste Vitrification Process," PNNL-11056, March, 1996. ${ }^{\mathrm{r}}$ DWPF Melter Technology Manual, Section 5, Reference 1, Processing Facilities Basis, Glass Melting, DPSP-80-1033, Part 5, Item 255, June, 1984.

${ }^{\mathrm{s}}$ D. Whit, personal communication, Dec. 4, 2001.

${ }^{\mathrm{t}}$ K. J. Perry, R. R. Kimmitt, N. R. Soelberg, R. D. Tillotson, A. N. Olson, Test Results for SBW-FY01-PS-01 Vitrification Demonstration of Sodium-Bearing Waste Simulant Using WM-180 Surrogate, INEEL/EXT-01-01073, August, 2001.

${ }^{u}$ B. L. Haroldsen, D. Y. Ariizumi, B. E. Mills, B. E. Brown, D. C. Rousar, Transpiring Wall Supercritical Water Oxidation Test Reactor Design Report, SAND96-8213, February, 1996; S. F. Rice, B. C. Wu, W. S. Winters, C. D. Robinson, Engineering Modeling of the Pine Bluff Arsenal Supercritical Water Oxidation Reactor, SAND2000-8656C, April 9, 2000.
} 
T. Nichols

November 5, 2001

Page 12

\section{Melter Off-gas Scrubbing (Alternatives 11-14, 17)}

Alternative systems and equipment for scrubbing solids and acid gas from Idaho Waste Vitrification Facilities (IWVF) melter off-gas are discussed in the following report:

(21) R. Wood, D. Tyson, B. Bonnema, C. Olsen, A. P. Pinto, D. Wendt, S. Reese, B. Raivo, Feasibility Study for the Idaho Waste Vitrification Facilities Off-gas Treatment for Sodium-Bearing Waste, INEEL/EXT-01-00995, September, 2001.

The baseline off-gas scrubbing components are expected to meet process functional and operational requirements that have been identified for the IWVF. At the present time there is considerable uncertainty in melter DFs, off-gas mercury speciation, particle size distribution (PSD) of particulate in the off-gas, and $\mathrm{NO}_{\mathrm{x}}, \mathrm{SO}_{\mathrm{x}}$ and $\mathrm{Hg}$ reactions that occur prior to and within the early off-gas treatment steps. Optimization and evaluation of off-gas scrubbing components will require additional melter offgas characterization data and data from tests using the alternative and baseline scrubbing components. Alternative systems could be required if future testing (a) shows baseline components do not perform as presently assumed, (b) melter off-gas characterization is different from what is presently assumed in ways that affect scrubbing requirements, or (c) alternative components are shown to offer significant cost or performance advantages.

\section{Cascaded Acid Scrub (Alternative 15)}

The baseline flowsheet contains a single acid scrub tank which collects liquid from the quench tower, venturi scrubber and HEME. The scrub tank acts as a settling tank to concentrate solids for recycle to the melter and return liquid relatively free of solids to the quench tower and venturi scrubber.

The SBW Vitrification Feasibility Study ${ }^{\mathrm{v}}$ shows a cascaded scrub system which includes separate collection tanks for venturi scrub and quench tower liquids. Make-up is supplied to the venturi scrub collection tank, and overflow from the venturi scrub tank is sent to the quench tank. No solids separations is done in the collection tanks, but rather in a separate tank containing the purge from the quench tank.

Additional off-gas solids characterization data is needed to better evaluate the feasibility of separating solids in the scrub tank. If solids separation in the scrub tank is feasible, the single tank scheme should remove solids from the off-gas with greater efficiency than the cascaded system. This is because in the cascaded system, the amount of solids returned in the scrub and quench solutions to the quench tower and venturi scrubber is several times greater than that contained in the off-gas coming to these unit operations. A cascaded scrub system would be beneficial if the acid scrub components had requirements to remove soluble species from the off-gas. However, no requirement for removal of any soluble species has yet been identified for the acid scrub system.

The make-up to the acid scrub is water; the scrub is acidic only because of the absorption of $\mathrm{NO}_{2}$ by water in the quench tower and venturi scrubber. The acidity of the scrub will influence whether particulate captured in the scrub will dissolve. Dissolution of certain radionuclide and hazardous species affects secondary waste compositions. Thus, if the scrub acidity is different from what has been assumed, it may affect which scheme is preferable.

${ }^{v}$ J. J. Quigley, B. D. Raivo, S. O. Bates, S. M. Berry, D. N. Nishioka, P. J. Bunnell, Feasibility Study for Vitrification of Sodium-Bearing Waste, INEEL/EXT-2000-00952, September, 2000. 
Until additional off-gas solids and scrub composition data is received, mass balances help in evaluating different scrub schemes. After data from the RSM-2 tests and the Clemson-2 tests is received, this decision can be reevaluated. This additional data plus the phase equilibrium capabilities of ASPEN Plus may indicate that ASPEN Plus simulations can be of benefit in evaluating the different scrub schemes.

\section{Separate HEME Scrub Tank (Alternative 16)}

The Feasibility Study for Vitrification of Calcine ${ }^{\mathrm{w}}$ assumes an off-gas treatment scheme that includes a separate tank for receiving water from and recycling water to the HEME. The baseline flowsheet uses make-up water supplied from the make-up water header, along with condensate from cooling coils within the HEME or an external cooler to the HEME. Cost differences between these two schemes are expected to be very small. The rationale behind the baseline flowsheet was that at times the HEME liquid would contain significant solids and recycling these solids to the HEME could negatively impact its performance. Evaluation of this alternative should be deferred to future design studies, after additional test data provides better characterization of the HEME liquid solids and dissolved specie concentrations.

\section{Mercury Removal from Scrub (Alternatives 18-20)}

Based on the present mass balance assumptions, the concentration of mercury in the acid scrub will increase to an equilibrium level. For the average SBW feed, the mercury concentration in the scrub reaches $28 \mathrm{~g} /$ liter, for WM-189, the concentration reaches $53 \mathrm{~g} /$ liter. ${ }^{\mathrm{x}}$ Mercury concentrations in the grouted scrub purge for these two cases are $390 \mathrm{mg} / \mathrm{kg}$ and $580 \mathrm{mg} / \mathrm{kg}$ respectively. Because the concentration of mercury puts the grout into the "high" mercury (greater than $260 \mathrm{mg} / \mathrm{kg}$ ) category, land disposal would require obtaining an equivalency agreement with the disposal site and regulating agencies. Amalgamation is the required treatment process for high mercury waste; thus grouting would need to be demonstrated and accepted as producing equivalent results. ${ }^{\mathrm{y}}$. While the concentration of mercury in the grouted waste puts the waste in the high $\mathrm{Hg}$ category, the fraction of mercury in the feed that is contained in the grout is small, only $1-4 \%$, depending on the feed case. The bulk of the mercury is contained in the activated carbon, producing a high volume $\left(54 \mathrm{~m}^{3}\right)$ of a second high mercury waste. An equivalency agreement would also be needed to dispose of the spent carbon. Removal of mercury from the scrub provides two benefits - reducing the level of mercury in the grout to below $260 \mathrm{mg} / \mathrm{kg}$, and reducing the quantity of spent carbon waste. These advantages need to be weighed against the costs of additional equipment to remove mercury from the scrub plus the disposal costs an additional waste.

Data defining mercury speciation in the off-gas is needed in order to better determine mercury scrub concentrations and to evaluate mercury removal methods. Data from RSM-2 may provide a basis for initial evaluations. Additional information that can be used in this evaluation is contained in the following:

(22) J. A. DelDebbio, L. G. Olson, J. Pao, Final Report on Mercury Vapor/Liquid Equilibrium to Support Wet Scrubber Process Models for NWDF Upgrade, JAD-02-2000, June 19, 2000.

\footnotetext{
${ }^{\text {w }}$ S. O. Bates, B. D. Raivo, J. J. Quigley, S. M. Berry, W. H. Landman, S. L. Palmer, T. M. Hipp, Feasibility Study for Vitrification of Calcine in the Idaho Waste Vitrification Facility, INEEL/EXT-01-00978, September, 2001.

"The "equilibrium" level of mercury in mass balance off-gas streams is determined by assumed separation factors, not vaporliquid equilibrium (VLE) data.

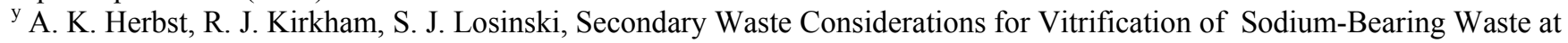
the Idaho Nuclear Technology and Engineering Center FY-2001 Status Report, INEEL.EXT-01-01172, September, 2001.
} 
(23) D. W. Marshall, Mercury Removal from Adjusted 10-cm Pilot Plant Scrub Solutions by Electrochemical Reduction, DRM-02-00, May 25, 2000.

(24) J. A. DelDebbio, L. G. Olson, Status Report on Wet Scrubbing for Mercury Removal from Simulated NWCF Off-Gas, JAD-01-00, April 19, 2000.

(25) D. D. Siemer, The "Hows \& Whys" of Electrodeposition of Mercury from NWCF Off-gas Scrub, Recent Experimentation, DDS-06-00, August 15, 2000.

(26) D. D. Siemer, Reprise of "Scrubability of Mercury from NWCF Off-gas," DDS-05-00, August 8, 2000.

(27) D. R. Marshall, Mercury Removal from Simulated INTEC Acid Waste Solutions by Electrochemical Reduction, DRM-01-99, September 29, 1999.

(28) R. E. Schindler, Status Report on Development of an ASPEN Electrolyte NRTL Parameter Set for Process Simulation of INTEC Aqueous Wastes, INEEL/INT-2000-0025, January, 2000.

(29) S. C. Ashworth, et. al, NWCF Mercury Removal Feasibility Study, INEEL/INT-2000-00539, September, 2000.

It is recommended that mercury removal evaluations be done using the ASPEN mass balance model, because of the importance of $\mathrm{Hg}$ vapor-liquid equilibria (VLE) in the results. The mass balance model used in the past does no (VLE) thermodynamic calculations, but relies on assumed (inputted) separation factors. Comparison of recent mass balances to VLE data in DelDebbio ${ }^{22}$ shows that the mass balance scrub $\mathrm{Hg}$ concentrations are low by factors of 1.7-5.1. The VLE data generated by DelDebbio ${ }^{22}$ can be $^{2}$ used as a check of ASPEN NRTL parameters derived by Schindler. ${ }^{28}$

The previous mercury testing and evaluations have concerned mercury removal from the NWCF scrub and off-gas, ${ }^{22-29}$ and have focused on scrubbing mercury from off-gas and removal of mercury from NWCF scrub by electrochemical reduction. The data in these studies will be of help "calibrating" an ASPEN mass balance model to then use in simulating the vitrification process. The only feasible method of removing mercury from NWCF scrub solution was determined to be by electrochemical reduction. However, the vitrification scrub solution is not expected to be nearly as acidic as NWCF scrub, hence mercury removal methods other than electrochemical reduction may also be feasible. Sulfide precipitation would require neutralizing the scrub. Removal by ion exchange may be feasible, but would generate larger quantities of waste than electrochemical reduction or sulfide precipitation. Therefore analysis by ASPEN modeling is recommended only for these later two alternatives.

Acid Scrub Blowdown Split between Recycle and Purge (Alternatives 21-22)

Total recycle of the acid scrub purge to the melter would eliminate the acid scrub purge and hence eliminate the equipment in the baseline flowsheet to neutralize and remove cesium from the acid scrub purge. Total recycle would also reduce the quantity of grouted waste. Zero recycle of scrub purge would reduce the quantity of glass and increase the quantity of grout. The grout waste classification would likely change, becoming a TRU mixed waste. With no recycle of scrub, the melter feed composition can be more easily determined and will likely be more homogeneous. Total recycle would likely require removal of mercury from the scrub. Mass balance simulations can provide an initial evaluation of these two alternative schemes. Some assumptions used to generate the mass balances may need to be validated by test data. Because VLE will have a strong impact on these mass balances, it is recommended that the ASPEN model be used. 
T. Nichols

November 5, 2001

Page 15

\section{Filtration of Scrub Solids (Alternatives 23-24)}

In the baseline flowsheet, the acid scrub tank acts as a settling tank to minimize solids in the quench and venturi scrub feeds and concentrate solids in the scrub recycled to the melter. The purge acid scrub is filtered, neutralized and then passes through ion exchange columns to remove cesium. Scrub solids characterization data are needed to confirm the feasibility of separation by settling. If not feasible, an alternative solid/liquid separation system would be needed.

Questions have been raised regarding whether precipitation will occur when the scrub purge is neutralized. If precipitates do form, the filter on the scrub purge should be moved downstream of neutralization.

Relative to the mass balance, alternative schemes 23 and 24 result in negligible changes to waste product quantities and compositions and most flowrates through the process. Thus it is recommended that any evaluation of these two alternatives be deferred until additional data is obtained on (a) scrub solids and (b) acid scrub neutralization.

\section{Treatment of Scrub Purge (Alternatives 25-29)}

Several variations of the baseline flowsheet have been suggested that relate to treatment of the scrub purge. One alternative, suggested in order to simplify the process, is to eliminate the ion exchange columns. This change would eliminate both the ion exchange removal equipment and the spent cesium ion exchange waste. Alan Herbst has addressed this suggestion in his recent report on secondary Waste Considerations: ${ }^{\mathrm{z}}$

"If the cesium were left in the (grouted) waste, the waste form would be (Hanford) Category $3 /$ Class C. The real answer to this issue is in the grouting process as to whether the process will be contact handled or remote handled. By removing the cesium, the radiation dose from a drum of grout is reduced from over 900 millirem per hour $(\mathrm{mR} / \mathrm{hr})$ to less than 1 millirem per hour. The trade off is then the requirement to add shielding to the grouting process for remove handling of $900 \mathrm{mR} / \mathrm{hr}$ as opposed to no shielding for contact handled. It is thought that the expense of an ion exchange system is less expensive than a remote-handled, shielded grout mixing system."

For reasons stated by Herbst, primarily that the expected cost and complexity of a remote-handled grout mixing system exceeds the cost of the ion exchange system, it is recommended that no further evaluation be performed on the scheme which deletes the cesium ion exchange column.

In the same report, ${ }^{\mathrm{z}}$ Herbst recommends combining the acid and caustic scrub purges, and then removing cesium and strontium from the combined stream. Removal of strontium reduces disposal costs by reducing the waste classification from Hanford as Category 3 to Hanford Category 1. Approximately $90 \%$ removal of the strontium would be required to meet Hanford Category 1 waste limits. The sorbent used for cesium removal in the baseline process, IONSIV IE-95, does remove strontium as well, although the present mass balance does show any strontium removal because insufficient data is available on the scrub solution composition. Because of expected savings in disposal costs by removing strontium, this alternative is recommended. Additional test data is needed to

\footnotetext{
${ }^{z}$ A. K. Herbst, R. J. Kirkham, S. J. Losinski, Secondary Waste Considerations for Vitrification of Sodium-Bearing Waste at the Idaho Nuclear Technology and Engineering Center FY-2001 Status Report, INEEL.EXT-01-01172, September, 2001.
} 
T. Nichols

November 5, 2001

Page 16

determine whether the existing cesium sorbent can achieve the required strontium removal efficiency, or if not, what sorbent should be used.

If a higher $\mathrm{pH}$ is required for efficient strontium removal, combining the acid and caustic scrub purges may be of benefit. However, combining the two scrub purges may result in precipitation that could complicate the $\mathrm{Cs} / \mathrm{Sr}$ removal system. Precipitation would result in a solids or sludge waste from which $\mathrm{Cs}$ and $\mathrm{Sr}$ could not be removed without redissolution. Also, the caustic scrub is expected to have lower cesium and strontium concentrations than the effluent from the acid scrub after ion exchange, hence there does not appear to be any benefit for combining the streams. Once melter and off-gas tests are able to provide better scrub solution composition data, tests of cesium and strontium removal of the scrub purge streams, over a range of acidity and with and without combining, should be done to optimize the scrub purge treatment system.

Testing of the cesium sorbent proposed in the baseline flowsheet has not been performed using INEEL waste simulants, and hence there is uncertainty regarding the performance of this sorbent. This uncertainty is the basis for alternative scheme 28 , which would evaluate alternative neutralization agents to reduce the amount of sodium present in the ion exchange column feed, and scheme 29 , which would replace the baseline sorbent with a different one.

The sorbent identified in the SBW Vitrification Feasibility Study ${ }^{\mathrm{a}}$ for removing cesium from the acid scrub is IONSIV IE-95, and the baseline flowsheet retained this selection. The Feasibility Study sorbent selection was based on its successful use over a seven year period at the West Valley Demonstration Project (WVDP) to remove cesium from waste supernate. ${ }^{b}$ This sorbent or very similar sorbents have also been tested or used to remove cesium from waste streams at Savannah River, Oak Ridge, Three Mile Island, and Hanford. ${ }^{\mathrm{c}}$ From 1963 to 1988, Savannah River generated a total of about 400,000 lb of spend Linde AW500 sorbent, which was used to remove cesium from evaporator overheads and other wastes, and is equivalent to UOP IONSIV IE-95. ${ }^{\mathrm{d}}$

At West Valley, approximately 550,000 gallons of nitric-acid based fuel reprocessing waste were neutralized with excess caustic. Neutralization resulted in a sludge layer forming and settling to the bottom of the storage tanks. Beginning in 1988, the liquid solution, called the supernate, was drawn off the tanks and processed by ion exchange using IONSIV IE-96. The $\mathrm{pH}$ of the supernate was about 10. (IONSIV IE-96 was produced in limited quantities for West Valley and Three Mile Island, and is presently commercially unavailable ${ }^{\mathrm{e}}$ ). IONSIV IE-95 is very similar to the former IE-96 product,

\footnotetext{
${ }^{\text {a }}$ J. J. Quigley, B. D. Raivo, S. O. Bates, S. M. Berry, D. N. Nishioka, P. J. Bunnell, Feasibility Study for Vitrification of Sodium-Bearing Waste, INEEL/EXT-2000-00952, September, 2000; V. A. Descamp, C. L. McMahon, Vitrification Facility at the West Valley Demonstration Project, DOE/NE/44139-77. July, 1996.

b J. J. Quigley, Trip Report of Visit to West Valley Demonstration Project, September 10, 1999.

${ }^{\mathrm{c}}$ L. A. Bray, K. J. Carson, R. J. Elovich, D. E. Eakin, HWVP Submerged Bed Scrubber Waste Treatment by Ion Exchange at High pH, PNNL-11033, March, 1996; S. M. DePaoli, D. T. Bostick, Process Wastewater Treatment with Hydrogen-Form CST and Chabazite Zeolite, ORNL/CP-98275; J. E. Miller, N. E. Brown, Development and Properties of Crystalline Silicotitanate (CST) Ion Exchanger for Radioactive Waste Applications, SAND97-0771, April, 1997; W. J. Dalton, Qualification Testing and Full Scale Demonstration of Titanium-Treated Zeolite for Sludge Wash Processing, DOE/NE/44139-72, June 30, 1997; J. A. Sundquist, J. C. Gillings, T. L. Sonntag, R. P. Denault, Bench-scale Treatability Testing of Biological, UV Oxidation, Distillation and Ion-Exchange Treatment of Trench Water from a Low-Level Radioactive Waste Disposal Area at West Valley, New York; D. C. Koopman, Factors Potentially Influencing the Tackiness of DWPF Streams, WSRC-TR-2000-00239, September 13, 2000; P. P. Murphy, J. S. Budkingham, Preliminary Laboratory Investigation for the Removal of Radioactive Cesium from Purex Aqueous Waste Solutions, RHO-CD-456, 1978.

${ }^{\mathrm{d}}$ C. M. Jantzen, Conposition of Linde IE95 (AW500) Zeolite Fraction of Sludge, DPST-88-623, June $24,1988$.

e Personal communication with Dennis Fennely of UOP, October 17, 2001.
} 
T. Nichols

November 5, 2001

Page 17

containing more calcium and less sodium, both of which are minor components of both sorbents. ${ }^{\mathrm{e}}$ ) The spent sorbent was vitrified in the West Valley melter.

UOP IONSIV IE-95, and the very similar sorbents IE-96, Linde IE-95 and Linde AW500, are alkali metal alumino-silicates with partial substitution in the crystalline matrix by sodium, calcium and magnesium oxide. These sorbents are zeolites, a class of crystalline aluminosilicates with a highly regular structure of pores and chambers. Wastes processed with zeolite sorbents have been either alkaline or neutral, thus the baseline flowsheet includes neutralization of the acid scrub to a $\mathrm{pH}$ of prior to ion exchange. According to the manufacturer, the IE-95 can be used with wastes of $\mathrm{pH} 5$ or higher. ${ }^{\mathrm{f}}$ Bray $^{\mathrm{g}}$ references work he performed in 1990 which determined the $\mathrm{Cs}, \mathrm{Sr}$, and TRU distribution ratios for IE-95 and IE-96 as a function of sodium concentration, temperature and $\mathrm{pH}$. This data, contained in an internal Hanford document, has been requested. After obtaining and reviewing the Hanford data on IE-95 performance, additional data needs relative to ion exchange sorbent selection can be determined.

As previously stated, the basis for the selection of IE-95 as the cesium sorbent in the baseline flowsheet was (1) its successful use in treating the West Valley supernate and (2) the successful vitrification of the spent sorbent in the WVDF melter. The greatest uncertainty relative to the sorbent is its performance on the neutralized acid scrub of the IWVF. The primary alternatives to zeolite sorbents are crystalline silicotitanate (CST) and ammonium molybdophosphate (AMP). Tests have been performed of cesium removal from SBW simulants using both CST and AMP. ${ }^{\mathrm{h}}$ The acid scrub will differ in composition from SBW; however, the use of either of these sorbents would eliminate the need to neutralize the acid scrub prior to ion exchange. Vitrification of CST has also been demonstrated, although typically borosilicate glass has a $\mathrm{TiO}_{2}$ limit of around $1.0 \%$. The high phosphate content of AMP would also require either blending the spend sorbent with a large amount of SBW or calcine, reducing waste loading or using a special glass formulation.

Testing needs to be performed in order to validate selection of any ion exchange sorbent for the treatment of scrub solution in the IWVF process. Data is first needed from melter tests in order to define the range of scrub composition. Once the IX feed has been defined, testing of sorbents can proceed.

\section{Caustic Quench and Scrub (Alternatives 30-31)}

The caustic quench and scrub step cools the noxidizer effluent and removes acid gases, including $\mathrm{HNO}_{3}$ vapor $\mathrm{HCl}, \mathrm{HF}, \mathrm{HI}$, and $\mathrm{SO}_{2}$. Alternatives to the present single stage caustic quench/scrub step include a partial quench with water with no acid gas removal (Alternative 30) and quench and acid gas removal in more than one step (Alternative 31 ). The calcine vitrification feasibility study ${ }^{i}$ assumes separate quench and scrub steps.

\footnotetext{
${ }^{\mathrm{f}}$ Personal communication with Dennis Fenely of UOP, July 13, 2001.

${ }^{\mathrm{g}}$ L. A. Bray, K. J. Carson, R. J. Elovich, D. E. Eakin, HWVP Submerged Bed Scrubber Waste Treatment by Ion Exchange at High pH, PNNL-11033, March, 1996.

${ }^{\mathrm{h}}$ N. R. Mann, T. A. Todd, K. N. Brewer, D. J. Wood, T. J. Tranter, P. A. Tullock, Evaluation and Testing of IONSIV IE-911 for the Removal of Cesium-137 from INEEL Tank Waste and Dissolved Calcines, INEEL/EXT-99-00332, April, 1999; N. R. Mann, T. A. Todd, Removal of Cesium from Idaho Nuclear Technology Engineering Center Acidic Tank Waste Using IONSIV IE-911 Sorbent, INEEL/EXT-2000-01570, September, 2000 (unpublished draft); T. J. Tranter, R. S. Herbst, T. A. Todd, H. B. Eldredge, Evaluation and Testing of Ammonium Molybdophosphate-Polyacrylonitrile (AMP-PAN) as a Cesium Selective Sorbent for the Removal of Cs-137 from Idaho Nuclear Engieering and Technology Center Acidic Waste, INEEL/EXT-99-00645, June 22, 1999.

${ }^{i}$ S. O. Bates, B. D. Raivo, J. J. Quigley, S. M. Berry, W. H. Landman, S. L. Palmer, T. M. Hipp, Feasibility Study for Vitrification of Calcine in the Idaho Waste Vitrification Facility, INEEL/EXT-01-00978, September, 2001.
} 
T. Nichols

November 5, 2001

Page 18

The $\mathrm{HCl}$ concentration in the noxidizer off-gas is approximately one-tenth of the MACT limit for $\mathrm{HCl} / \mathrm{Cl}_{2}$ of $21 \mathrm{ppm}$, hence removal of $\mathrm{HCl}$ is not required. $\mathrm{HF}$ is expected to be at a comparable level or lower, and thus is not an emission concern. Based on present estimates, the SBW contains a total of about $0.2 \mathrm{Ci}$ of ${ }^{129} \mathrm{I}$. Based on information from Savannah River, ${ }^{\mathrm{j}}$ all iodine in the melter vaporizes as $\mathrm{NaI}$ and then condenses as a submicron aerosol as the off-gas cools. Depending on DF factors for the condensed iodine aerosol in off-gas treatment steps, removal could be required to meet the ${ }^{129}$ I Waste Acceptance Criteria (WAC) for the spent carbon waste. However, based on present assumptions, if no iodine is removed in the caustic scrub (by deleting the step) and all is captured on the GAC bed, the spent GAC will have an ${ }^{129} \mathrm{I}$ concentration of only about $5 \%$ of the Envirocare limit. Hence removal of iodine does not appear to be required.

Based on the present mass balance, the concentration of $\mathrm{SO}_{2}$ in the noxidizer effluent is about 20 ppm, which equates to a total $\mathrm{SO}_{2}$ emission of approximately 1 ton/year. According to EPA information for the year 1999, the Monsanto facility in Soda Springs emitted 7543 tons of SO 2 , J. R. Simplot in Pocatello emitted 7123 tons, FMC Corporation in Pocatello emitted 2935 tons, the INEEL emitted 658 tons, Ash Grove Cement in Inkom emitted 489 tons, and the total $\mathrm{SO}_{2}$ emissions for the state of Idaho was 23,671 tons. ${ }^{\mathrm{k}}$ Assuming no change in INEEL emissions from other sources, the IWVF would add $0.15 \%$ to the $\mathrm{SO}_{2}$ emissions if $\mathrm{SO}_{2}$ is not removed. The actual $\mathrm{SO}_{2}$ emission limit will be based on air quality modeling and how the emissions affect the air quality over Yellowstone and Grand Teton National Parks and Crators of the Moon National Monument. Recent modeling of emissions from the oil fired boilers at CPP-606 resulted in a requirement to limit the sulfur in the feed to $0.3 \%$, lower than the statewide limit of $0.5 \%$. However, based on the total possible rate of 1 ton/year $\mathrm{SO}_{2}$, it's likely that no removal would be required. ${ }^{1}$

Only trace amounts of nitric acid vapor are expected in the noxidizer effluent due to its destruction in the noxidizer. If not removed nitric acid emissions would be orders of magnitude lower that the emission limit of $0.333 \mathrm{lb} / \mathrm{hr}$ contained Idaho regulations, IDAPA 58.01.01.

The advantage of eliminating the caustic scrub step is the reduction in the amount of grout waste. The caustic scrub purge is about $50 \%$ as large as the neutralized acid scrub purge; eliminating the caustic scrub would reduce the amount of grouted waste by about 33\%. However both acid and caustic scrub purge streams are small, 1-2 liter/hr; hence the reduction is not expected to have a significant impact on capital or operating cost. Although it appears the caustic tower could be eliminated, there is significant uncertainty in the partitioning of species such as chloride and sulfate that volatilize in the melter and are captured in scrub solutions. More scrub and off-gas analyses are needed in order to verify that the caustic quench and scrub tower can be eliminated.

If additional off-gas system test data or regulatory decisions indicate that removal of $\mathrm{SO}_{2}$ of other acid gases is required, the question of single versus multiple stage removal becomes a mechanical issue with negligible impact to the mass balance and very little cost impact. Commercial caustic towers in industrial facilities typically have multiple sections, i.e., a packed bed scrub section on top of a quench section. Once requirements for removal are established, an optimal design can be developed. At that time other off-gas desulfurization technologies could be considered as well.

\footnotetext{
${ }^{\mathrm{j}}$ C. Randall, Iodine in HLW Off-gas, e-mail note to Bill Holtzscheiter, August 24, 2000.

${ }^{\mathrm{k}}$ Data available through EPA air data website http://www.epa.gov/air/data/netemis.html, Idaho statistics on webpage: http://oaspub.epa.gov/airsdata/net.ranking?geo=ID\&cnty=+\&pol=SO2\&year=1999\&rpp=25\&fld=percent\&fld=plt_name\&fl $\mathrm{d}=$ addr $\&$ fld $=$ state $\&$ fld $=$ county $\&$ fld $=$ year $\&$ fld $=$ sic $\& f l d=$ plantid $\&$ fld $=$ lat_lon $\&$ fld $=$ regn

${ }^{1}$ Personal communication with John Gill, October 18, 2001.
} 
T. Nichols

November 5, 2001

Page 19

\section{GAC Bed Location (Alternative 32)}

Because of the relatively large volume of spent carbon produced, $54 \mathrm{~m}^{3}$, it has been suggested to place the GAC bed downstream of the final HEPA filters to reduce the amount of radioactivity contained on the spent carbon waste. However the mass balances from the baseline flowsheet indicate that the radionuclide concentrations on the GAC bed are orders of magnitude less than limits of the most stringent disposal site, Envirocare. Unless changes in upstream off-gas treatment equipment result in higher levels of radioactivity on the carbon bed, there is no basis for changing the GAC bed and final HEPA filter arrangement.

\section{NO $O_{x}$ Abatement Technology (Alternative 33)}

Alternatives for $\mathrm{NO}_{\mathrm{x}}$ abatement are discussed in the IWVF Off-gas Treatment Feasibility Study. ${ }^{\mathrm{m}}$ The same report discusses the evaluation process that led to the selection of the noxidizer as the baseline $\mathrm{NO}_{\mathrm{x}}$ abatement technology. In a value engineering session, the noxidizer flow scheme alternative scored higher that schemes that has the Studsviks process, SCR reactors, or SNCR reactors. However, in a separate evaluation of noxidizer technology, the SCR reactor was rated slightly higher the noxidizer staged combustion technology. " Mass balances comparisons and capital cost estimates of the difference $\mathrm{NO}_{\mathrm{x}}$ abatement schemes show advantages for the SCR reactor.

One unresolved issue that could affect the choice of $\mathrm{NO}_{\mathrm{x}}$ abatement technology is the requirement for supplemental air to the noxidizer reduction chamber. The mass balance assumes this air rate is set by the reduction chamber temperature requirement. However, correspondence ${ }^{o}$ from John Zink, the noxidizer vendor, indicates that for burner stability, an air rate of $1900 \mathrm{scfm}$ may be required. This air rate is 11 times greater than what is shown in the mass balance, and would significantly increase flowrates through the off-gas treatment equipment downstream of the noxidizer. Testing of an SCR reactor in the off-gas train of the Clemson Environmental Technologies Laboratory melter is planned and data from these tests should be reviewed to re-evaluate the selection of $\mathrm{NO}_{\mathrm{x}}$ abatement technology.

\section{Conclusions from Initial Screening}

Based on the initial screening, the following alternatives can be eliminated from further consideration:

1. (3b) Total denitration

2. (20) Hg removal by ion exchange

3. (25) No treatment of acid scrub purge

4. (32) GAC bed downstream of final HEPA filters.

It is recommended that four changes be made to the baseline - blending SBW feed, use of granular sugar, removal of strontium from the neutralized acid scrub, and changing the melter plenum temperature to $500^{\circ} \mathrm{C}$. Five schemes are evaluated in the next section based on results of the Visual Basic mass balance model. It is recommended that the evaluation of five other schemes be performed using the ASPEN mass balance model that will be developed this year:

\section{1. (15) Cascaded acid scrub}

\footnotetext{
${ }^{\mathrm{m}}$ R. Wood, D. Tyson, B. Bonnema, C. Olsen, A. P. Pinto, D. Wendt, S. Reese, B. Raivo, Feasibility Study for the Idaho Waste Vitrification Facilities Off-gas Treatment for Sodium-Bearing Waste, INEEL/EXT-01-00995, September, 2001.

${ }^{\mathrm{n}}$ D. R. Tyson, "Vitrification Melter Off-Gas NO $\mathrm{x}$ Abatement," EDF-IWVF-006, June 1, 2001.

${ }^{\circ}$ L. Crynes, Revised Noxidizer Design, e-mail to S. J. Reese, January 17, 2001.
} 
T. Nichols

November 5, 2001

Page 20

2. (18) Hg removal from scrub by electrolytic reduction

3. (19) $\mathrm{Hg}$ removal from scrub by sulfide precipitation

4. (21) Total scrub purge recycle

5. (22) No scrub purge recycle.

Test data from RSM-2 will also be used in some of these evaluations.

Two of the alternatives, a separate HEME wash water tank and multiple caustic quench/scrub steps, have little effect on the mass balance and can be deferred to later design studies. Additional test data is needed to evaluate the remaining 14 alternatives.

\section{Evaluations Based on Mass Balance Results}

Mass balances were determined for four SBW pretreatment schemes plus two variations of the baseline film cooler scheme. The results of these mass balances are discussed in the following sections. Of all the process alternatives, pretreatment schemes have the greatest potential for significant savings because they affect all downstream flowrates.

\section{Barium Sulfate Precipitation}

A mass balance was determined for the barium precipitation scheme assuming an $80 \%$ removal of sulfate and $20 \%$ excess barium, based on data in Reference 17 . SBW and barium nitrate would be fed to a precipitation tank and mixed for approximately one-hour. The mixture would then be filtered, with the filtrate sent to melter feed mix tanks, and the filtered solids periodically removed from the filter and packaged as secondary waste. A solids removal efficiency of $99 \%$ was assumed for the filter.

The mass balance assumes a glass waste loading of 35\%. Based on the results of FY-01 glass melt tests in which waste loading was varied between $25 \%$ and $45 \%$, Peeler et $\mathrm{al}^{\mathrm{p}}$ concludes that if not constrained by a sulfate salt layer, the waste loading in SBW glass would be constrained by PCT release or nepheline formation upon cooling at a waste loading greater than about $40 \%$. Thus a waste loading higher than $35 \%$ may be achievable if sulfate is removed from the feed. However, $35 \%$ was assumed to be conservative.

Assuming a 2 molar barium nitrate solution is used to precipitation sulfate, and that the processing schedule is unchanged, the total melter feed rate would increase by $2 \%$ and the glass rate decrease by $36 \%$ from rates of the baseline mass balance. The sulfur concentration in the glass would decrease by nearly $70 \%$ relative to the baseline mass balance. Off-gas and liquid scrub rates would remain unchanged.

The savings in disposal costs from the reduced glass volume are approximately $\$ 200$ million, based on disposal at Yucca mountain. ${ }^{\mathrm{q}}$ Additional savings would result from a smaller melter or reduced processing schedule. The savings would be partially offset by equipment to precipitate barium sulfate, and treat and dispose of the resultant solids. Approximately 45,000 kg of solids would be produced, including barium sulfate precipitates, small amounts of other precipitates and SBW UDS separated by the filter. If packaged in a dry form, about $30 \mathrm{~m}^{3}$ of TRU waste would be produced. If grouted at a 25

\footnotetext{
${ }^{\mathrm{p}}$ D. K. Peeler, T. B. Edwards, I. A. Reamer, R. J. Workman, J. D. Vienna, J. V. Crum, M. J. Schweiger, Glass Formulation Development for INEEL Sodium-Bearing Waste (FY-2001 WM-180), WSRC-TR-2001-00295, September 21, 2001

${ }^{\mathrm{q}}$ Disposal cost of $\$ 540 \mathrm{~K}$ per 10 -ft canister $\left(0.62 \mathrm{~m}^{3}\right.$ glass $)$ were taken from Appendix F of the Idaho High-Level Waste \& Facilities Disposition Draft Environmental Impact Statement, DOE/EIS-0287D.
} 
T. Nichols

November 5, 2001

Page 21

wt \% solids waste loading, about $100 \mathrm{~m}^{3}$ of waste would be produced. Using WIPP disposal costs consistent with the Idaho High-Level Waste and Facilities Disposition Draft EIS, ${ }^{\mathrm{r}}$ these two waste volumes equate to disposal costs of about $\$ 8$ million and $\$ 25$ million respectively. An alternative treatment and disposal path for these solids is to perform the precipitation in the Tank Farm tanks, letting the precipitates settle to the bottom of the tanks and be disposed of with the heel solids.

Siemer (Reference 18) determined that the precipitate would contain 1-2\% of the plutonium in the SBW. Assuming the precipitate would contain 1\% of all TRU elements in the SBW liquid, the precipitate would have a TRU concentration of $20,000 \mathrm{nCi} / \mathrm{g}$. Additional TRU will be contained in the solids from UDS in SBW; the total TRU concentration in the waste solids is estimated to be $40,000 \mathrm{nCi} / \mathrm{g}$ for the dry waste form or $5,000 \mathrm{nCi} / \mathrm{g}$ for the grouted waste. The solids chemical composition is given in Table 5 .

Table 5. Barium precipitation solids composition.

$$
\text { wt } \% \text { wt } \%
$$

$\begin{array}{lclc}\mathrm{Ag}+1 & 0.001 & \mathrm{NO}-1 & 8.56 \\ \mathrm{Al}+3 & 1.15 & \mathrm{~Pb}+2 & 0.01 \\ \mathrm{As}+5 & 0.0001 & \mathrm{Pd}+3 & 0.01 \\ \mathrm{~B}+3 & 0.01 & \mathrm{PO} 4-3 & 3.28 \\ \mathrm{Ba}+2 & 48.7 & \mathrm{Ru}+4 & 0.007 \\ \mathrm{Ca}+2 & 0.08 & \mathrm{Se}+4 & 0.03 \\ \mathrm{Cd}+2 & 0.003 & \mathrm{Si}+4 & 0.41 \\ \mathrm{Cl}-1 & 0.02 & \mathrm{Sr}+2 & 0.001 \\ \mathrm{Cr}+3 & 0.01 & \mathrm{SO} 4-2 & 34.36 \\ \mathrm{Cs}+1 & 0.01 & \mathrm{~V}+5 & 0.0002 \\ \mathrm{Cu}+2 & 0.003 & \mathrm{Zn}+2 & 0.004 \\ \mathrm{~F}-1 & 0.001 & \mathrm{Zr}+4 & 0.55 \\ \mathrm{Fe}+3 & 0.40 & \mathrm{Be}+2 & 0.00004 \\ \mathrm{Gd}+3 & 0.002 & \mathrm{Ce}+4 & 0.001 \\ \mathrm{Hg}+2 & 0.18 & \mathrm{Co}+2 & 0.0003 \\ \mathrm{~K}+1 & 0.29 & \mathrm{Nb}+5 & 0.20 \\ \mathrm{Li}+1 & 0.003 & \mathrm{Sb}+4 & 0.001 \\ \mathrm{Mg}+2 & 0.03 & \mathrm{Sn}+4 & 0.04 \\ \mathrm{Mn}+4 & 0.03 & \mathrm{Ti}+4 & 0.02 \\ \mathrm{Mo}+6 & 0.007 & \mathrm{Tl}+3 & 0.03 \\ \mathrm{Na}+1 & 1.54 & \mathrm{U}+4 & \underline{0.02} \\ \mathrm{Ni}+2 & 0.005 & \mathrm{Total} & 100.000\end{array}$

Based on the magnitude of the potential savings for the barium precipitation scheme, testing is recommended to confirm the glass waste loading for a reduced-sulfur SBW surrogate, and to develop a waste form for the barium sulfate precipitate.

\section{SBW Absorption on Silica Gel}

In this scheme, SBW would be absorbed on silica gel and the resultant slurry would be fed to an evaporator in which it would be evaporated to dryness. Kirkham provides data from tests of this scheme in Reference 2. These tests showed that the solids produced are flowable at waste loadings up to $84 \%$, and at high waste loadings and a temperature of $140^{\circ} \mathrm{C}$, evaporation resulted in a loss of $76-78 \%$ of the mass of the original SBW.

\footnotetext{
${ }^{\mathrm{r}} \$ 205 \mathrm{~K}$ per $0.8 \mathrm{~m}^{3}$ cask.
} 
T. Nichols

November 5, 2001

Page 22

A comparison of the simulant composition used by Kirkham to the total SBW composition is shown in Table 3.

Table 3. Comparison of test surrogate and projected SBW composition.

\begin{tabular}{|l|c|c|c|}
\hline Species & $\begin{array}{c}\text { Test Surrogate } \\
\text { Concentration, } \\
\text { Mol/liter }\end{array}$ & $\begin{array}{c}\text { Projected Total SBW } \\
\text { Concentration, } \\
\text { Mol/liter }\end{array}$ & $\begin{array}{c}\text { Ratio, } \\
\text { Surrogate/Present } \\
\text { Projected Composition }\end{array}$ \\
\hline $\mathrm{H}^{+}$ & 1.94 & 2.4 & 1.24 \\
\hline $\mathrm{Al}^{+3}$ & 0.784 & 0.557 & 0.71 \\
\hline $\mathrm{Ca}^{+2}$ & 0.576 & 0.514 & 0.89 \\
\hline $\mathrm{K}^{+}$ & 0.245 & 0.164 & 0.67 \\
\hline $\mathrm{Na}^{+}$ & 2.36 & 1.52 & 0.64 \\
\hline $\mathrm{NO}_{3}^{-}$ & 6.95 & 5.93 & 0.85 \\
\hline $\mathrm{SO}_{4}^{-2}$ & 0.0637 & 0.0506 & 0.79 \\
\hline
\end{tabular}

Because Kirkham's simulant was more concentrated than the present projected SBW composition, a higher fractional loss on evaporation could possibly be expected with SBW, as currently projected.

The present baseline mass balance for the total SBW case shows consumption of $813,000 \mathrm{~kg}$ of $\mathrm{SiO}_{2}$, the primary glass forming component. The baseline mass balance assumes the GFCs are $65 \% \mathrm{SiO}_{2}$; a more recent glass formulation increases the $\mathrm{SiO}_{2}$ content to $68 \%$. ${ }^{\mathrm{s}}$ A mass balance was calculated for the silica gel absorption scheme assuming consumption of the same quantity of $\mathrm{SiO}_{2}, 813,000 \mathrm{~kg}$, as the present baseline mass balance. This is equivalent to a SBW waste loading on silica gel of $85 \%$. The mass balance also assumes $80 \%$ of the original SBW mass lost in evaporation, well within the range seen in Kirkham's tests considering the feed composition differences. The evaporation mass loss is equivalent to the loss of all the water and initial nitric acid in the SBW plus the loss of an additional $23 \%$ of the nitrate through reactions of silica gel with the waste that produce additional nitric acid.

A glass waste loading for the SBW absorption scheme was unchanged from the baseline flowsheet, hence the glass rate is unchanged. With less nitric acid and nitrate in the dry SBW feed, the rate of sugar was reduced by $80 \%$ for the SBW absorption scheme mass balance. Also, granular sugar was used rather than a sugar solution. Other mass balance comparisons are shown in Table 4.

Table 4. SBW absorption scheme flowrate comparison.

$\begin{array}{lccc}\text { SBW absorption } & \begin{array}{c}\text { Ratio } \\ \text { Scheme }\end{array} & \begin{array}{c}\text { Baseline } \\ \text { Scheme }\end{array} & \begin{array}{c}\text { SBW absorption/ } \\ \text { Baseline }\end{array} \\ \text { Melter off-gas rate, sm3/hr } & 68 & 814 & 0.083 \\ \text { Film cooler effluent rate, sm3,hr } & 166 & 1,915 & 0.086 \\ \text { Quench column feed rate, sm3/hr } & 311 & 2,060 & 0.15 \\ \text { Quench liquid rate, liters/hr } & 3,185 & 20,477 & 0.16 \\ \text { First HEPA bank effluent, sm3/hr } & 316 & 2,057 & 0.15 \\ \text { Noxidizer effluent rate, sm3/hr } & 809 & 3,356 & 0.24 \\ \text { Caustic scrub rate, liters/hr } & 4,044 & 16,780 & 0.24 \\ \text { Off-gas to stack, sm3/hr } & 809 & 3,359 & 0.24\end{array}$

${ }^{\mathrm{s}}$ J. D. Vienna, SBW-22, e-mail to Keith Perry, July 12, 2001. 
Based on the flowrate ratios in Table 4, savings of $50-70 \%$ could be expected in off-gas system equipment. ${ }^{\mathrm{t}}$ The cost estimate for the baseline off-gas treatment is $\$ 18.2$ million, as per the Off-gas Feasibility Study. ${ }^{\mathrm{u}}$ Thus the potential savings from reduced off-gas equipment costs are \$9-13 million. Additional savings should be realized from a significant reduction in facility size due to reduced off-gas treatment equipment space requirements.

The SBW absorption scheme would have additional costs over the baseline due to (1) feed treatment (evaporation) (2) incremental costs of silica gel relative to silica, and (3) costs to treat and dispose of the recovered nitric acid. Incremental feed treatment costs are expected to be small. Wendt and Haefner (Reference 1) estimated cost savings in feed treatment for SBW evaporation to dryness compared to the baseline scheme. Based on typical costs for bulk silica gel, the total cost for the silica gel would be about $\$ 500 \mathrm{~K}$.

About 880,000 gallons of evaporator condensate, with a nitric acid concentration of 3.5 molar, would be produced from the evaporation of the absorbed SBW. Concentration of the condensate in the LET\&D would reduce the volume to about 310,000 gallons of 10 molar acid. If neutralized with caustic and packaged as dried sodium nitrate waste, about 3,300 55-gal drums would be produced. Disposal of this waste at Hanford would cost about $\$ 600 \mathrm{~K} .^{\mathrm{v}}$ Energy costs for evaporation of SBW plus evaporation of the condensate in the PEW followed by concentration in the LET\&D, are estimated to be about $\$ 100 \mathrm{~K}$, based on an energy cost of $\$ 5 /$ million Btu.

Based on this initial review, the silica gel absorption process appears to offer significant savings in facility costs by reducing the size of the off-gas treatment system. Further development is recommended. Data is needed on impurities in the SBW evaporator condensate in order to better determine requirements for treating the condensate and disposing of the final waste. Melt tests are needed to confirm that the silica gel has no detrimental effect on glass properties and to optimize waste loading in the glass. At the present time, the glass waste loading appears to be limited to approximately $20 \%$ due to the sulfur content of the waste; a higher waste loading would result in significant savings due to reduced glass waste disposal costs (See section on barium sulfate precipitation). However, Kirkham ${ }^{2}$ prepared three glasses from his evaporated SBW-silica gel products, using higher waste loadings ( $28-40 \%$ based on SBW oxides). Should higher waste loadings be feasible because of sulfate removal or through increased sulfate retention with the absorbed SBW, additional evaporation tests would be needed to confirm flowability of the dried melter feed. Melter tests are also needed to better determine the effects of the dry feed on volatile and entrained particulate concentrations in the melter off-gas. Finally, scale tests of SBW evaporation equipment would be needed prior to final design.

\section{Partial SBW Evaporation}

To evaluate partial SBW Evaporation, mass balances were prepared for two different schemes. From SBW evaporation test results of John McCray (References 4-5) it appears that 70-80\% of the SBW volume could be evaporated without forming a product that is sticky or sets up upon cooling. Assuming $73 \%$ volume reduction, an ASPEN Plus simulation indicated that about $82 \%$ of the water and $80 \%$ of the nitric acid in the evaporator feed would be removed. The resultant concentrate would be a slurry

\footnotetext{
${ }^{t}$ Using the 0.6 power rule with reduced capacity factors, the reduction would be $57 \%-78 \%$. However, considering the low flowrates for the new scheme and the uncertainties in the mass balance, the range was rounded down to $50-70 \%$.

${ }^{u}$ R. Wood, D. Tyson, B. Bonnema, C. Olsen, A. P. Pinto, D. Wendt, S. Reese, B. Raivo, Feasibility Study for the Idaho Waste Vitrification Facilities Off-gas Treatment for Sodium-Bearing Waste, Appendix K, INEEL/EXT-01-00995, September, 2001.

${ }^{\mathrm{v}}$ Based on $\$ 1,900$ per $40,000 \mathrm{lb}$ truckload plus $\$ 710 / \mathrm{m}^{3}$.
} 
T. Nichols

November 5, 2001

Page 24

containing precipitated nitrates of sodium and aluminum. For one mass balance, this slurry was then assumed to be fed to the melter. A second mass balance was based on filtration of and separate treatment of the solids. For this second case, the melter feed is thus only the liquid concentrate.

The mass balance for the slurry feed scheme shows 50-60\% reduction in off-gas flowrates upstream of the noxidizer and $25-30 \%$ downstream of the noxidizer compared to the baseline mass balance. The reduced flowrates would result in capital cost savings from smaller off-gas equipment and reduced plot space requirements. From evaporation of SBW, 2.7 million liters of condensate would be produced. If processed through the LET\&D, 180,000 gal of 10 molar nitric acid would be produced. The acid would contain small amounts of fluorides, mercury and chlorides. If neutralized with caustic, dried and grouted, about 2,000 drums of waste would be produced. The savings, as well as the incremental costs, from this partial evaporation scheme are not as great as for the total evaporation (silica gel absorption) scheme discussed above. However, the scheme offers a means to significantly reduce off-gas flowrates without changing to a solid melter feed system.

John McCray's SBW evaporation/precipitation test results (Reference 5) indicate that as SBW is sequentially evaporated and cooled, first sodium nitrate crystallizes and then aluminum nitrate. Based on his results, perhaps $70 \%$ of the sodium nitrate could be crystallized before significant amounts of other species precipitated. Reducing the level of sodium alone or both sodium and aluminum would not significantly reduce the volume of glass produced because the glass waste loading, and hence the glass volume, is controlled by sulfate in the waste. However, if sulfate were also removed from the waste, reducing the amount of sodium and aluminum would be beneficial. ${ }^{\mathrm{w}}$

A sketch of this scheme is shown in Figure 1.

The mass balance for the sulfate/nitrate precipitation scheme is based on the following assumptions:

1. $70 \%$ sulfate removal by barium precipitation

2. 1.2 moles barium nitrate added per mole of sulfate in SBW

3. $100 \%$ removal of $\mathrm{BaSO}_{4}$ precipitate along with UDS in SBW by filtration

4. $73 \%$ volume reduction by evaporation ( $81.5 \mathrm{wt} \%$ removal of $\mathrm{H}_{2} \mathrm{O}, 80 \mathrm{wt} \%$ removal of $\mathrm{HNO}_{3}$ )

5. Precipitation upon cooling of $80 \%$ of the $\mathrm{NaNO}_{3}$ and $55 \%$ of the $\mathrm{Al}\left(\mathrm{NO}_{3}\right)_{3}$ in the waste

6. $100 \%$ removal of the precipitated nitrates

7. $35 \%$ waste loading in the glass.

The mass balance results show, relative to the baseline mass balance:

1. $91 \%$ reduction in the waste feed rate

2. $75 \%$ reduction in the melter feed rate

3. $70 \%$ reduction in the glass rate

4. a slight reduction $(2 \%)$ in the sulfate concentration in the glass

5. $70 \%$ reduction in the melter off-gas rate

6. $65 \%$ reduction in quench, scrub and noxidizer feed off-gas rate

7. $65 \%$ reduction in quench and scrub liquid rates

8. $40-45 \%$ reduction in off-gas flowrates downstream of noxidizer

9. Generation of about $30 \mathrm{~m}^{3}$ (150 55-gal drums) of TRU waste

10. Generation of about $660 \mathrm{~m}^{3}$ (3,300 55-gal drums) of Hanford Category 3 waste.

\footnotetext{
${ }^{\text {w }}$ Personal communication with John Vienna, October 25, 2001.
} 


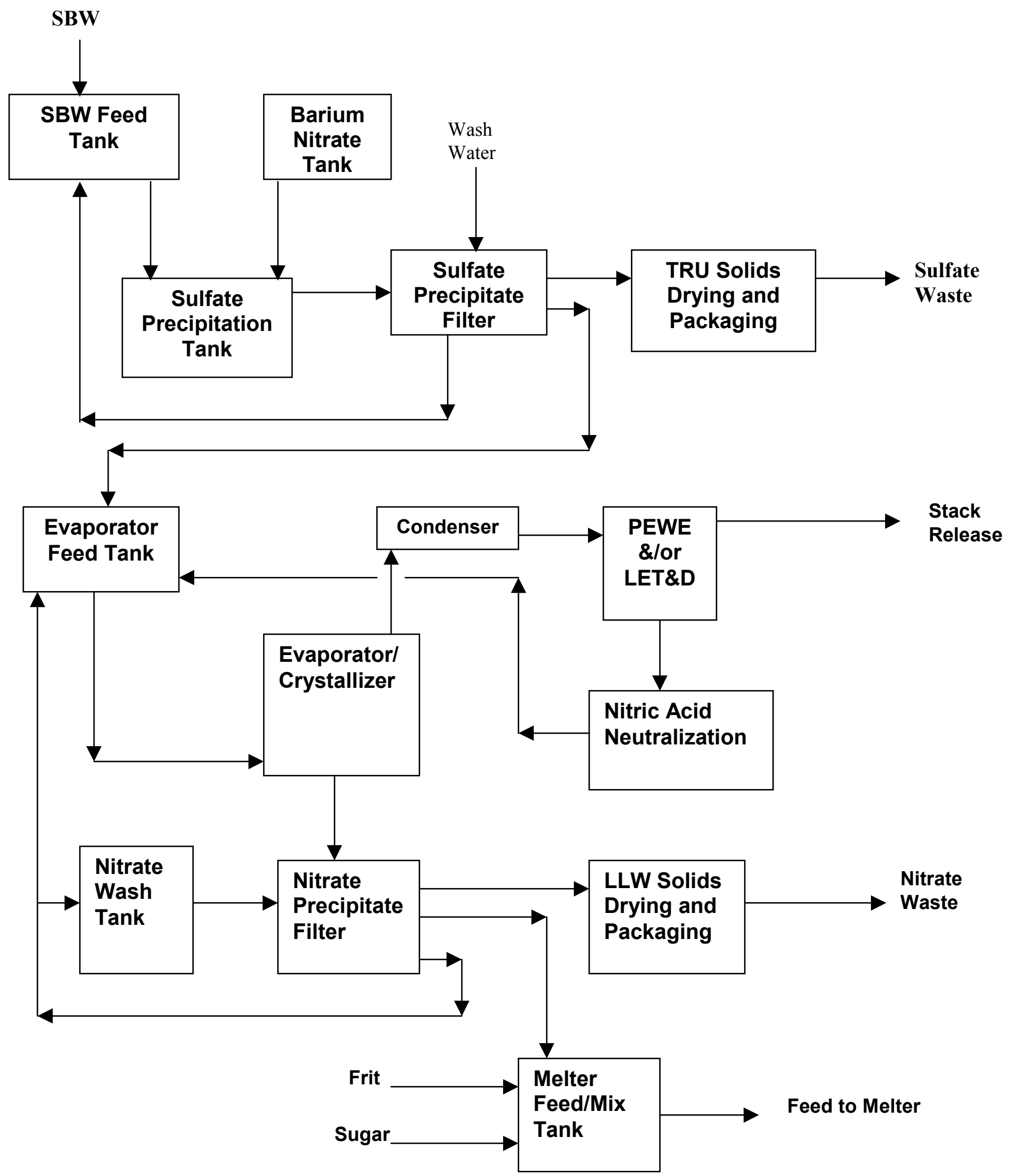

Figure 1. Sulfate/Nitrate Precipitation Pretreatment Scheme. 
The estimated savings in HLW glass disposal costs is about $\$ 380$ million. The estimated cost of disposal of the TRU waste at WIPP is $\$ 8$ million, and of the LLW at Hanford is $\$ 5$ million. The waste volumes are based on dried precipitates; if the precipitates were grouted instead of dried, the volumes (and disposal costs) would increase. The cost estimate for disposal of LLW assumes charges for Category 3 waste. Data in Reference 5 shows $0.1-0.25 \mathrm{ml}$ of entrained liquid per g of precipitate. Assuming a value of $0.2 \mathrm{ml}$ entrained liquid per $\mathrm{g}$ of solids and $95 \%$ removal of the entrained liquid per wash, a single wash will bring the TRU concentration in the solids to about $30 \mathrm{nCi} / \mathrm{g}$. The waste would be Category 3 due to concentrations of ${ }^{137} \mathrm{Cs},{ }^{90} \mathrm{Sr},{ }^{238} \mathrm{Pu},{ }^{239} \mathrm{Pu}$, and ${ }^{241} \mathrm{Am}$. A second wash of the same efficient would bring the actinide concentrations to less than $2 \mathrm{nCi} / \mathrm{g}$ and below Hanford Category 1 levels, but ${ }^{137} \mathrm{Cs}$ and ${ }^{90} \mathrm{Sr}$ would still be above Category 3 limits. A wash removal efficiency greater than about $97 \%$ would be required to remove ${ }^{137} \mathrm{Cs}$ to below the Category 1 limit and about $99 \%$ to remove ${ }^{90} \mathrm{Sr}$ to below Category 1 limits. Additional tests are needed to better determine the classification of this waste.

Additional savings for the sulfate/nitrate scheme would result from the reduced off-gas flowrates.

As previously stated, the assumed SBW waste loading in glass has dropped from $36 \%$ to $20 \%$ in the past two years. This change increases the glass waste volume by $80 \%$, and increases the disposal cost by $\$ 200$ million. Sulfate precipitation offers a method to reduce the glass volume back to that assumed in the FY-2000 Feasibility Study. ${ }^{x}$ Sulfate precipitation combined with evaporation has the potential to not only reduce the cost of the IWVF back to near the Feasibility Study estimate, but to reduce it by another \$200 million or so.

\section{Chilled Air Film Cooler and Transpiring Wall Cooler}

The baseline mass balance assumes inlet air to the film cooler is $60^{\circ} \mathrm{F}$ and the film cooler air to steam ratio is 1.4. If the air to steam ratio is increased to 10 and the air is cooled to $41^{\circ} \mathrm{F}$, off-gas rates downstream of the film cooler are reduced by $7-8 \%$. More detailed design calculations and cost estimates would be required to determine if the savings from the reduced off-gas flow compensate for the cost of chilling the film cooler air. However, since the savings appear to be low, chilling the fill cooler air is not recommended at this time.

Replacing the film cooler with a transpiring wall cooler results in a 54\% reduction in off-gas flow upstream of the noxidizer and about a $40 \%$ reduction downstream of the noxidizer. More feed air is required in the noxidizer reduction section for the transpiring wall cooler case because less oxygen is contained in the noxidizer feed. A comparison of noxidizer feed and effluent streams is shown in Table 6.

\footnotetext{
${ }^{x}$ S. O. Bates, B. D. Raivo, J. J. Quigley, S. M. Berry, W. H. Landman, S. L. Palmer, T. M. Hipp, Feasibility Study for Vitrification of Calcine in the Idaho Waste Vitrification Facility, INEEL/EXT-01-00978, September, 2001.
} 
T. Nichols

November 5, 2001

Page 27

Table 6. Effect of replacing film cooler with transpiring wall cooler.

Noxidizer Feed Noxidizer Effluent

Baseline Trans. Wall Baseline Trans. Wall

$\begin{array}{lcccc}\text { sm3/hr } & 2,057 & 1,104 & 3,356 & 2,076 \\ & \text { Mole Fraction } & \text { Mole Fraction } & \text { Mole Fraction } & \text { Mole Fraction } \\ \mathrm{CO} 2 & 0.029 & 0.054 & 0.071 & 0.081 \\ \mathrm{CO} & 0.004 & 0.007 & 0.000 & 0.000 \\ \mathrm{H} 2 \mathrm{O} & 0.496 & 0.643 & 0.559 & 0.562 \\ \mathrm{~N} 2 & 0.360 & 0.217 & 0.356 & 0.344 \\ \mathrm{NO} & 0.014 & 0.026 & 0.001 & 0.001 \\ \mathrm{NO} 2 & 0.010 & 0.019 & 0.000 & 0.000 \\ \mathrm{O} 2 & 0.081 & 0.028 & 0.009 & 0.009 \\ \mathrm{HNO} 3 & 0.001 & 0.002 & 0.000 & 0.000 \\ \mathrm{Ar} & 0.004 & 0.003 & 0.004 & 0.004\end{array}$

Rates and compositions of secondary waste streams are expected to be essentially the same for the transpiring wall cooler compared to the baseline flow scheme. Given no pretreatment scheme that reduces melter off-gas rates, the magnitude of the reduction in off-gas rates would justify further study to better evaluate the evaporative cooler design, i.e, Studsvik-type, SCWO-type or other design, and then to test the preferred design in order to demonstrate performance. However, if an evaporation pretreatment scheme is adopted as recommended above, no change is recommended at this time to the baseline film cooler design. Off-gas rates for evaporation schemes are in range of $60-240 \mathrm{sm}^{3} / \mathrm{hr}$; air or steam requirements to cool this off-gas in a film cooler are similarly small, and hence saving from a different type of cooler would be small.

$\mathrm{cmb}$

cc: C. M. Barnes Letter File CMB-11-01

L. Lauerman, MS 5218

W. H. Landman, MS 3211

A. L. Olson., MS 5218

D. D. Taylor, MS 3779

Uniform File Code: 6153.102

Disposition Authority: ENV1-k2b

Retention Schedule: EPI* Cutoff after project/program completion, cancellation or termination or in 5 year blocks. Retire to FRC 2 years after termination of project/program. Destroy 25 years after termination of project/program.

NOTE: Original disposition authority, retention schedule, and Uniform Filing Code applied by the sender may not be appropriate for all recipients. Make adjustments as needed. 